Old Dominion University

ODU Digital Commons

Summer 2006

\title{
Continuously Stratified Flow Dynamics Over a Hollow
}

David Salas-Monreal

Old Dominion University

Follow this and additional works at: https://digitalcommons.odu.edu/oeas_etds

Part of the Oceanography Commons

\section{Recommended Citation}

Salas-Monreal, David. "Continuously Stratified Flow Dynamics Over a Hollow" (2006). Doctor of Philosophy (PhD), Dissertation, Ocean \& Earth Sciences, Old Dominion University, DOI: 10.25777/ wpct-1r18

https://digitalcommons.odu.edu/oeas_etds/70

This Dissertation is brought to you for free and open access by the Ocean \& Earth Sciences at ODU Digital Commons. It has been accepted for inclusion in OES Theses and Dissertations by an authorized administrator of ODU Digital Commons. For more information, please contact digitalcommons@odu.edu. 


\title{
CONTINUOUSLY STRATIFIED FLOW DYNAMICS OVER A HOLLOW
}

by

\author{
David Salas-Monreal
}

B.S. June 2000, National Autonomous University of Mexico (UNAM)

M.S. December 2002, Old Dominion University

A Dissertation Submitted to the Faculty of Old Dominion University in Partial Fulfillment of the Requirement for the Degree of

\section{DOCTOR OF PHILOSOPHY \\ OCEANOGRAPHY \\ OLD DOMINION UNIVERSITY}

August 2006

Approved by:

Larry P. Atkinson (Director)

Ann Gargett (Member)

Joßn A. Adam (Member)

Arnoldo Valle-Levinson (Member) 


\author{
ABSTRACT \\ CONTINUOUSLY STRATIFIED FLOW DYNAMICS OVER A HOLLOW \\ David Salas-Monreal \\ Old Dominion University, 2006 \\ Director: Dr. Larry P. Atkinson
}

Acoustic Doppler current profiles (ADCP) and density profiles were measured over three lower Chesapeake Bay bathymetric depressions (hollows) in order to determine the effects of a hollow on a continuously stratified flow. Measurements showed an acceleration of the near-bottom flow as it moved toward the deepest part of the hollows, in contrast to the deceleration expected from two-dimensional Bernoullitype dynamics. The acceleration was attributed to lateral water intrusions that were most apparent during floods. The presence of lateral water intrusions was corroborated by observations in a transverse section that crossed the deepest part of the hollows. The observed deceleration of the along-hollow flow as it moved toward decreasing bathymetry was attributed to lateral flows toward the shoals. The current acceleration toward the deepest part of the hollows during flood, favored by vertical and lateral water intrusions, was deflected toward the right (looking landward) owing to Coriolis accelerations. In general during ebb and flood, the dynamics over the hollows could be explained with three-dimensional Bernoulli-type dynamics modified by Coriolis acceleration. At only one of the hollows, Cape Charles hollow, the sampling strategy allowed resolution of internal lee waves with periodicities of $1.42 \mathrm{~h}$ during flood and ebb tide periods. These internal waves were produced by the interaction of the sloping pycnocline and tidal currents. The formation of internal waves over the leeward side 
favored the development of vertical shear in the horizontal velocity. Large vertical shears enhanced turbulence and internal waves should have increased form drag resulting in locations in the water column of weakest along-hollow velocities. The phase of the semidiurnal tidal currents increased monotonically from the depth equivalent to the maximum depth of the shoals surrounding the hollow toward the bottom and surface, in contrast to the expected increment from bottom to surface over an estuary influenced by bottom friction. 
This dissertation is dedicated to my family: Mayra Lorena Riveron Enzastiga, David Alberto and Mayra Lorena Salas Riveron, David A. Salas de Leon and M. Adela Monreal Gomez with love. 


\section{ACKNOWLEDGMENTS}

This work could only be done with help from a lot of people who gave me their friendship and support during these years. I want to thank all my colleagues and friends who helped me to continue, the professors who gave me the knowledge to pursue, and to my family for their unconditional support.

I am thankful to my advisor, Dr. Arnoldo Valle Levinson, for his guidance during this work, for the support he gave me and for his friendship. I also would like to express appreciation to the members of my committee, Dr. Larry P. Atkinson, Dr. Ann Gargett, and Dr. John Adam, for their help and comments. To the people who helped edit this dissertation, especially Dr. Arnoldo Valle Levinson and Dr. Ann Gargett, thank you for the time you invested in this work.

I appreciate the Center for Coastal Physica Oceanography (CCPO), and the Department of Ocean, Earth and Atmospheric Sciences (OEAS) at Old Dominion University (ODU), and the "Consejo Nacional de Ciencia y Tecnologia" (Mexico) for all the financial support during my Ph.D. through scholarship 149091.

I want to extend my gratitude to the National Oceanic and Atmospheric Administration (NOAA), the U.S. Geological Survey (USGS), Dr. Arnoldo Valle Levinson and Dr. William C. Boicourt for providing the data which was indispensable for this work. 
TABLE OF CONTENTS

Page

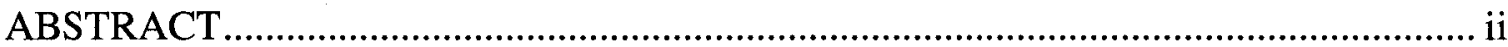

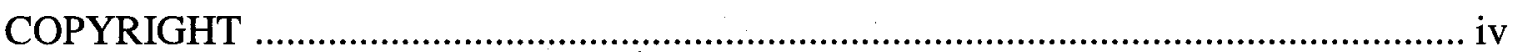

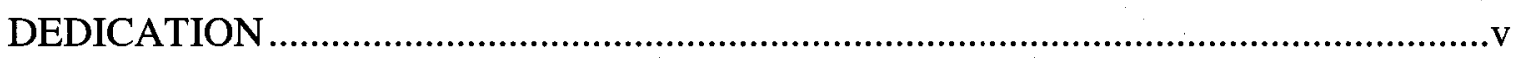

ACKNOWLEDGMENTS ……………………………......................................... vi

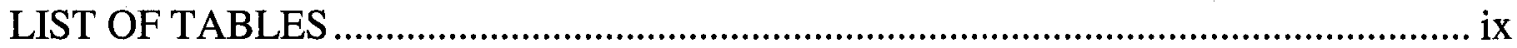

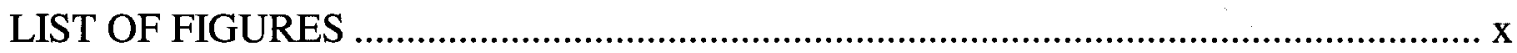

Chapter

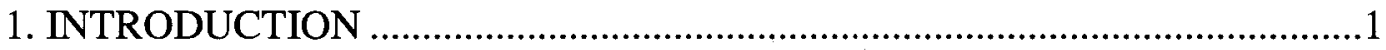

2. DATA COLLECTION AND PROCESSING .............................................6

2.1 Cape Charles Hollow.......................................................................6

2.2 Rappahannock Hollow .....................................................................10

2.3 Chesapeake Bay Mouth Hollow......................................................12

2.4 Data Processing for All Sites............................................................15

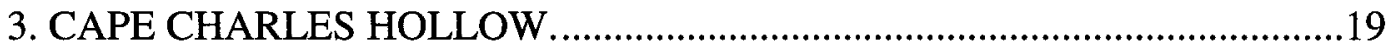

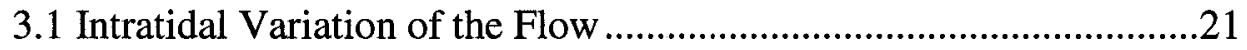

3.2 Amplitude of Semidiurnal Tidal Currents ........................................32

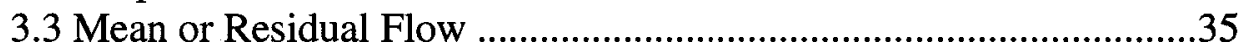

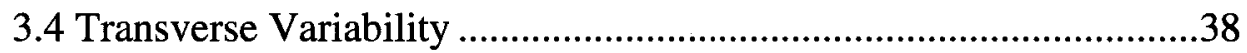

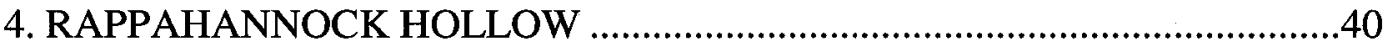

4.1 Flood Tide Periods .............................................................................42

4.2 Ebb Tide Periods .............................................................................48

4.3 Amplitude of Semidiurnal Tidal Currents ........................................53

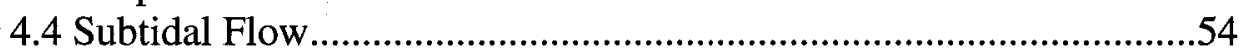

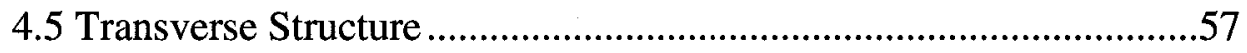

5. THE CHESAPEAKE BAY MOUTH HOLLOW ………………………….......59

5.1 Establishment and Evolution of the Flow .........................................59

5.2 Amplitude of the Semidiurnal Tidal Currents ..................................69

5.3 Residual Flow .....................................................................................69

6. COMMON FEATURES ............................................................................. 


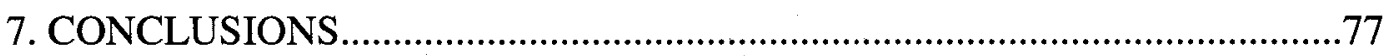

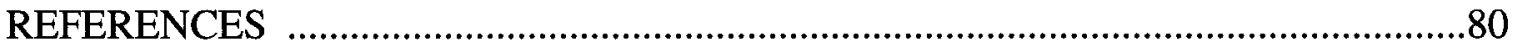

VITA 


\section{LIST OF TABLES}

Table

1. Location of the Hydrographic Stations and the Anchored ADCP .9

2. Location of the Hydrographic Stations and the Chesapeake Bay Bridge Tunnel (CBBT) Station..

3. Typical Values During Ebb and Flood Tides at Cape Charles Hollow. .32

4. Typical Values During Ebb and Flood Tides at Rappahannock Hollow. 


\section{LIST OF FIGURES}

Figure

1. Location of Cape Charles Hollow in the Lower Chesapeake Bay...... .8

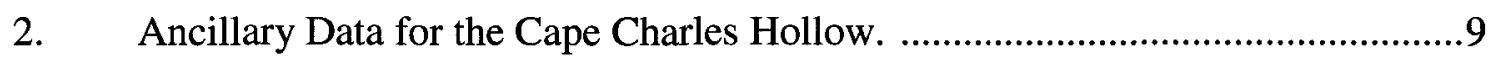

3. Location of the Rappahannock Hollow in the Lower Chesapeake Bay. ..............11

4. Ancillary Data for the Rappahannock Hollow.................................................12

5. Study Area in the Chesapeake Bay Mouth, and the Ship Track During the Experiment on February 25, 2000. ................................................................ 14

6. Ancillary Data for the Chesapeake Bay Mouth Hollow................................... 14

7. Time Series 1 at Cape Charles Hollow.......................................................20

8. Instantaneous Velocities 1 at Cape Charles Hollow.........................................24

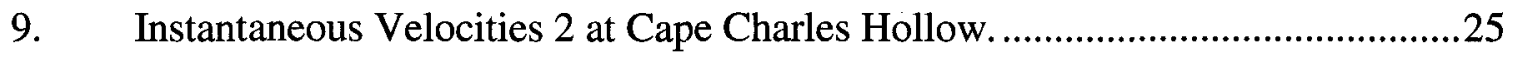

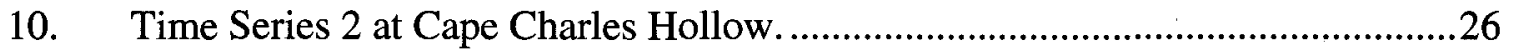

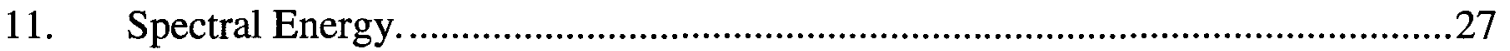

12. Time Series 3 at Cape Charles Hollow........................................................28

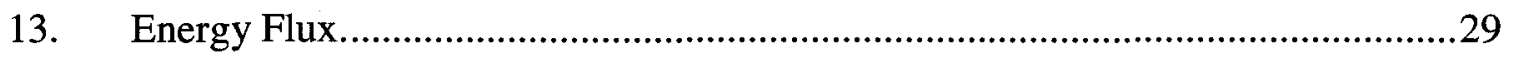

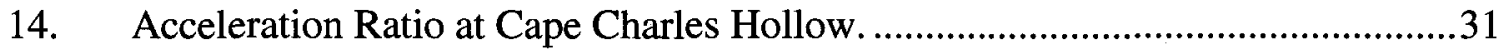

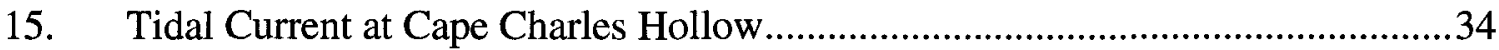

16. Density Derivatives at Cape Charles Hollow. .................................................36

17. Residual Flow at Cape Charles Hollow .........................................................37

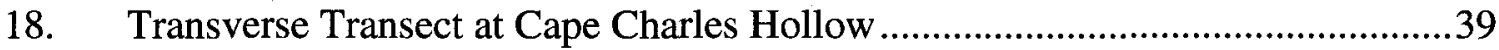

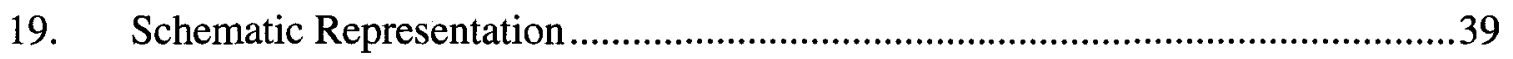

20. Instantaneous Velocities 1 at Rappahannock Hollow ......................................41 
Figure

21. Instantaneous Velocities 2 at Rappahannock Hollow .45

22. Instantaneous Velocities 3 at Rappahannock Hollow 46

23. Acceleration Ratio 1 at Rappahannock Hollow 47

24. Instantaneous Velocities 4 at Rappahannock Hollow........................................51

25. Instantaneous Velocities 5 at Rappahannock Hollow .......................................52

26. Acceleration Ratio 2 at Rappahannock Hollow...........................................53

27. Contours of the Tidal Current Amplitude on April 21-22, 1998.....................54

28. Residual Flow at Rappahannock Hollow..................................................56

29. Density Derivatives at Rappahannock Hollow ................................................57

30. Transverse Transect at Rappahannock Hollow...............................................58

31. Time Series 1 at Chesapeake Bay Mouth ...................................................61

32. Instantaneous Velocities 1 at Chesapeake Bay Mouth ...................................62

33. Instantaneous Velocities 2 at Chesapeake Bay Mouth ...................................66

34. Instantaneous Velocities 3 at Chesapeake Bay Mouth ....................................67

35. Instantaneous Velocities 4 at Chesapeake Bay Mouth ......................................68

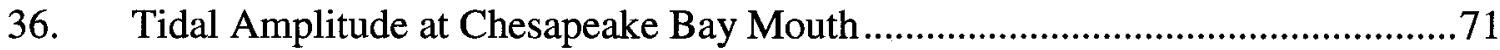

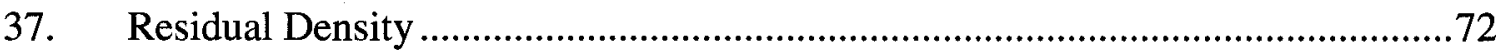

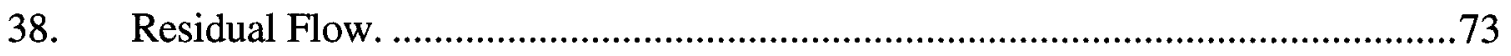




\section{CHAPTER 1}

\section{INTRODUCTION}

The understanding of fluid dynamics over irregular bathymetries in the shape of elongated-holes, or seamounts is crucial to advance the knowledge of, among other phenomena: planktonic and organic matter concentration (e.g., Trasvina-Castro et al., 2003; Genin, 2004; Monreal-Gomez and Salas-de-Leon, 2005); formation of lee waves (Farmer and Armi, 1986); predict flow patterns (Stommel and Farmer, 1952); and calculate atmospheric drag coefficients (Baines, 1995). Stratified flow over irregular bathymetries in the shape of sills, and through constrictions has been known to mediate water exchange between adjoining basins (e.g., Broenkow and McKain, 1972; Gade and Edwards, 1980; Farmer and Freeland, 1983). However, little attention has been paid to the modifications to the flow produced by bathymetric depressions such as elongated holes, which are extensively found in shallow waters.

Several studies have previously documented the dynamics over irregular bathymetries in the shape of canyons (e.g., Broenkow and McKain, 1972; Hickey, 1995; Klinck, 1995; Klymak and Gregg, 2001; Salas-de-León et al., 2004); sills (e.g., Stommel and Farmer, 1952; Farmer and Smith, 1980; Farmer and Freeland, 1983; Farmer and Armi 1986; Armi and Farmer, 1988; Del-Rosario and Odriozola, 2005); through constrictions (e.g., Broenkow and McKain, 1972); and at a scour-hole (e.g., Ginsberg and Perillo, 1999; Pierini et al., 2005) using the two-dimensional hydraulic theory. Hogg et al. (2001) found that over straits where the amount of mixing due to wind stress or

This dissertation conforms to the journal model Deep-Sea Research. 
bottom friction is small compared to the volume exchanged, the dominant balance is between inertia and buoyancy forces. This is a good approximation for short, deep straits. In cases where mixing is relevant, like in a mixed shallow strait, the dominant balance is between turbulent viscosity, diffusion and buoyancy forces (Hogg et al., 2001). Those dynamics may also be applied to other shallow systems such as holes. While the basic dynamics of flow over sills and through constrictions has been well documented (e.g., Farmer and Armi, 1986; Eriksen, 1991; Stenstrom, 2003), little attention has been paid to the flow dynamics over bathymetric depressions in the shape of elongated holes, hereafter called "hollows". In some cases, hollows produce stronger vorticities (Park and Wang, 1991), recirculation (Chao and Paluszkiewicz, 1991) and convergence zones (Cenedese and Linden, 1999) than over sills or through constrictions. Thus, a study on the dynamics of continuously stratified flows over hollows in shallow waters is timely.

The investigative approach that has most resembled the study of stratified flow over a hollow is the hydraulic theory over sills and through constrictions, which has been addressed extensively. The hydraulic theory over sills and through constrictions explains the pycnocline adjustment near the sill crest and downstream (e.g., Farmer and Armi, 1986; Eriksen, 1991; Bryden and Kinder, 1991; Hibiya and LeBlond, 1993; ValleLevinson and Wilson, 1994). The internal waves produced by the interaction between density currents and irregular bathymetries in the shape of sills and constrictions can be predicted using the hydraulic theory (e.g. Farmer and Smith, 1980; Pratt, 1986; Chao and Paluszkiewicz, 1991; Cummins and Oey, 1997; Farmer and Armi, 1999; Del-Rosario and Odriozola, 2005), which may be applied to other bathymetric asymmetries, such as hollows, under the assumption that the pressure gradient balances the along-advective 
term in the momentum equation, i.e., assuming that lateral variations of streamwise flow are weak enough to be negligible (Armi, 1986).

The basic dynamics over sills and through constrictions has been represented with a simplified two-dimensional Benoulli-type dynamics, usually assumed when interpreting observational data. For instance, the basic dynamics in the Strait of Gibraltar (Armi and Farmer, 1988) and over Knight Inlet sill, British Columbia (Farmer and Smith, 1980), were described with the two-dimensional simplified dynamics. However, a study by Wesson and Gregg (1994) showed that the temperature and salinity properties near the bottom of the Strait of Gibraltar were related to lateral water intrusion of Atlantic Intermediate Water, i.e., three dimensional dynamics. At Knight Inlet (British Columbia), the downstream acceleration of the flow was explained with three-dimensional flow dynamics, owing to lateral water intrusion (Pickard and Rodgers, 1959; Baker and Pond, 1995; Klymak and Gregg, 2001). Therefore, three-dimensional flow dynamics needs to be considered over irregular bathymetries where strong lateral variations of streamwise flow are common.

Most of actual knowledge of irregular bathymetries in the shape of hollows constrictions, and sills, were obtained with numerical simulations. Chao and Paluszkiewicz (1991) simulated strong flows over irregular bathymetries. One of the most interesting findings was that the strongest vertical recirculation was associated with a strong pycnocline and sharp bottom slopes. The vertical recirculation over sills also explained the tidal asymmetry of the volume flux. For instance, at Knight Inlet sill the recirculation of buoyant water explained more than $25 \%$ of total up-inlet flux during flood tide periods (Klymak and Gregg, 2001). The recirculation also transported denser 
water into the mixing zone. This pattern usually concentrates nutrients near the surface in shallow waters, producing high biological productivity areas (Monreal-Gomez and Salasde-Leon, 2005). Therefore, irregular bathymetries in the shape of sills and hollows modify the density currents, and may produce vertical recirculation induced by strong currents when they interact with an increasing slope.

Numerical simulations of elongated holes in the shape of trenches are mainly concerned with the generation of internal tides, produced by the interaction between the barotropic tides and the irregular topography. The generation of internal tides over ridges (e.g., Baines, 1982; Balmforth, 2002) has been shown to be insensitive to the ridge width, in contrast to trenches where the generated energy flux is width-dependent (St. Laurent, et al., 2003). Internal tides over a top-hat trench are most likely generated when the width of the trench is greater than the depth of the trench, under the assumption that the bottomslope remains constant (St. Laurent et al., 2003). Depicted the extensive number of simulations of internal tide propagation over irregular bathymetries, observational studies of bathymetry-related internal tides in shallow waters are scarce.

The main objective of the research described in this study is to elucidate the flow dynamics over an elongated-hole (hollow) in shallow water. This study is based on acoustic Doppler current profiles and density profiles along and across three bathymetric depressions in the lower Chesapeake Bay, and focuses on the variability observed at temporal scale of 15 minutes to 12 hours, and spatial scale of 200 to $20,000 \mathrm{~m}$. This study thus contributes to advance our understanding on stratified flow dynamics over hollows, using observational data in shallow waters. Among other findings, it is one of the first studies showing two pycnoclines, and strong lateral variation of streamwise flow over a 
hollow in shallow waters.

The structure of this study is outlined next: Chapter 2 provides details on data collection, and the methodology used during data analysis. The following chapters give a description and discussion of the three bathymetric depressions (hollows) analyzed in this study. Chapter 3 gives a description and discussion of the density and velocity observations at Cape Charles hollow. Chapter 4 provides details of the flow and density fields at Rappahannock hollow, followed by the description and discussions of the Chesapeake Bay mouth hollow in Chapter 5. The general characteristics of the continuously stratified flow over the three bathymetric depressions are discussed in Chapter 6. Finally Chapter 7 presents the general conclusion of this study. 


\section{CHAPTER 2}

\section{DATA COLLECTION AND PROCESSING}

In order to elucidate the dynamics of a continuously stratified flow over a hollow, acoustic Doppler current profiles (ADCP) and density profiles were collected over three bathymetric depressions in the lower Chesapeake Bay: Cape Charles Hollow, Rappahannock Hollow and Chesapeake Bay Mouth Hollow. In all experiments, towed acoustic Doppler current profiler data set were combined with conductivity-temperaturedepth profiles at fixed stations or obtained from an undulating vehicle, as in the case of the Rappahannock Hollow. The details of each of the three hollows are presented next.

\subsection{Cape Charles Hollow}

The first data set was sampled over the 45-m deep Cape Charles Hollow located in the lower Chesapeake Bay (Fig. 1). Two experiments were carried out along transect-I during at least one diurnal tidal cycle on November 7-8, 2001 and May 28-30, 2002. The first $25-\mathrm{h}$ long experiment yielded fourteen repetitions of the $20 \mathrm{~km}$-long transect. Density profiles were collected at both ends of each transect repetition. This experiment was carried out under local southerly wind and relatively weak river discharge conditions (Fig. 2a). During the period of May 28-30, 2002, a total of 23 transect repetitions were sampled over 49-h. Sampling started $3 \mathrm{~h}$ before high tide (16:57 GMT) under local winds below $2 \mathrm{~m} \mathrm{~s}^{-1}$, and high river discharge (Fig. 2b). Five hydrographic stations (A, B, C, D and E) were sampled along transect-I to sketch the density structure and buoyancy frequency over the hollow (Fig. 1 and table 1). These two experiments were carried out 
six months apart to determine the effects of seasonal density variation on the flow over the hollow.

Subsequent to the November 7-8, 2001 experiment, a 25-h long experiment was carried out across the bay and hollow (transect-II) on November 8-9, 2001 (Fig. 1). This $\sim 20 \mathrm{~km}$-long transect was repeated nine times. The transect crossed the deepest part of the hollow and sought to assess the flow transverse structure over the hollow. Furthermore, velocity profiles were obtained on February 12-13, 2002 from an anchored station located over the east side of the deepest part of the hollow (Fig. 1 and table 1). Frequencies higher than 0.0667 cycles per minute (periods below 15 minutes) were filtered from the $1 \mathrm{~Hz}$ acoustic Doppler current profiler (ADCP) data using a low-pass cosine-Lanczos filter to emphasize variability in the band of internal waves and lower frequencies. Unfortunately density profiles were not available during this period.

During transect sampling, current velocity profiles were recorded with a $600-\mathrm{kHz}$ ADCP towed at a speed of approximately $2.5 \mathrm{~m} \mathrm{~s}^{-1}$. The velocity profiler had a vertical resolution of $1 \mathrm{~m}$, with a ping rate of $1 \mathrm{~Hz}$ averaged every $40 \mathrm{~s}$, yielding a spatial resolution of $\sim 100 \mathrm{~m}$. The $600 \mathrm{kHz}$ ADCP compass was calibrated according to Trump and Marmorino (1997) using a Global Positioning System (GPS) data set. The data were modified in order to emphasize the velocity structure over the hollow. This was done by rotating the calibrated velocities to the angle of their maximum standard deviation $\left(119.15^{\circ}\right)$. Density profiles were obtained with a conductivity-temperature-depth recorder (CTD) Seabird SBE19 with a salinity and temperature accuracy of \pm 0.2 and $\pm 0.1{ }^{\circ} \mathrm{C}$, and a resolution of 0.01 and $0.01{ }^{\circ} \mathrm{C}$, respectively. The CTD sampling interval of $2 \mathrm{~Hz}$ $(0.5 \mathrm{~s})$ was averaged to bins of $0.5 \mathrm{~m}$ depth. Tidal range and wind velocities were taken 
from Kiptopeke station maintained by the National Oceanographic and Atmospheric Administration (NOAA). Values of river discharge were obtained from the Susquehanna, Potomac and James River stations (Fig. 1) maintained by the U.S. Geological Survey (USGS). Those rivers represent the main freshwater input affecting the area studied.
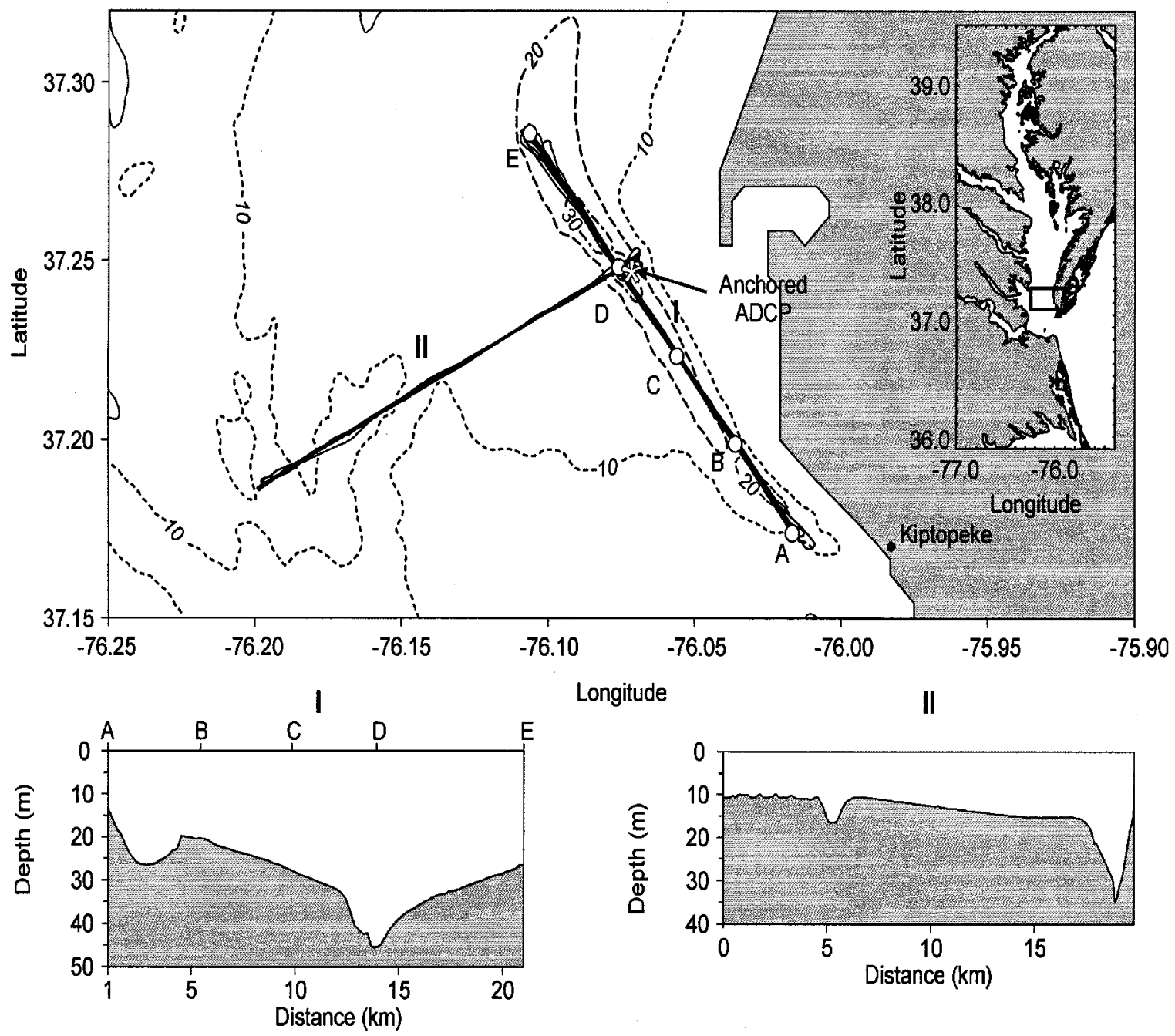

Fig. 1. Location of Cape Charles Hollow in the lower Chesapeake Bay. The ship track during the experiment on November 7-8 (along transect I), November 8-9 (along transect II) 2001, and May 28-30, 2002 (along transect I). Location of Kiptopeke station (•), the CTD stations (A, B, C, D and E), and the position of the anchored ADCP (*) during February 12-13, 2002. 
a)
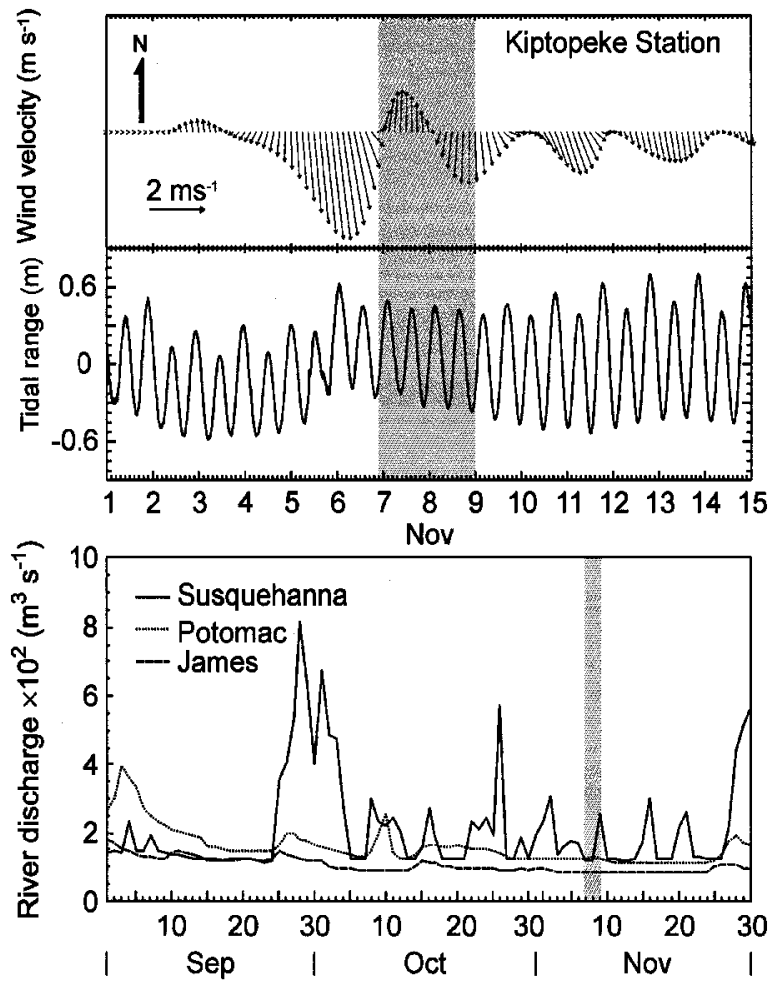

b)
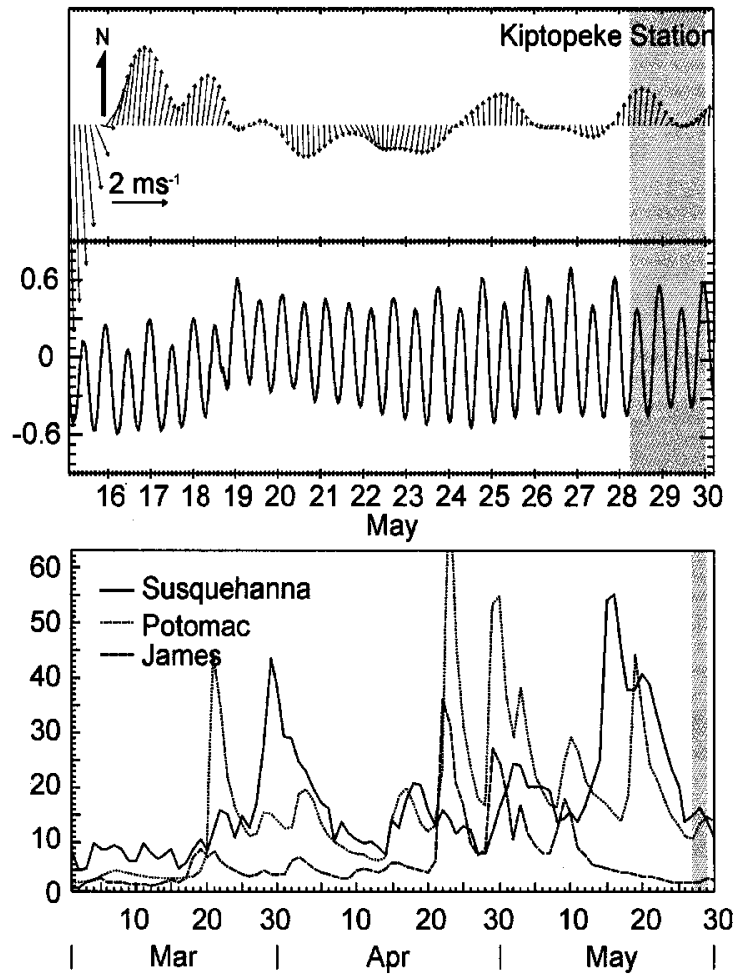

Fig. 2. Ancillary data for the Cape Charles Hollow. Wind velocity and tidal range at Kiptopeke station and river discharge at Susquehanna, Potomac and James Rivers during the experiments on a) November 7-8, 2001 November 8-9, 2001 and b) May 28-30, 2002.

Table 1

Location of the hydrographic stations and the anchored ADCP

\begin{tabular}{ccc}
\hline CTD stations & Latitude $(\mathrm{N})$ & Longitude $(\mathrm{W})$ \\
\hline A & $37^{\circ} 10^{\prime} 26^{\prime \prime}$ & $76^{\circ} 01^{\prime} 00^{\prime}$, \\
B & $37^{\circ} 11^{\prime} 56^{\prime \prime}$ & $76^{\circ} 02^{\prime} 11^{\prime \prime}$ \\
C & $37^{\circ} 13^{\prime} 24^{\prime \prime}$ & $76^{\circ} 03^{\prime} 23^{\prime}$, \\
D & $37^{\circ} 14^{\prime} 53^{\prime}$, & $76^{\circ} 04^{\prime} 34^{\prime \prime}$ \\
E & $37^{\circ} 17^{\prime} 08^{\prime \prime}$ & $76^{\circ} 06^{\prime} 23^{\prime}$, \\
Anchored ADCP & $37^{\circ} 17^{\prime} 02^{\prime}$, & $76^{\circ} 06^{\prime} 29^{\prime}$, \\
\hline
\end{tabular}




\subsection{Rappahannock Hollow}

Acoustic Doppler current profiles (ADCP) and water density profiles were also recorded over the $35 \mathrm{~m}$ depth Rappahannock Hollow in order to find a common pattern of the flow and density structure over a hollow. The sampling was performed during April 21-23, 1998 along two transects over the Rappahannock Hollow (Fig. 3). During April 21-22, 1998, eleven repetitions of a $30 \mathrm{~km}$-long transect-I were executed for $\sim 25$ hrs. Each repetition was accomplished in approximately $2.3 \mathrm{~h}$. Density profiles were recorded along transect-I with a conductivity-temperature-depth recorder (CTD) Seabird SBE19. During April 22-23, 1998, a total of nine transect-II repetitions were carried out over a $\sim 24 \mathrm{~h}$ period. The $25 \mathrm{~km}$-long transverse transect sought to assess the influence of the bathymetric depression (hollow) in the transverse structure of the flow. Unfortunately no density profiles were available during this period.

The velocity profiles were recorded with a $600-\mathrm{kHz}$ ADCP towed from a vessel at a speed of $\sim 3.5 \mathrm{~m} \mathrm{~s}^{-1}$. The ADCP ping rate of $1 \mathrm{~Hz}$ was averaged every $30 \mathrm{~s}$, giving a spatial resolution of approximately $100 \mathrm{~m}$, with a vertical resolution of $1 \mathrm{~m}$. As for Cape Charles Hollow, the $600-\mathrm{kHz}$ ADCP compass was calibrated using a global positioning system (GPS) data set, according to Trump and Marmorino (1997). The calibrated velocities were rotated to the angle of their maximum standard deviation to emphasize the velocity structure along the hollow. Density profiles were recorded with a conductivity-temperature-depth recorder (CTD) Seabird SBE19, with a sampling interval of $2 \mathrm{~Hz}(0.5 \mathrm{~s})$ averaged to bins of $0.5 \mathrm{~m}$ depth, as for the previous experiment. However, one of the innovations of this experiment when compared to the previous one was the vertical and horizontal resolution of the density profiles. The CTD was mounted in an 
undulating towed instrumentation vehicle Scanfish MK-II. The Scanfish tow body system sought to assess the vertical density structure over the hollow, with an undulated vertical rate of $0.5 \mathrm{~m} \mathrm{~s}^{-1}$ within $2 \mathrm{~m}$ from the surface and bottom. This yielded a horizontal resolution of approximately $125 \mathrm{~m}$. The ADCP and the Scanfish had a separation of approximately $50 \mathrm{~m}$ at the surface which was taken into account to correct the location of each measurement recorded by the CTD. In addition, wind velocities used in the wind stress estimate were obtained from Lewisetta station $\left(37^{\circ} 59.7^{\prime} \mathrm{N}, 76^{\circ} 27.9^{\prime} \mathrm{W}\right)$, and tidal range at Windmill Point $\left(37^{\circ} 36.9^{\prime} \mathrm{N}, 76^{\circ} 17.4^{\prime} \mathrm{W}\right)$, were obtained to describe flood and ebb tide periods (Fig. 4). These stations are maintained by the National Oceanographic and Atmospheric Administration (NOAA). Values of river discharges were obtained from the Susquehanna, Potomac and James River maintained by the U.S. Geological Survey (USGS), since they represent the main freshwater input affecting the area studied.

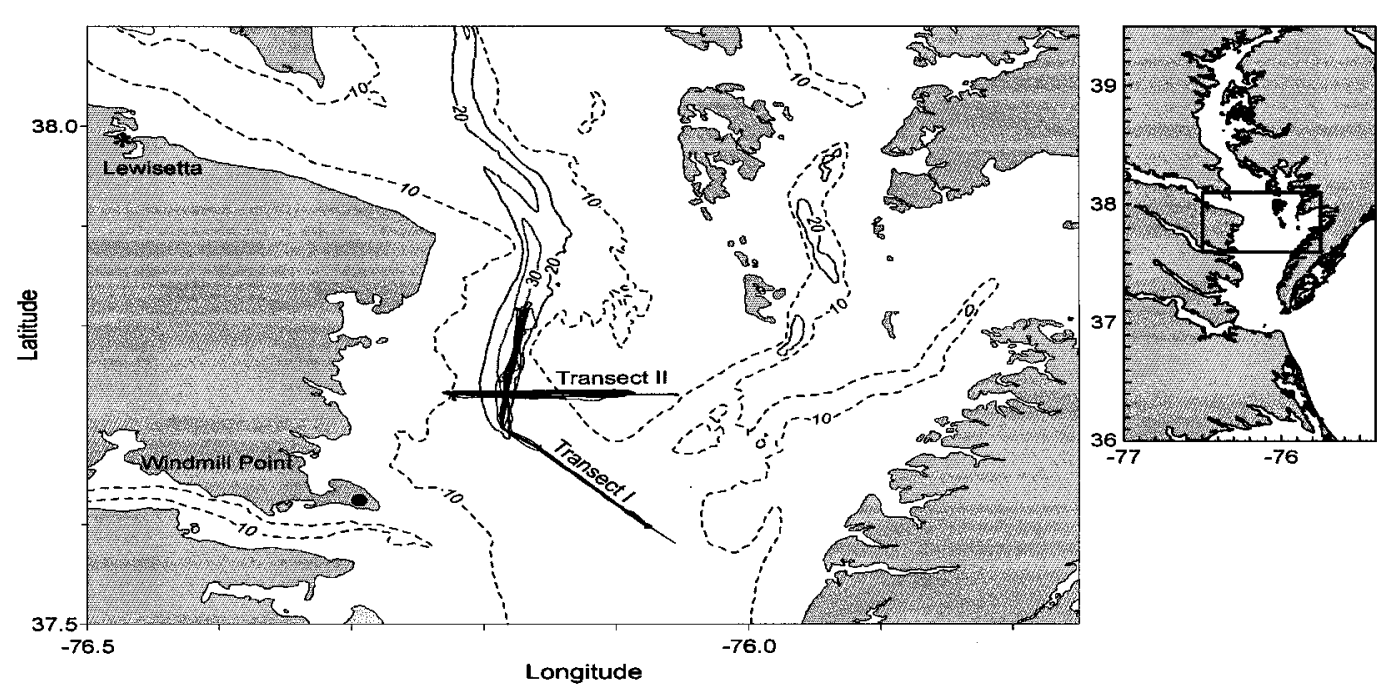

Fig. 3. Location of the Rappahannock Hollow in the lower Chesapeake Bay. Bathymetry contours at $10 \mathrm{~m}$ interval, and ship track during the experiments on April 21-22, 1998 along transect I and April 22-23, 1998 along transect II. Lewisetta station (*), and Windmill Point station $(\bullet)$ are shown. 


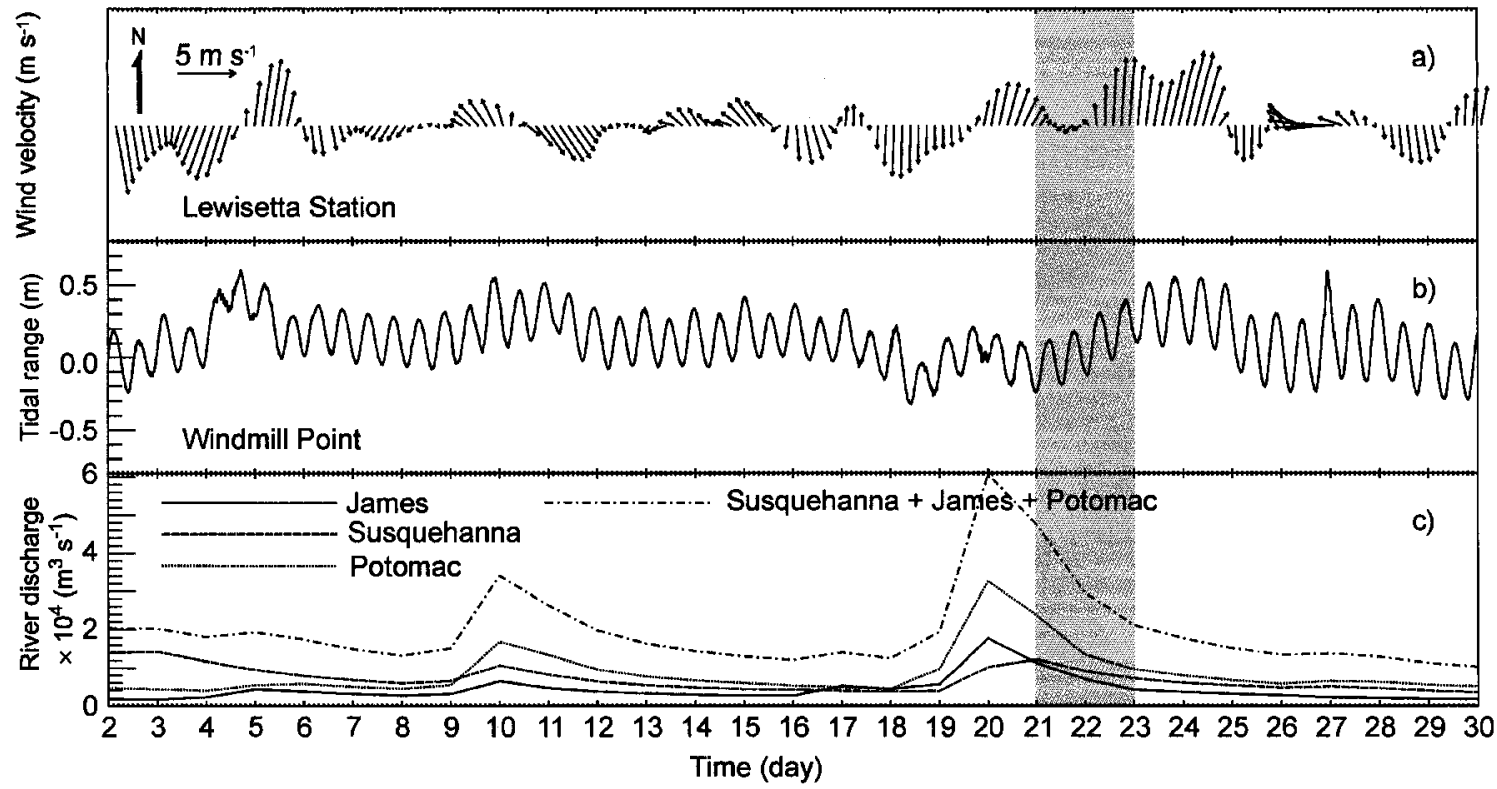

Fig. 4. Ancillary data for the Rappahannock Hollow. a) Wind velocity at Lewisetta Station, b) tidal range at Windmill Point Station and, c) river discharges at James, Susquehanna and Potomac Rivers are shown.

\subsection{Chesapeake Bay Mouth Hollow}

Finally, acoustic Doppler current profiles (ADCP) and density profiles were collected along a transect that crossed a $25 \mathrm{~m}$ deep hollow, located in the Chesapeake Bay mouth (Fig. 5), in order to find a common pattern of the along-hollow flow, and elucidate any possible variation of the flow owing to vertical stratification, sharpness of the bottom slope, and horizontal and vertical scale of the bathymetric depression. The third sampling hollow was carried out on February 25, 2000. Eight repetitions of a 15 $\mathrm{km}$-long transect were performed during approximately $12 \mathrm{~h}$, each transect repetition was accomplished in approximately $1.5 \mathrm{~h}$. The sampling started $6 \mathrm{~h}$ before high tide $(8: 24$ GMT) with dominant southerly winds (Fig. 6). Density profiles at three stations along the 
transect were performed (Fig. 5, Table 2) in order to elucidate the density structure over the bathymetric depression.

The velocity profiles were recorded with a $600-\mathrm{kHz}$ acoustic Doppler current profiler towed at a speed of approximately $3 \mathrm{~m} \mathrm{~s}^{-1}$ with a vertical resolution of $0.5 \mathrm{~m}$, as for the previous experiments. The ADCP ping rate of $1 \mathrm{~Hz}$ was averaged every $30 \mathrm{~s}$, yielding a spatial resolution of $\sim 100 \mathrm{~m}$. The ADCP compass was calibrated with the same method as for the Cape Charles and the Rappahannock Hollow data set. This was done according to Trump and Marmorino (1997) using a GPs data set. Density profiles at three locations of the transect (Table 2), were recorded with a conductivity-temperature-depth (CTD) Seabird SBE19, previously described. Wind stress estimates were obtained with wind velocity data from Chesapeake Bay Bridge Tunnel (CBBT) station, owing to the proximity of this station to the area studied.

Table 2

Location of the hydrographic stations and the Chesapeake Bay Bridge Tunnel (CBBT) station

\begin{tabular}{lll}
\hline CTD stations & Latitude $(\mathrm{N})$ & Longitude $(\mathrm{W})$ \\
\hline A & $36^{\circ} 56.896^{\prime}$ & $75^{\circ} 59.361^{\prime}$ \\
B & $36^{\circ} 57.500^{\prime}$ & $76^{\circ} 01.771^{\prime}$ \\
C & $36^{\circ} 58.073^{\prime}$ & $76^{\circ} 04.111^{\prime}$ \\
CBBT station & $36^{\circ} 58.000^{\prime}$ & $76^{\circ} 06.800^{\prime}$
\end{tabular}



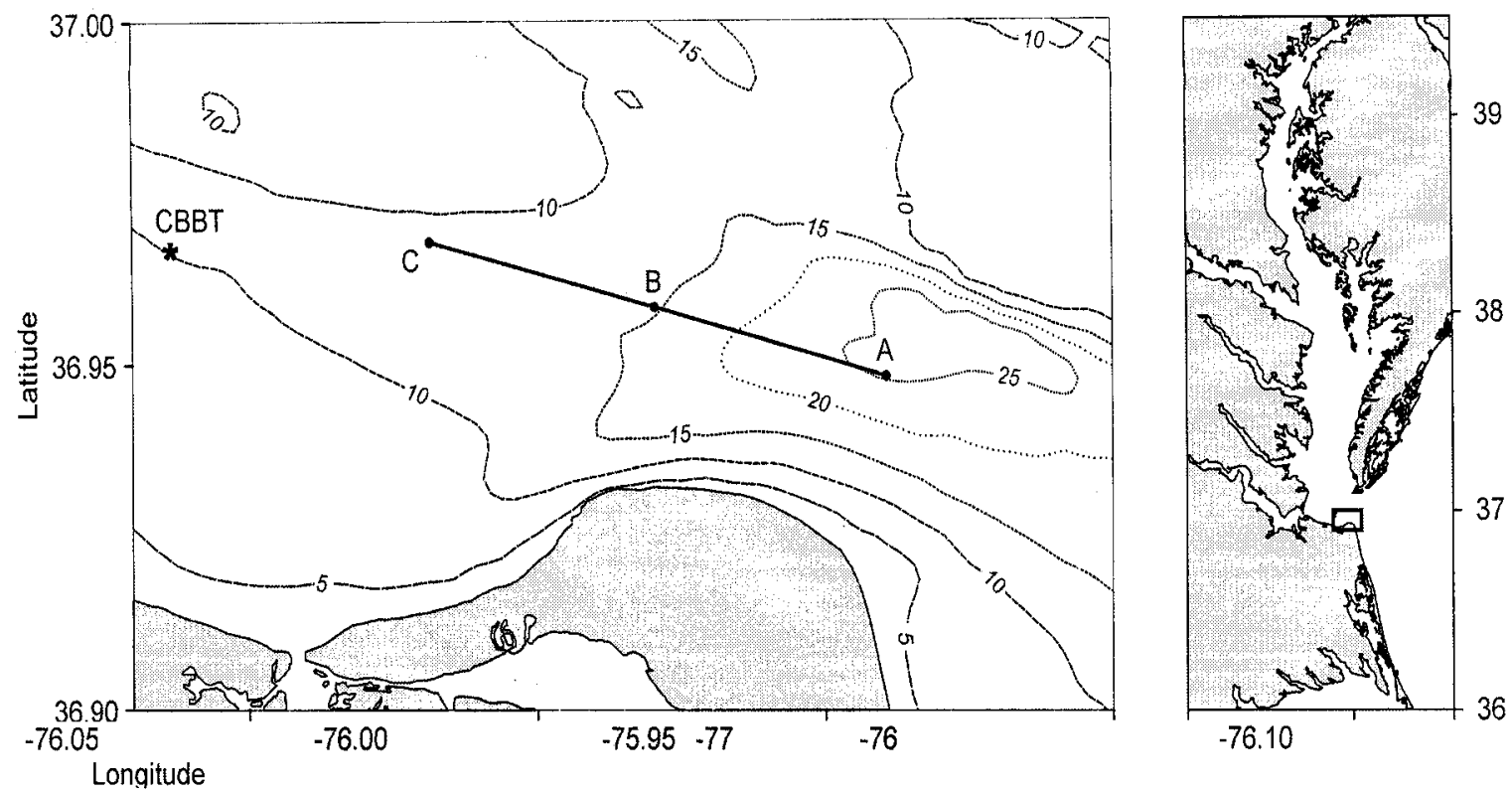

Fig. 5. Study area in the Chesapeake Bay mouth, and the ship track during the experiment on February 25, 2000. Chesapeake Bay Bridge Tunnel (CBBT) station (*), and CTD (A,B and C) stations $(\bullet)$ are shown.
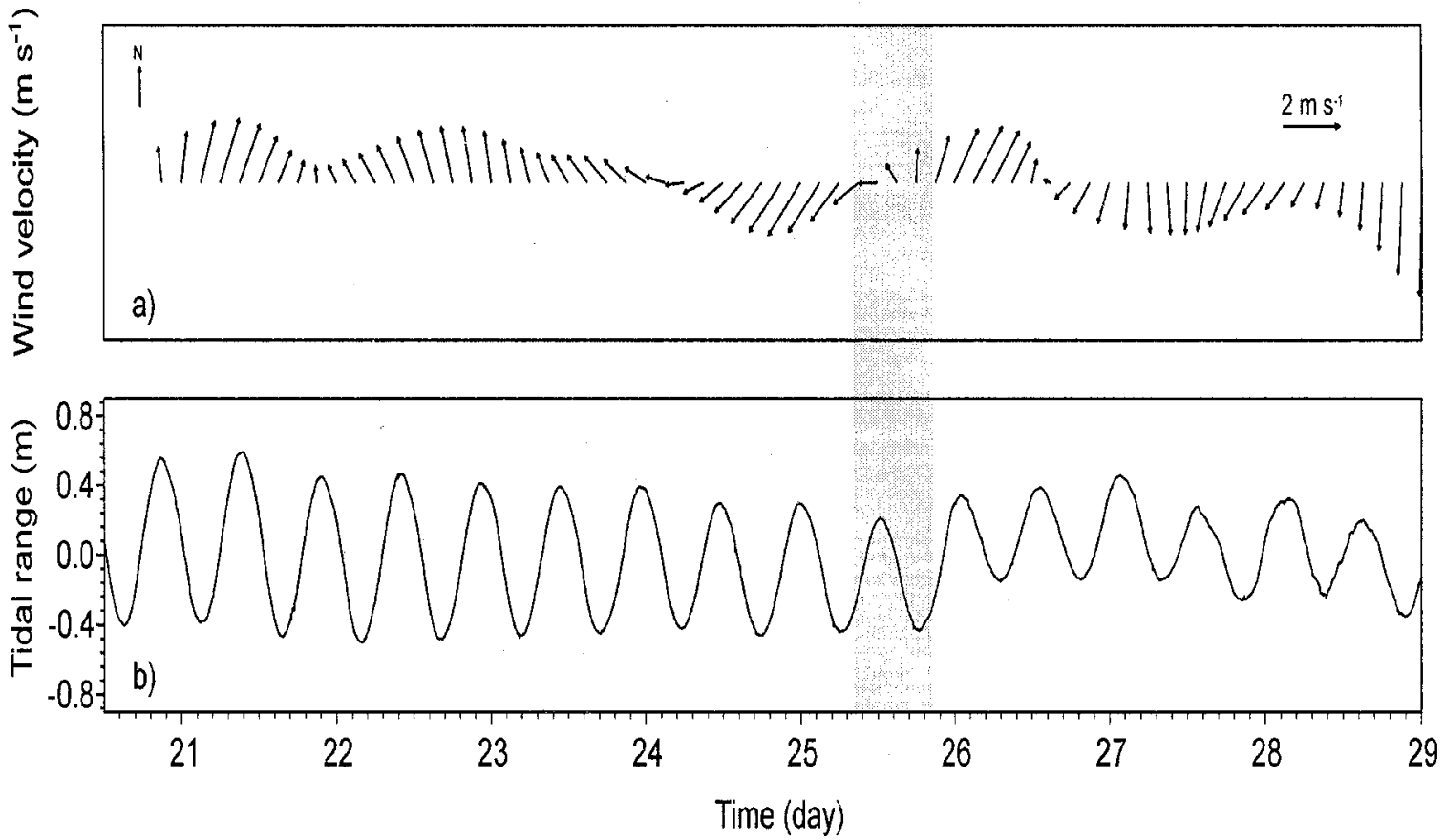

Fig. 6. Ancillary data for the Chesapeake Bay Mouth Hollow. a) Wind velocity and b) tidal range at Chesapeake Bay Bridge Tunnel station during the experiment on February $25,2000$. 


\subsection{Data processing for all sites}

Buoyancy frequencies $(N)$ were derived from data collected at CTD stations (Table 1,2) and over the Rappahannock Hollow according to Pond and Pickard (1986):

$$
N^{2}=g E
$$

where $g$ is the acceleration due to gravity; and $E$ is the stability of the water column. In turn, $E \cong-\frac{1}{\rho} \frac{\partial \sigma_{t}}{\partial z} ; \rho_{z}$ is the density of sea water at depth $z$; and $\sigma_{t}$ is the density anomaly $\left(\mathrm{kg} \mathrm{m}^{-3}\right)$.

The Richardson number calculated using the buoyancy frequency (1) provides information on the competition between the stabilizing effect of buoyancy and the destabilizing effect of velocity shear and was calculated to determine turbulence effects following Gill (1982):

$$
R i=\frac{N^{2}}{(\partial v / \partial z)^{2}+(\partial v / \partial y)^{2}}
$$

where $v$ is the along-hollow velocity component, respect to $y$ at depth $z$. As a first attempt to determine the dynamics of a stratified flow over a hollow, a scaling analysis of the vertically integrated along-hollow momentum equation (3) was performed:

$$
\left\langle\frac{\partial v}{\partial t}\right\rangle+\left\langle u \frac{\partial v}{\partial x}\right\rangle+\left\langle v \frac{\partial v}{\partial y}\right\rangle+\left\langle w \frac{\partial v}{\partial z}\right\rangle+\langle f u\rangle=-\left\langle\frac{1}{\rho} \frac{\partial P}{\partial y}\right\rangle+\left\langle\frac{\partial}{\partial z}\left(A_{v} \frac{\partial v}{\partial z}\right)\right\rangle
$$


where $t$ is time; $u, v$, and $w$ are water velocity components in $x$ (across hollow), $y$ (along hollow), and $z$ (positive upward) direction; respectively; $f$ is the Coriolis parameter; $g$ is the acceleration due to gravity; $\rho$ is the density of sea water; $P$ is total pressure; and $A_{v}$ is the vertical eddy viscosity obtained according to Pacanowski and Philander (1981) as follows: $\left[A_{v}=0.01(1+5 R i)^{-2}+10^{-4}\right]$. The vertical velocity used in equation (3) was calculated by averaging the vertical velocity from the ADCP through 6 $\mathrm{h}$ periods over $5 \mathrm{~km}$ distance. In addition to the scaling analysis of the vertically integrated along-hollow momentum equation, contours of the ratio between horizontal advective acceleration versus Coriolis accelerations and versus friction were used to compare the different accelerations in the momentum equation (3). The ratio of bottom friction to horizontal advective acceleration at the bottom (4) provides information on the relative relevance of each term in the along-hollow momentum equation.

$$
\frac{\left|\frac{1}{\rho} \frac{\partial \tau_{z}}{\partial z}\right|}{\left|v \frac{\partial v}{\partial y}\right|}
$$

where $\rho$ is the density of sea water; and $\tau_{z}=\rho C_{z} v^{2}$ is the bottom stress. In turn, $v$ is the along-hollow velocity at the bottom; and $C_{z}$ is the bottom drag coefficient calculated as in Mellor (1998) as follows: 
$C_{z}=\frac{k^{2}}{[\ln (0.05 H / r)]^{2}}$

where $k$ is the von Karman constant $(0.4) ; H$ is the water depth; and $r$ is the roughness parameter set to $0.1 \mathrm{~cm}$ (Guo and Valle-Levinson, 2005).

The depth-integrated energy flux (6) was calculated using the theory of Llewellyn Smith and Young (2002) to estimate the energy of the generated internal waves. Those waves are produced by the interaction between the barotropic tide and the irregular bathymetry (St. Laurent et al., 2003).

$$
F_{\text {slope }}=F_{0} \delta^{2} \ln \left(1-e^{-4^{\delta^{k(2-\delta)}}}\right)
$$

where $\delta$ is the depth ratio $\left(h_{0} / H\right) ; h_{o}$ is the depth of the trench relative to the maximum depth of the surrounding shoals $(H) ; \varepsilon$ is the ratio of the bottom-slope relative to the wave slope $(s / \alpha) ; s$ is the bathymetric slope $(\partial h / \partial y)$; and $\alpha$ is the wave slope calculated using the lateral $(k)$ and vertical $(m)$ wave numbers as follows:

$$
\alpha=\left|\frac{k}{m}\right|=\left(\frac{W^{2}-f^{2}}{N^{2}-W^{2}}\right)^{1 / 2}
$$

where $f, N$, and $W$ are the inertial, buoyancy and tidal frequencies, respectively. In turn, $F_{0}$ is the energy flux amplitude calculated following St. Laurent et al. (2003): 
$F_{0}=\frac{1}{2 \pi} \rho \frac{\left(\left(N^{2}-W^{2}\right)\left(W^{2}-f^{2}\right)\right)^{1 / 2}}{W} U_{0}^{2} H^{2}$

In equation (8), $\rho$ is the density of sea water; and $U_{0}$ is the barotropic tidal velocity at depth $H$. The ratio of the non-dimensional energy flux $\left(F_{\text {slope }} / F_{0}\right)$ to the bathymetric slope $(s)$, provides information on the internally generated wave energy as a function of the slope.

Finally, the vertically integrated Froude number $\left(F_{r}\right)$ was calculated following Farmer and Armi (1998b) in order to elucidate any possible transition from subcritical $\left(F_{r}\right.$ $<1)$ to supercritical $\left(F_{r}>1\right)$ flow.

$$
F_{r}=\int \sqrt{\frac{\rho}{g} \frac{v^{2}}{\partial \rho / \partial z}} d z
$$

Where $\rho$ is the density of sea water; $v$ is the along-hollow velocity at depth $z$; and $\mathrm{g}$ is the acceleration due to gravity. 


\section{CHAPTER 3}

\section{CAPE CHARLES HOLLOW}

The wind velocities during November 7-8, 2001 and May 28-29, 2002 had a dominant southerly wind component, with velocities below $2 \mathrm{~m} \mathrm{~s}^{-1}$ (Fig. 2). However, there was a marked difference in the amount of fresh water input. The river discharge during May 28-29, 2002 was ten times greater than during November 7-8, 2001, which resulted in stronger vertical stratification during May 28-29, 2002 than during November 7-8, 2001.

The density structure on May 28-29, 2002 showed a continuously stratified water column, ranging from 1014 to $1022 \mathrm{~kg} \mathrm{~m}^{-3}$ (Fig. 7). As expected, the highest density values were found at CTD station A (Fig. 1), owing to its close proximity to the ocean. During flood and ebb tides, the pycnocline was displaced vertically up to $5 \mathrm{~m}$ at both ends of the transect (CTD stations A and E in Fig. 7) and up to $20 \mathrm{~m}$ over the deepest part of the hollow (CTD station D in Fig. 7). This feature, the adjustment of the pycnocline with time over one side of the sill will suggest a hydraulic jump. The hydraulic jumps are common features founded over sills, but that has never been documented over hollows before. The buoyancy frequency showed the strongest vertical density gradients during ebb tide at a depth of $5 \mathrm{~m}$ (Fig. 7). During flood tide, the incoming denser ocean water produced a more homogeneous water column damping the vertical density gradient. During ebb, buoyant water above $5 \mathrm{~m}$ depth was flushed from the estuary which increased the vertical density gradient. This was consistent with tidal straining (Rippeth et al., 2001). 

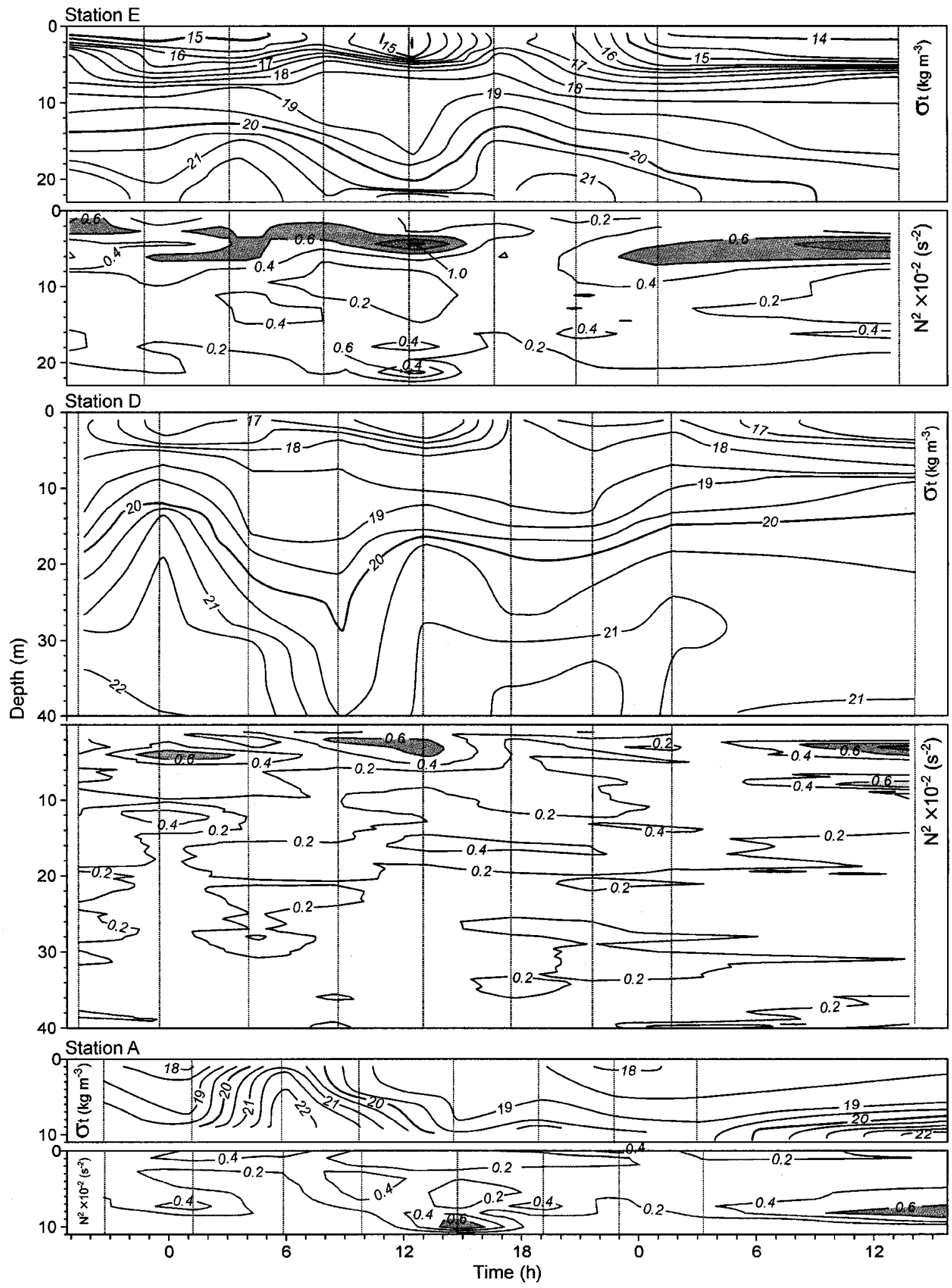

Fig. 7. Time series 1 at Cape Charles Hollow. Time series of sigma-t and bouyancy frequencies at CTD station E, D and A during May 28-29, 2002. CTD locations are indicated by dotted lines. 


\subsection{Intratidal variations of the flow}

During flood tide, an evident acceleration of the flow was observed as it moved toward the deepest part of the hollow (Figs. 8a, c), in contrast to the deceleration expected from two-dimensional Bernoulli-type dynamics. In two-dimensional Bernoulli-type dynamics, without lateral water intrusion, the flow is expected to decelerate as it moves through an increasing water column, or through an expansion in cross sectional area owing to mass conservation (Gill, 1982). The acceleration of the mid-depth flow $(\sim 20 \mathrm{~m})$ as it moved toward the deepest part of the hollow (contours of $30 \mathrm{~cm} \mathrm{~s}^{-1}$ in Fig. $8 \mathrm{a}$ and $70 \mathrm{~cm} \mathrm{~s}^{-1}$ in Fig. 8c), should have been caused by lateral water intrusions. Once the flow passed through the deepest part of the hollow, it decelerated. This feature should have resulted from lateral water outflow, as suggested by the horizontal convergence of the alonghollow flow on the landward side of the hollow (Figs. 8b, d). The convergence along the hollow indicated lateral water outflow, i.e. for mass conservation to exist, $\partial \mathrm{u} / \partial \mathrm{x}+\partial \mathrm{w} / \partial \mathrm{z}$ must be positive if $\partial \mathrm{v} / \partial \mathrm{y}$ is negative, while the divergence indicated lateral water intrusion.

The acceleration of the near bottom flow, and the hollow bathymetry caused the pycnocline to tilt down approximately $20 \mathrm{~m}$, suggesting the formation of lee waves (e.g. Cummin and Oey, 1997; Farmer and Armi, 1986). The down sill pycnocline adjustment was qualitative evidence of hydraulic controls (Farmer and Armi, 1986). Therefore two mechanisms accelerated the along-hollow flow as it moves toward an increasing bathymetry, lateral water intrusion at mid-depth and the adjustment of the pycnocline near the bottom. 
During ebb tide, the strongest outflow was observed in the upper $\sim 5 \mathrm{~m}$ and was driven by the barotropic and baroclinic pressure gradient, which flushed the buoyant water from the estuary (Figs. 9a, c). However, the interesting feature was the acceleration of the mid-depth layer flow as it moved toward the deepest part of the hollow (contours of $-45 \mathrm{~cm} \mathrm{~s}^{-1}$ in Figs. 9a, c). This feature was attributed to lateral water intrusion (Figs. $9 \mathrm{~b}, \mathrm{~d})$, as during flood tide. Once the flow passed through the deepest part of the hollow, there was a deceleration of the flow near the bottom owing to lateral water outflow, as suggested by the convergence of near-bottom flow. The divergence near the bottom (positive values in Figs. 9b, d) suggests lateral water intrusion over the landward side of the hollow, while the convergence (negative values in Figs. 9b, d) suggest lateral water outflow.

The velocity patches of the instantaneous velocities (contours of $-45 \mathrm{~cm} \mathrm{~s}^{-1}$ in Fig. 9a) over the southern (seaward) side of the hollow suggested a wave pattern (e.g. Benjamin and Seaman, 1985; Armi, 1986; Davis, 1997) appearing on the leeward side of the hollow. These patches could represent internal waves that are produced by the interaction between the increasing bottom-slope and the stratified flow but that were not resolved appropriately by the sampling. The internal waves at low periodicities $(\sim 10$ min), were only observed during maximum ebb tide periods when the strongest alonghollow flow (Fig. 9a) was present. The flow acceleration was attributed to lateral water intrusion (Fig. 9b) and to the adjustment of the pycnocline to bathymetry, i.e. hydraulic control.

The development of lee waves was also suggested by data from the anchored ADCP station. From February 12-13, 2002, a clear wave internal signal was observed 
between 13 and $16 \mathrm{hrs}$, during flood tide (contours of 30 and $40 \mathrm{~cm} \mathrm{~s}^{-1}$ in Fig. 10). The frequencies of the waves obtained via a Fourier analysis for all depths was 0.7 cycles per hour (Fig. 11), which is equivalent to $1.42 \mathrm{hrs,} \mathrm{respectively.} \mathrm{During} \mathrm{the} \mathrm{period} \mathrm{of}$ observations at the anchored station, the highest spectral energy was found below $20 \mathrm{~m}$ depth, while the smaller spectral energy was located near $10 \mathrm{~m}$ depth (Fig. 11). At this depth (10 m), vertical shears should enhance turbulence as noted by the low Richardson numbers ( $R i<0.25$ around $10 \mathrm{~m}$ in Fig. 12).

The vertical shear effect on the flow field was also discerned on the instantaneous velocities. During ebb (Fig. 9a, c) and flood tide (Fig. 8c), the minimum horizontal velocities were observed near $10 \mathrm{~m}$ depth over the northern (landward) side of the hollow, which also coincided with low Richardson numbers $(R i<0.25)$. The minimum horizontal velocity is most likely created by shear instability $(R i<0.25)$ produced by the interaction of the barotropic tide to changes in topography, i.e. internal waves. Theoretically, for internal tides to be generated over a bathymetric depression, such as hollows, the width parameter $\xi=S \pi L / H$ should be close to $\pi / 2$, for small depth ratios $\delta=h_{0} / H(<1)$, where $h_{0}$ is the depth of the hollow relative to the maximum depth of the surrounding shoals, and $H$ is the total water depth; and $L$ is the width of the hollow with slope $S$ (St. Laurent, 2003). In the case of Cape Charles Hollow, the width parameter is $\xi$ $=1.25(\sim \pi / 2)$, with a depth ratio of $\delta=0.77$; therefore, the minimum velocity at the depth of $10 \mathrm{~m}$ (Fig. 8c and 9a, c) could be generated by shear instability, attributed to internal waves. However, the minimum of the mid-depth along-hollow flow was observed over the landward side and not over the seaward side. This feature was then attributed to the slightly higher slope over the northern (landward) side when compared 
to the one over the southward (seaward) side of the hollow. The slope over the landward side of the hollow was generally $>0.006$ while over the seaward side of the hollow it was $<0.005$, generating less internal wave energy than over the landward slope (St. Laurent, 2003) (Fig. 13).
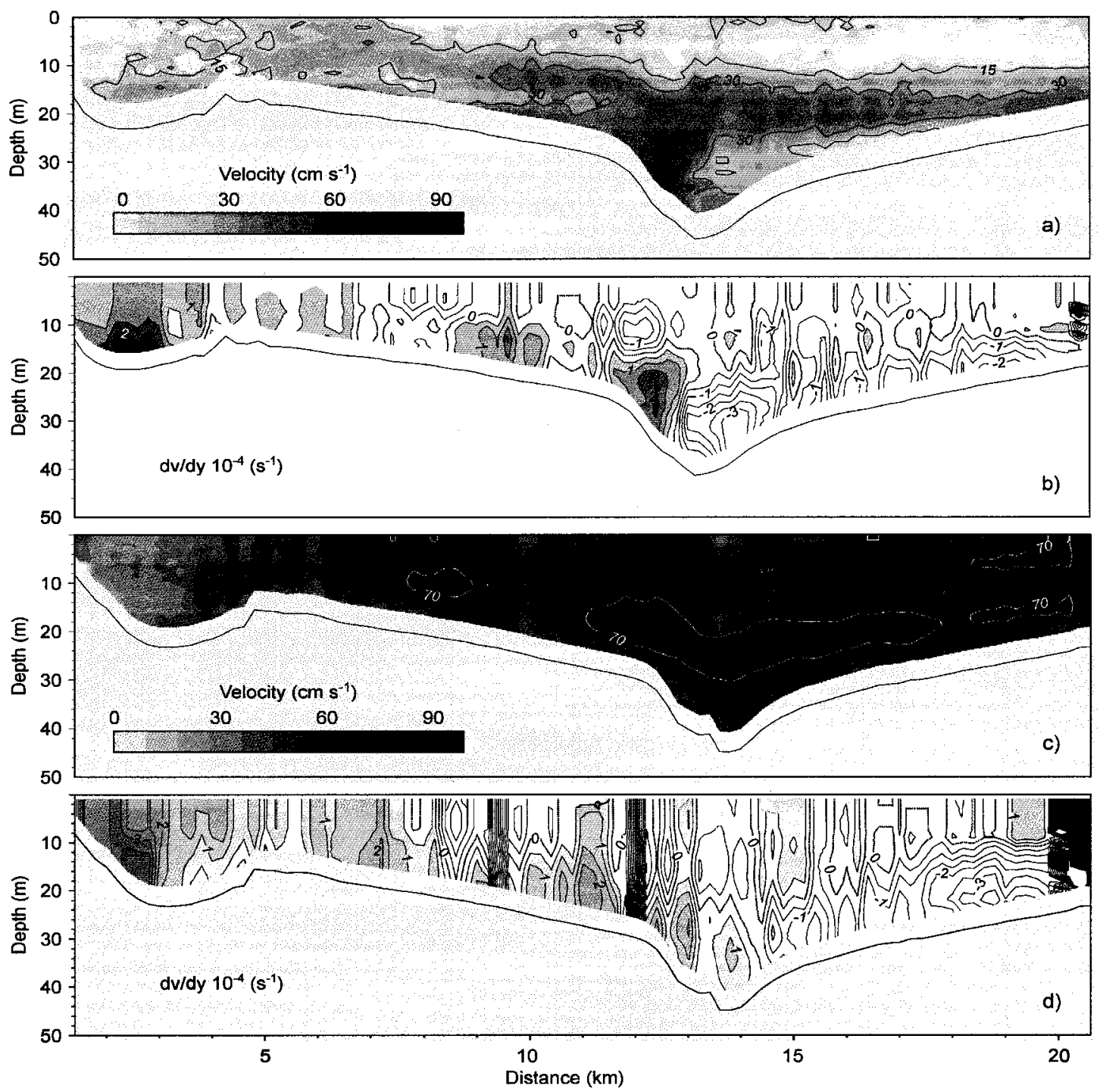

Fig. 8. Instantaneous velocities 1 at Cape Charles Hollow. The along-hollow instantaneous velocity, during flood tide periods, for the a) first repetition, b) seventh repetition, c) the divergence for the first, and d) seventh repetition during May 28-30, 2002. 

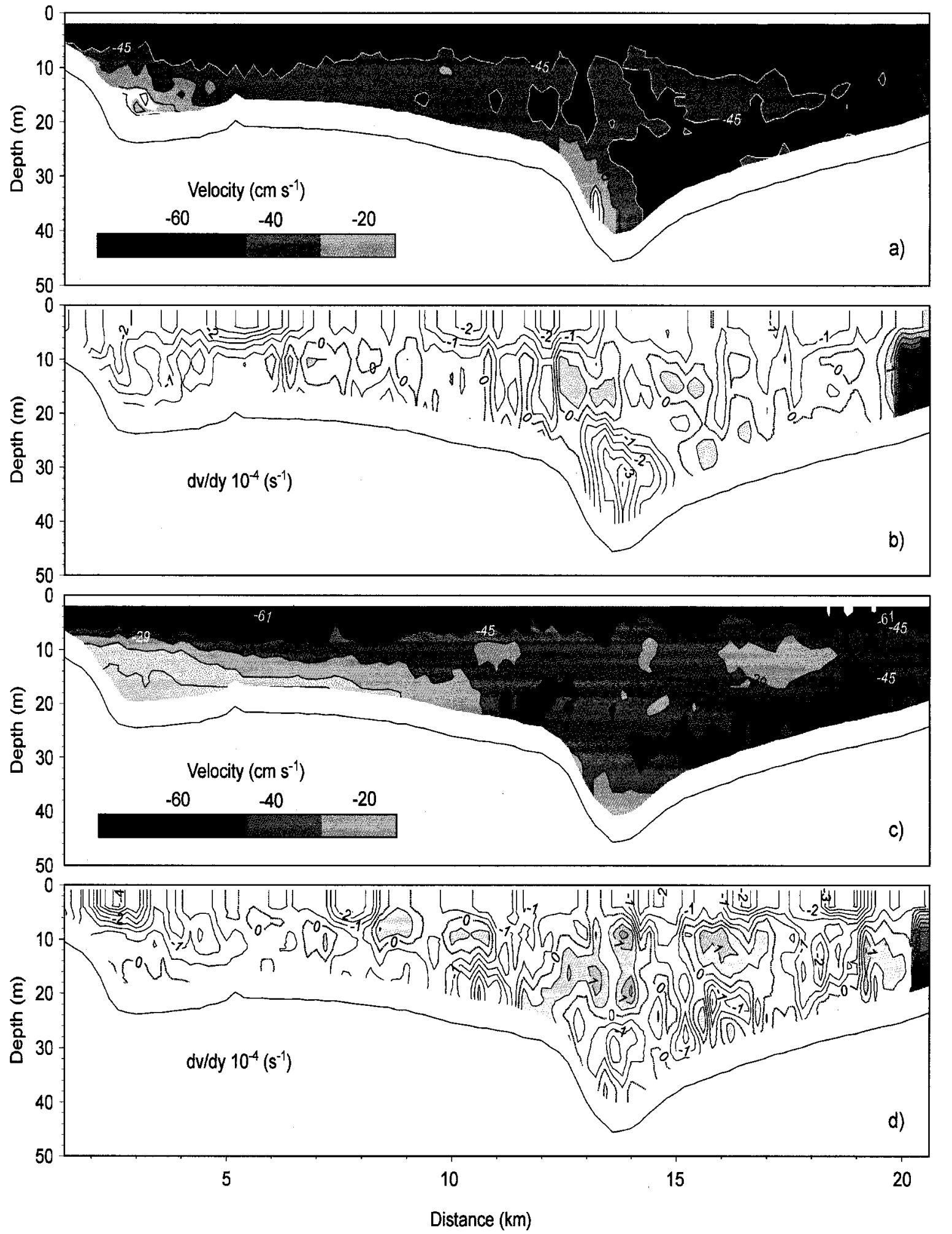

Fig. 9. Instantaneous velocities 2 at Cape Charles Hollow. The along-hollow instantaneous velocity, during ebb tide periods, for the a) fourth repetition, b) tenth repetition, c) the divergence for the fourth, and d) tenth repetition during May 28-30, 2002. 


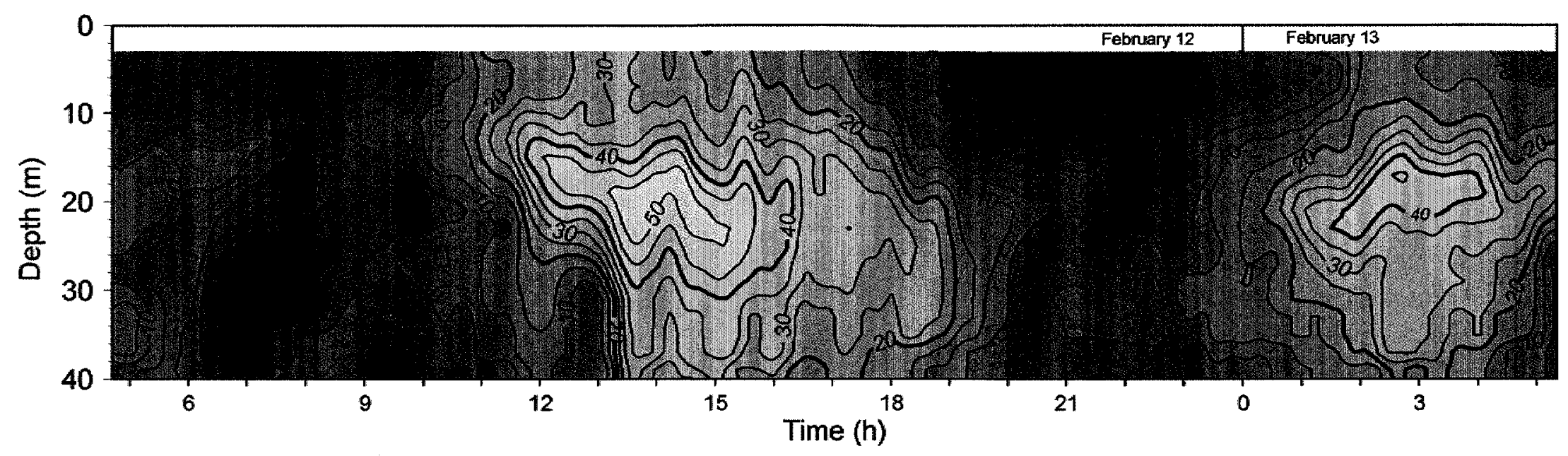

Fig. 10. Time series 2 at Cape Charles Hollow. Time series contours for the along-hollow velocity obtained with the anchored ADCP during February 12-13, 2002. 


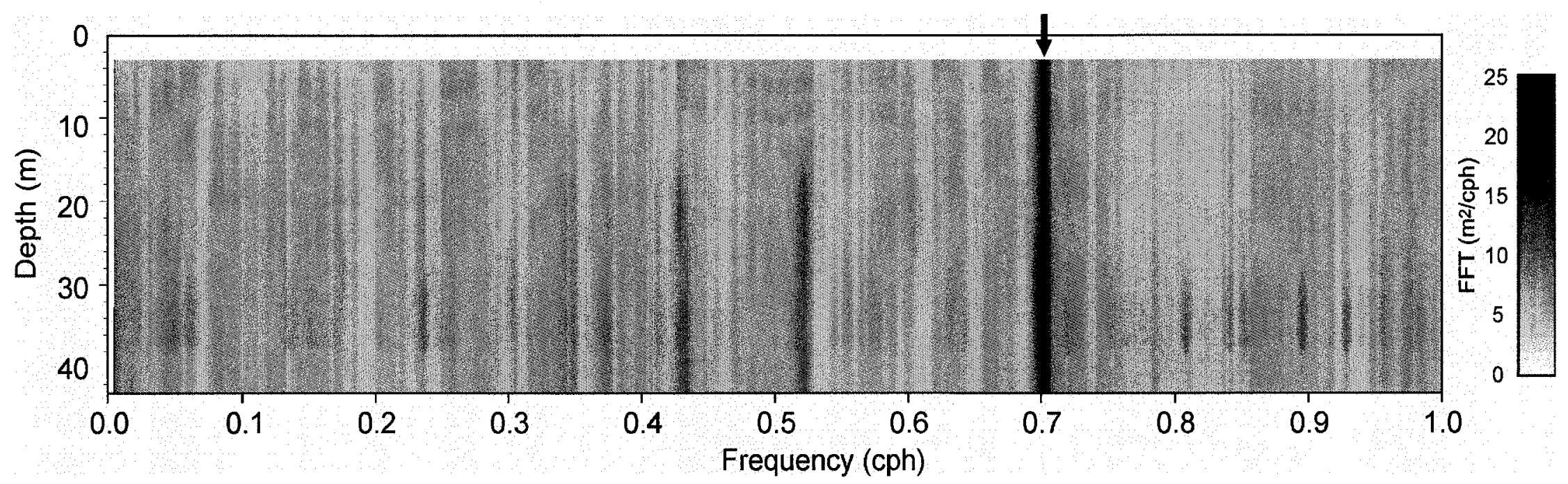

Fig. 11. Spectral energy. Spectral energy contours of the along-hollow velocity obtained with the anchored ADCP data during February 12-13, 2002. 


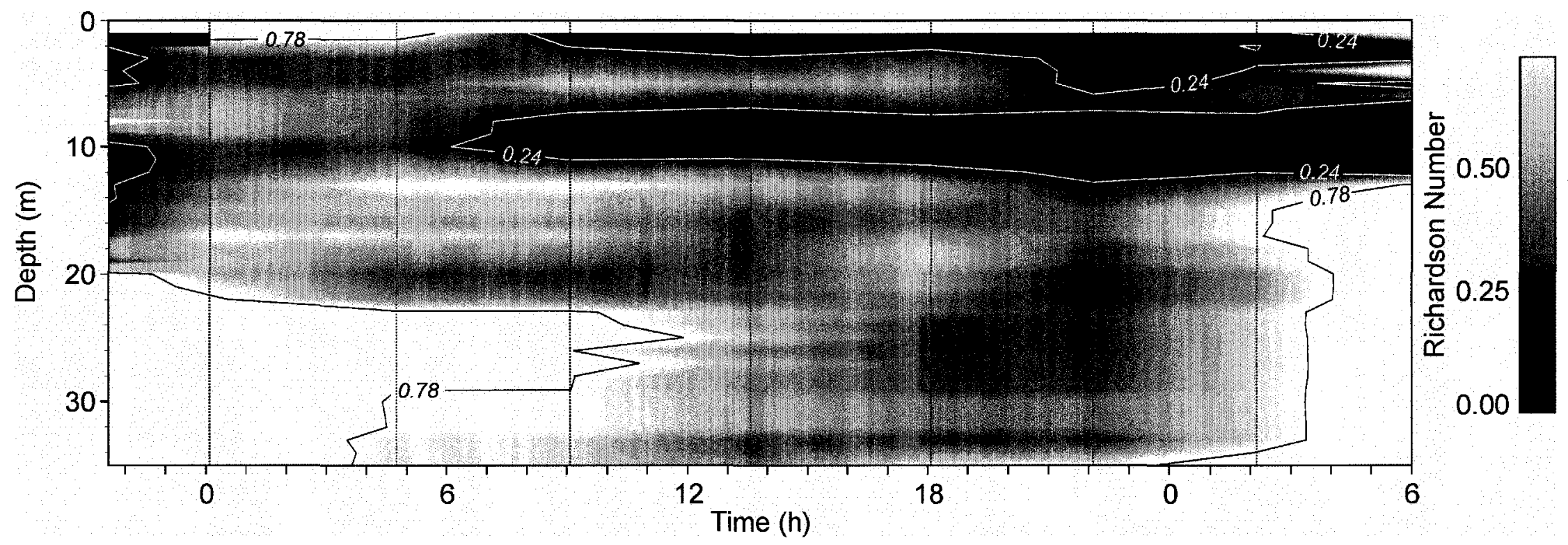

Fig. 12. Time series 3 at Cape Charles Hollow. Time series contours of the Richardson number at CTD station D, during May 2829, 2002. CTD locations are indicated by dotted lines. 


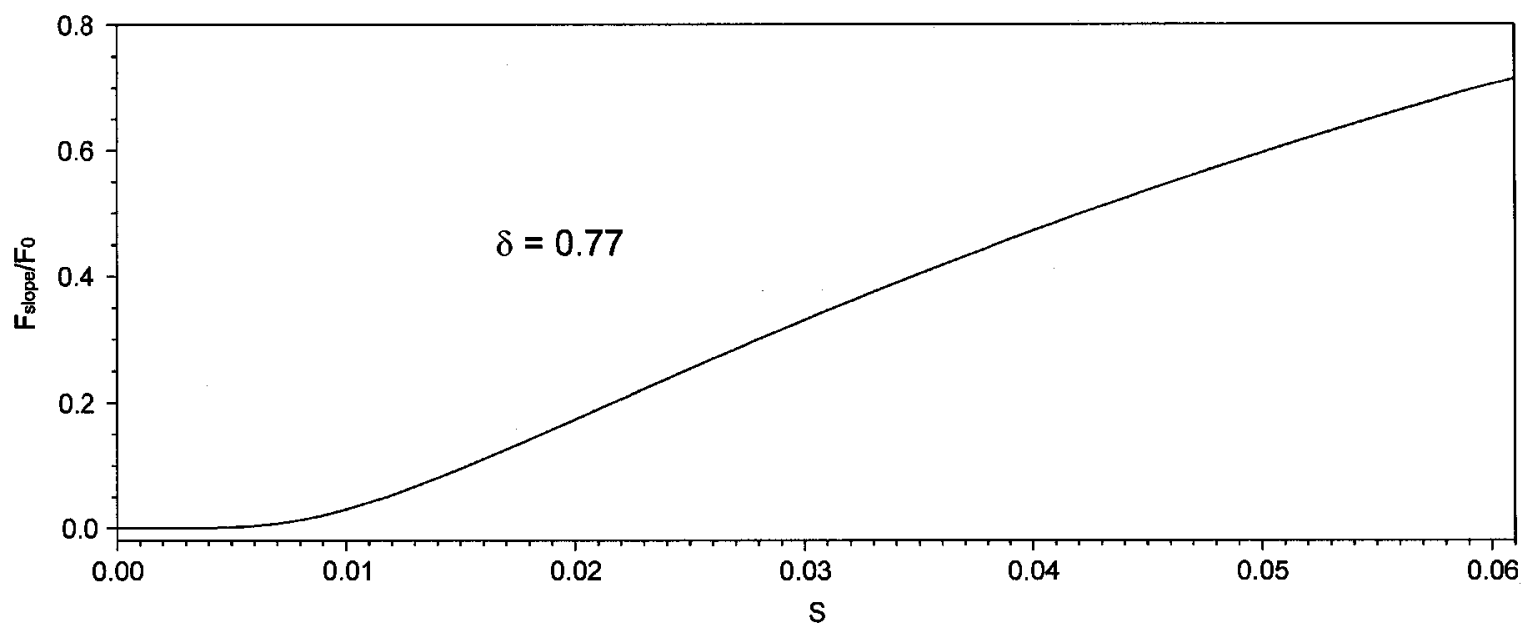

Fig. 13. Energy flux. Nondimensional energy flux for a hollow versus the bathymetric slope with depth ratio of 0.77 , as for Cape Charles Hollow.

As a first attempt to elucidate the dynamics over the hollow, an along-hollow momentum scaling analysis was carried out during flood and ebb tide periods with the values given in Table 3. The results of this analysis using equation (3) indicate that horizontal advection, pressure gradient and Coriolis acceleration should contribute to the dynamics. During flood, all the terms in equation (3) were of the same order of magnitude with the exception of the frictional term, which was two orders of magnitude smaller. The dynamics were obtained with a vertically integrated scaling analysis, using a representative value for the entire water column. However, internal friction should be important at the density interface $\sim 10 \mathrm{~m}$ depth as it explains part of the local minimum during ebb and flood tidal current periods. The values of equation (3) during flood were, respectively: $0.46 \times 10^{-4}+1.7 \times 10^{-4}+5 \times 10^{-4}+0.1 \times 10^{-4}+0.45 \times 10^{-4}=7.7 \times 10^{-4}+$ $0.006 \times 10^{-4}$ in $\mathrm{m} \mathrm{s}^{-2}$. Similarly during ebb tide, the values for equation (3) were: $0.46 \times 10^{-4}$ 
$+1.7 \times 10^{-4}+5 \times 10^{-4}+0.05 \times 10^{-4}+0.45 \times 10^{-4}=7.2 \times 10^{-4}+0.0028 \times 10^{-4}$ in $\mathrm{m} \mathrm{s}^{-2}$. The dominant terms were horizontal advection, pressure gradient and Coriolis acceleration.

The vertically integrated scaling analysis was corroborated by comparing the different acceleration in the along-hollow momentum equation. The magnitude of horizontal advective acceleration and Coriolis acceleration (Fig. 14a, b) were comparable during ebb and flood tide periods. The largest ratios were related to low values of $\langle U\rangle$. The contribution of internal friction in the along-hollow momentum equation was determined using the ratio of the horizontal advective acceleration versus internal fiction. The dominance of horizontal advective acceleration over internal friction along the hollow also suggested that internal friction could be negligible in the along-hollow dynamics (Fig. 14c, d). However, near $10 \mathrm{~m}$ depth over the landward side of the hollow internal friction was less than 5 times smaller than horizontal advective acceleration, which is consistent with low Richardson numbers $(R i<0.25)$. For the along-hollow momentum equation to balance, the pressure gradient term should then contribute effectively to the momentum equation. Therefore, during ebb and flood tide periods the intratidal dynamics over the hollow can be explained with three-dimensional Bernoullitype dynamics modified by Coriolis acceleration. The acceleration of the near-bottom current as it moved toward the deepest part of the hollow was a consequence of the pycnocline adjustment to bathymetry. In turn, the acceleration of the mid-depth current was attributed to lateral water intrusion, i.e. three-dimensional Bernoulli-type dynamics. The three-dimensional Bernoulli-type dynamics is the balance between pressure gradient, the baroclinic plus the barotropic pressure gradient, and advective acceleration, which includes the vertical and horizontal part in the along hollow momentum equation. 

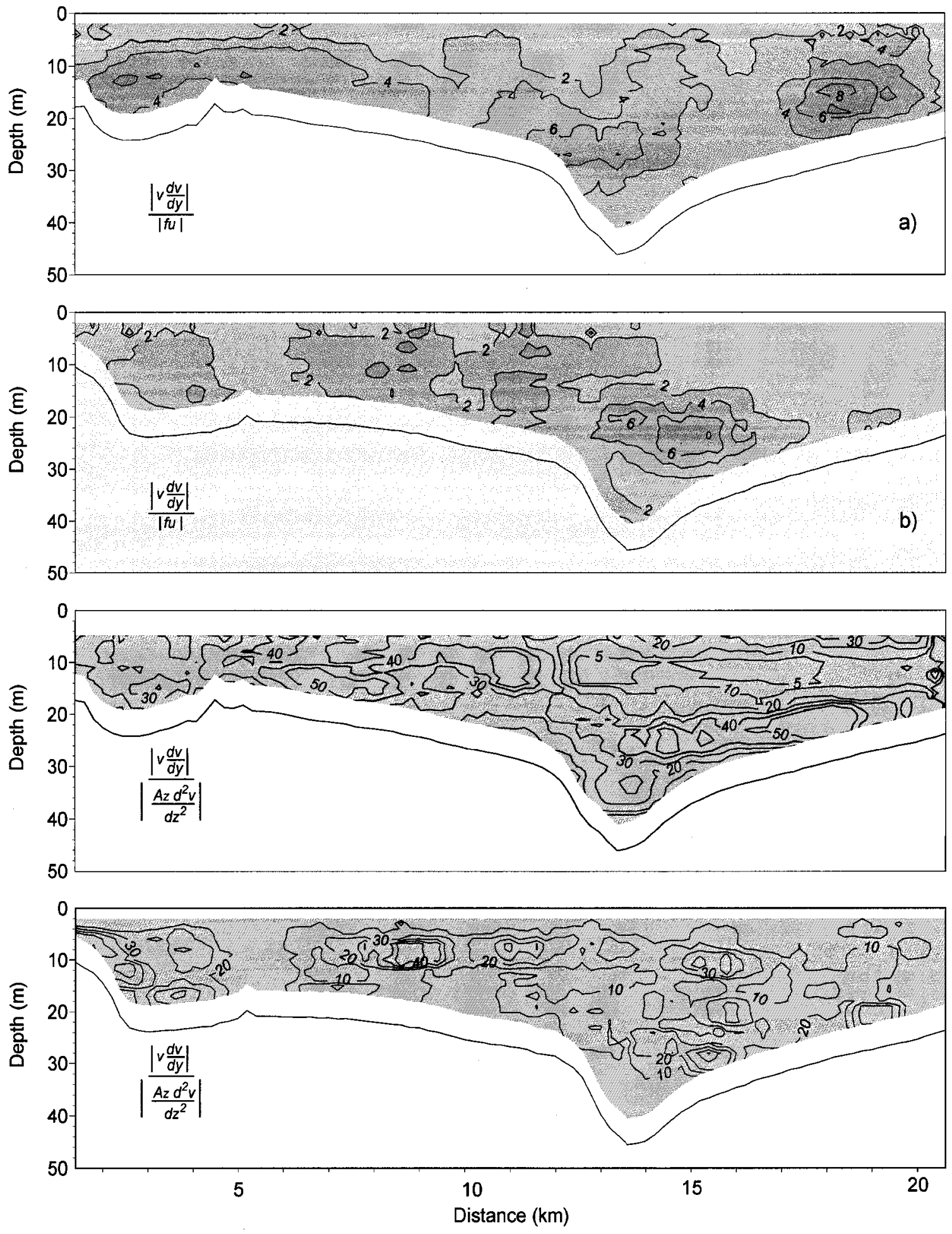

Fig. 14. Acceleration Ratio at Cape Charles Hollow. Absolute value of the ratio between the along-axis advective acceleration versus Coriolis acceleration, a) during flood, b) ebb, and versus internal friction for the fourth repetition, c) during flood tide period for the first repetition, and d) during ebb tide period for the fourth repetition during May 28-30, 2002. 
Table 3

Typical values during ebb and flood tides at Cape Charles Hollow. Typical values for instantaneous $(u, v, w)$ and residual water velocities, length scale $(x, y, z)$, densities $(\rho)$, vertical eddy viscosity $\left(A_{v}\right)$, and time interval $(T)$, for the residual flow, and during ebb and flood tide periods

\begin{tabular}{lccccccccc}
\hline \multicolumn{1}{c}{$u$} & $v$ & $w$ & $x$ & $y$ & $z$ & $\rho$ & $A_{v}$ & $\mathrm{~T}$ \\
\hline & $\left(\mathrm{m} \mathrm{s}^{-1}\right)$ & $\left(\mathrm{m} \mathrm{s}^{-1}\right)$ & $\left(\mathrm{m} \mathrm{s}^{-1}\right)$ & $(\mathrm{m})$ & $(\mathrm{m})$ & $(\mathrm{m})$ & $\left(\mathrm{kg} \mathrm{m}^{-3}\right)$ & $\left(\mathrm{m}^{2} \mathrm{~s}^{-1}\right)$ & $(\mathrm{s})$ \\
\hline$<v>$ & 0.2 & 0.45 & $1 \times 10^{-4}$ & $3 \times 10^{3}$ & $2 \times 10^{4}$ & 40 & 1018.5 & $3.9 \times 10^{-4}$ & 86400 \\
Flood & 0.5 & 1 & $4 \times 10^{-4}$ & $3 \times 10^{3}$ & $2 \times 10^{4}$ & 40 & 1019.9 & $3.3 \times 10^{-4}$ & 21600 \\
Ebb & 0.5 & 1 & $2 \times 10^{-4}$ & $3 \times 10^{3}$ & $2 \times 10^{4}$ & 40 & 1018.1 & $4.5 \times 10^{-4}$ & 21600 \\
\hline
\end{tabular}

\subsection{Amplitude of semidiurnal tidal currents}

During November 7-8, 2001, the amplitude of the tidal current obtained via a least-squares fit to diurnal and semidiurnal harmonics revealed the largest values at the surface (50 $\mathrm{cm} \mathrm{s}^{-1}$ ) (Fig. 15a). However, the lowest values, over the northern (landward) side of the hollow were found at a mid-depth of $\sim 10-12 \mathrm{~m}$ depth, where the strongest vertical gradient in density was found (Figs. 16a, b). The minimum tidal current amplitude was not found near the bottom as is usually observed in shallow estuaries influenced by bottom friction. This interesting distribution (Fig. 15a, b) was attributed to conversion of barotropic to baroclinic energy which generated vertical shear in the horizontal currents enhancing turbulence at this depth and to near-bottom acceleration owing to the adjustment of the pycnocline to bathymetry. The energy conversion was suggested by the Richardson number with contours of $R i<0.25$ (Fig. 16c), which reduced the tidal amplitudes at this depth. This was consistent during the sampling 
performed on May 28-30, 2002, where the along-hollow tidal amplitude showed a minimum at $\sim 10 \mathrm{~m}$ depth (Fig. 15b). The phase of the along-hollow tidal current over the southern side of the hollow had a phase lag of approximately 6 minutes from surface to bottom (Fig 15c). This pattern has been attributed to weak bottom friction reducing the near-bottom flows and making them slightly more rapidly responsive to tidal forcing than the near-surface flow. If friction were relevant over the hollow, a higher vertical phase lag should be expected. The interesting feature, however, was located over the northern (landward) side of the hollow and was attributed to vertical shear of horizontal flow owing to the generation of internal waves at this location. The shear instability (low Richardson numbers), produced weaker tidal currents near $10 \mathrm{~m}$ depth allowing the water column between 7 and $12 \mathrm{~m}$ depth to respond faster to tidal changes than its overlying and underlying waters. 


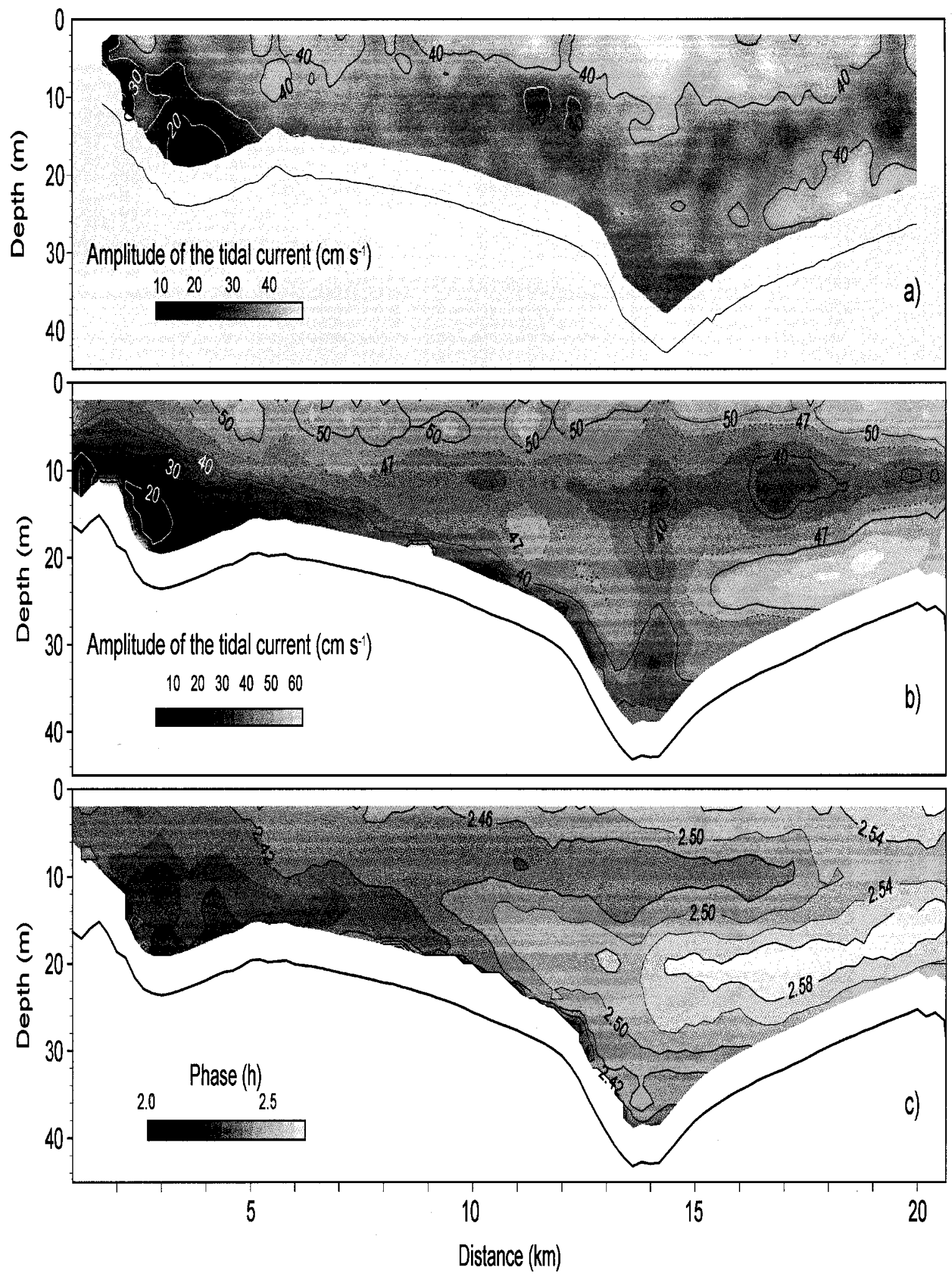

Fig. 15. Tidal current at Cape Charles Hollow. a) Amplitude of the tidal current during November 7-8, 2001 and, b) amplitude of the tidal current, and c) phase along transect I during May 28-30, 2002. 


\subsection{Mean or residual flow}

The residual flow over the hollow, during November 7-8, 2001 (Fig 17a) was characterized by surface outflow and bottom inflow as expected for a partially mixed estuary (Pritchard, 1965). The most distinctive feature, however, was the subsurface acceleration of the inflow as it moved toward the deepest part of the hollow. The flow acceleration was most likely produced by lateral water intrusion from the shoals in the southern (seaward) part of the hollow, as suggested by the along-hollow vertically integrated volume flux in $\mathrm{m}^{2} \mathrm{~s}^{-1}$ per unit channel width (Fig. 17b). The volume flux indicated an increase over the seaward portion of the hollow and a decrease over the landward part of the hollow. This increase in volume should result from water that is suctioned from the sides toward the hollow. Similarly, the volume decrease should represent extrusion of water to the sides of the hollow. The evident deceleration of the flow once it passed through the deepest part of the hollow was then exclusively attributed to lateral water outflow (Fig. 17b). The residual flow features were consistent six months later (Fig. 17c) under wet conditions (Fig. 2b). The residual flow during May 28-30, 2002 accelerated as it moved toward the deepest part of the hollow. This was again attributed to lateral water intrusion, as suggested by the sign change in the divergence of the alonghollow residual flow (Fig. 17d). The residual flow during May, 2002 also showed a subsequent deceleration after it passed through the deepest part of the hollow, attributed to lateral water outflow. The vertically integrated scaling analysis for the residual flow, using equation (3) and Table 3 leads to: $5.2 \times 10^{-4}+30 \times 10^{-4}+2 \times 10^{-4}+3.4 \times 10^{-4}+17 \times 10^{-4}$ $=57 \times 10^{-4}+0.19 \times 10^{-4}$ in $\mathrm{m} \mathrm{s}^{-2}$. The values obtained indicated that the residual flow, as 
was the case with the tidal flow, could be explained as a three-dimensional Bernoulli-type dynamics modified by Coriolis acceleration.
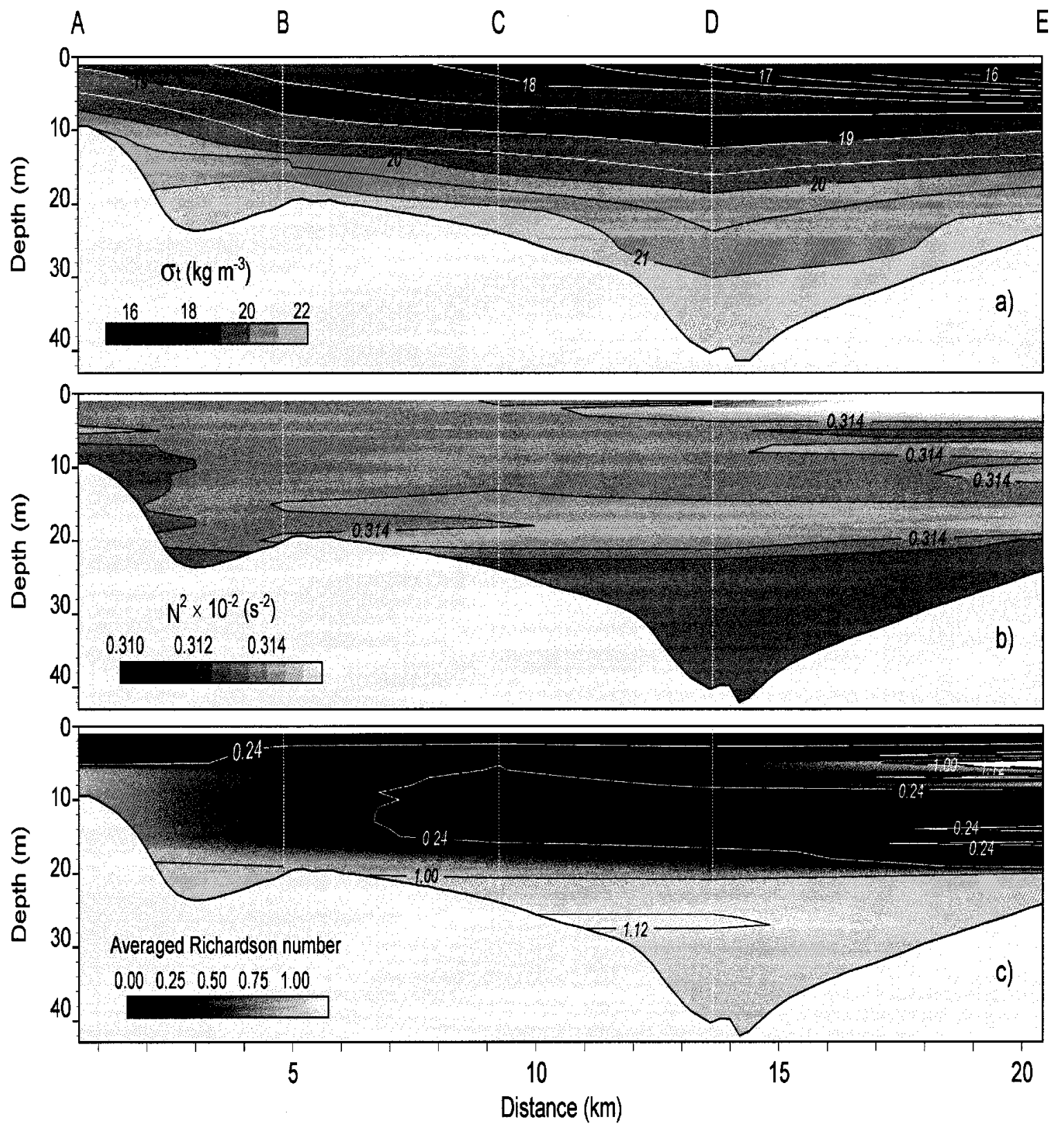

Fig. 16. Density derivatives at Cape Charles Hollow. a) Density contours, b) buoyancy frequency, and c) averaged Richardson number obtained with the residual velocities and density profiles during November 7-8, 2001. CTD locations are indicated with dotted lines. 

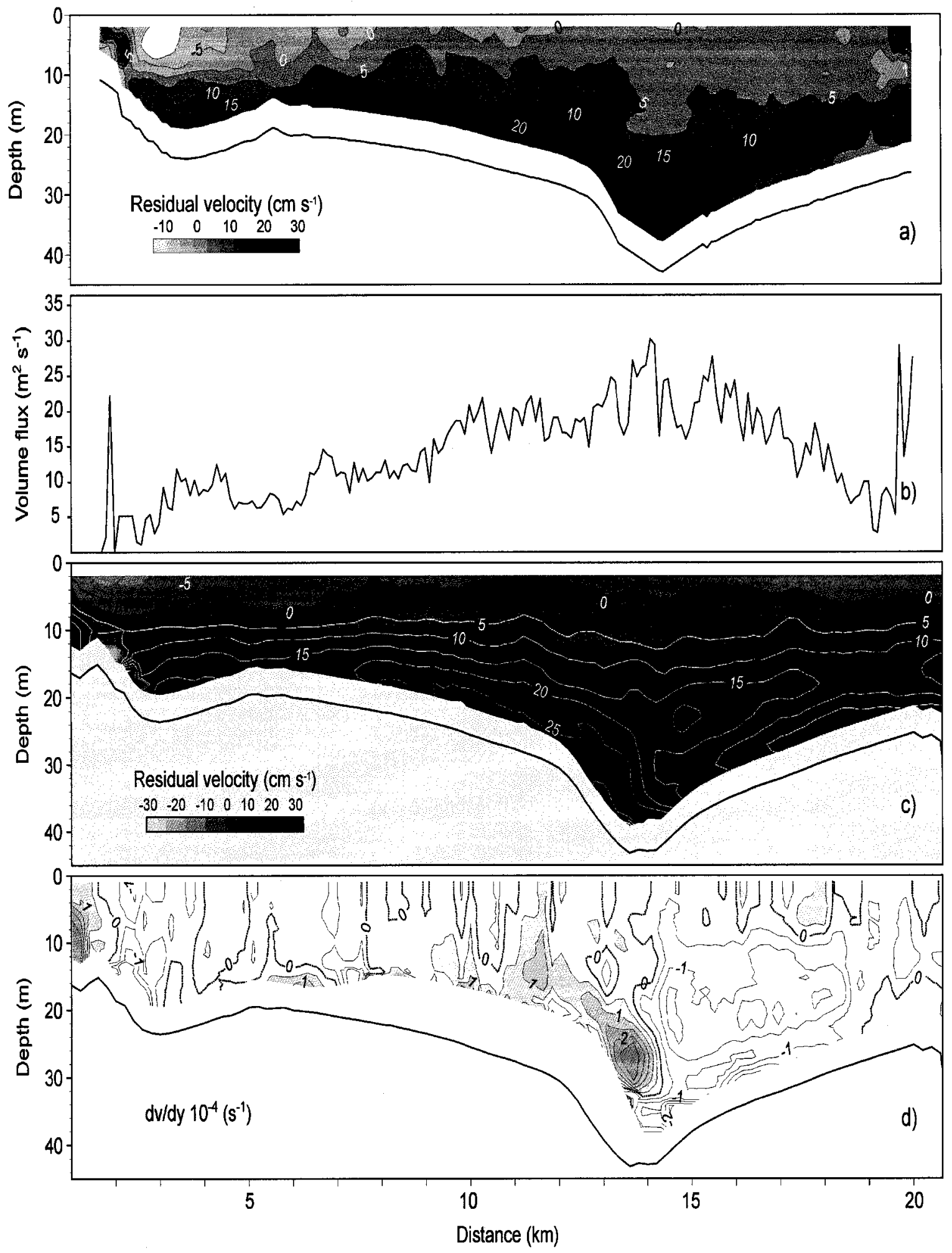

Fig. 17. Residual flow at Cape Charles Hollow. a) Residual flow, b) along-hollow vertically integrated volume fluxes during November 7-8, 2001, c) the residual flow, and d) divergence during May 28-30, 2002. 


\subsection{Transverse variability}

The suggestion of lateral intrusion and extrusion of water over the hollow was reinforced with a transverse section in the lower Chesapeake Bay that crossed the deepest part of the hollow (Fig. 18). The transverse residual flow (depicted by the arrows in Fig. 18a) showed a convergence at the surface over the deepest part of the hollows. The convergence zone should have been associated with lateral intrusions of water that may have contributed to increase downward vertical velocities. The strong lateral flow observed over the right side (looking into the estuary) of the hollow was further evidence of the lateral water intrusion. This feature also suggests a three-dimensional Bernoullitype dynamics over the hollow, owing to strong lateral variation of streamwise flow.

The observed intensification of the along-hollow residual flow (contours in Fig. 18a) over the east side of the hollow was produced by Coriolis acceleration. When rotation dominates over friction, it causes the exchange flow to appear asymmetrically distributed across the channel (Valle-Levinson et al., 2003). This pattern was also observed with the along-hollow tidal amplitude of the current (Fig. 18b). The intensification of the along-hollow flow as it moves toward an increasing bathymetry, produced by lateral water intrusion, and the waves formation at the edge of the hollow are represented schematically in Fig. 19. 

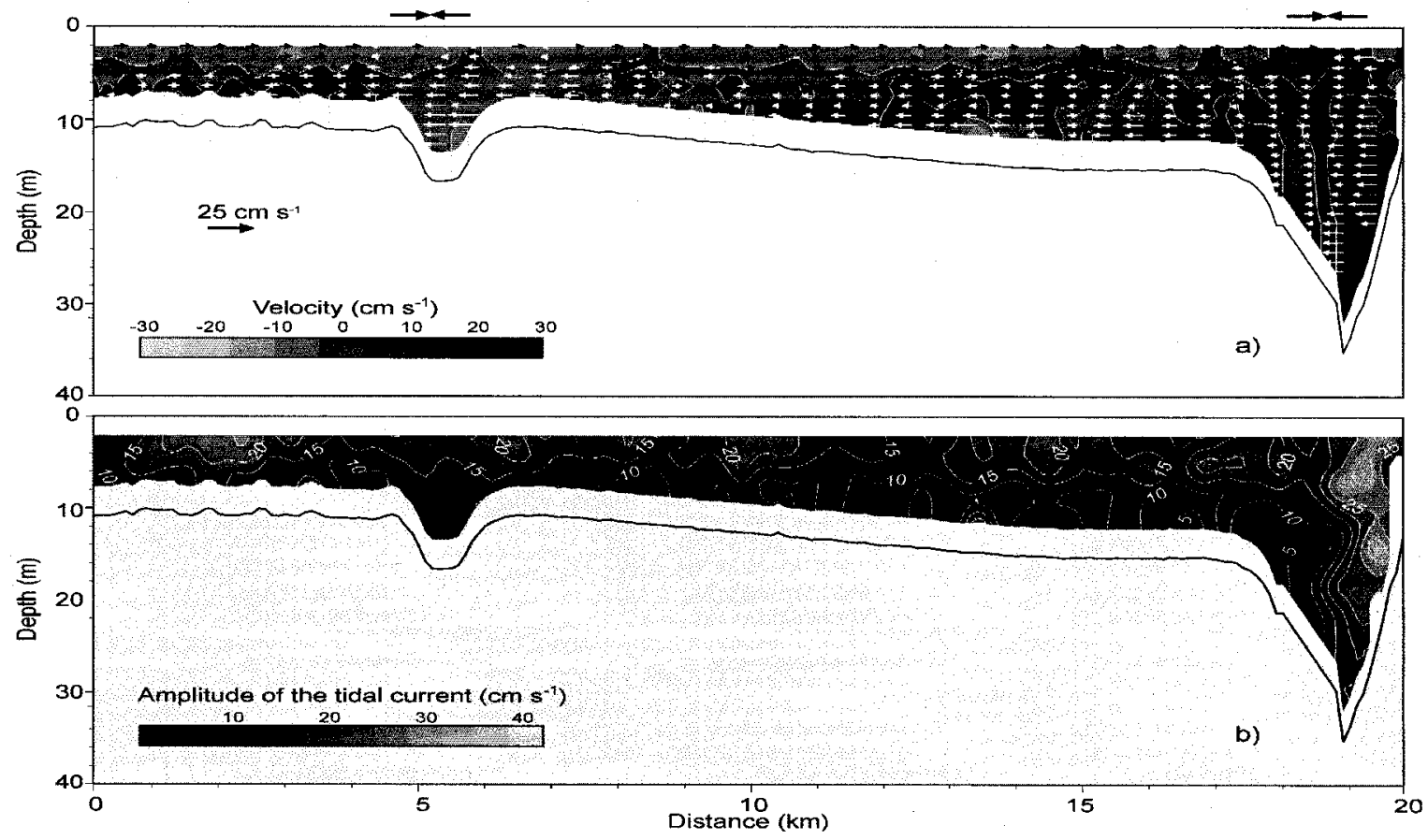

Fig. 18. Transverse transect at Cape Charles Hollow. a) Along-estuary residual velocity represented with contour, across-estuarine velocity represented with arrows, and b) the along-estuarine amplitude of the tidal current along transect II during November 8, 2001.

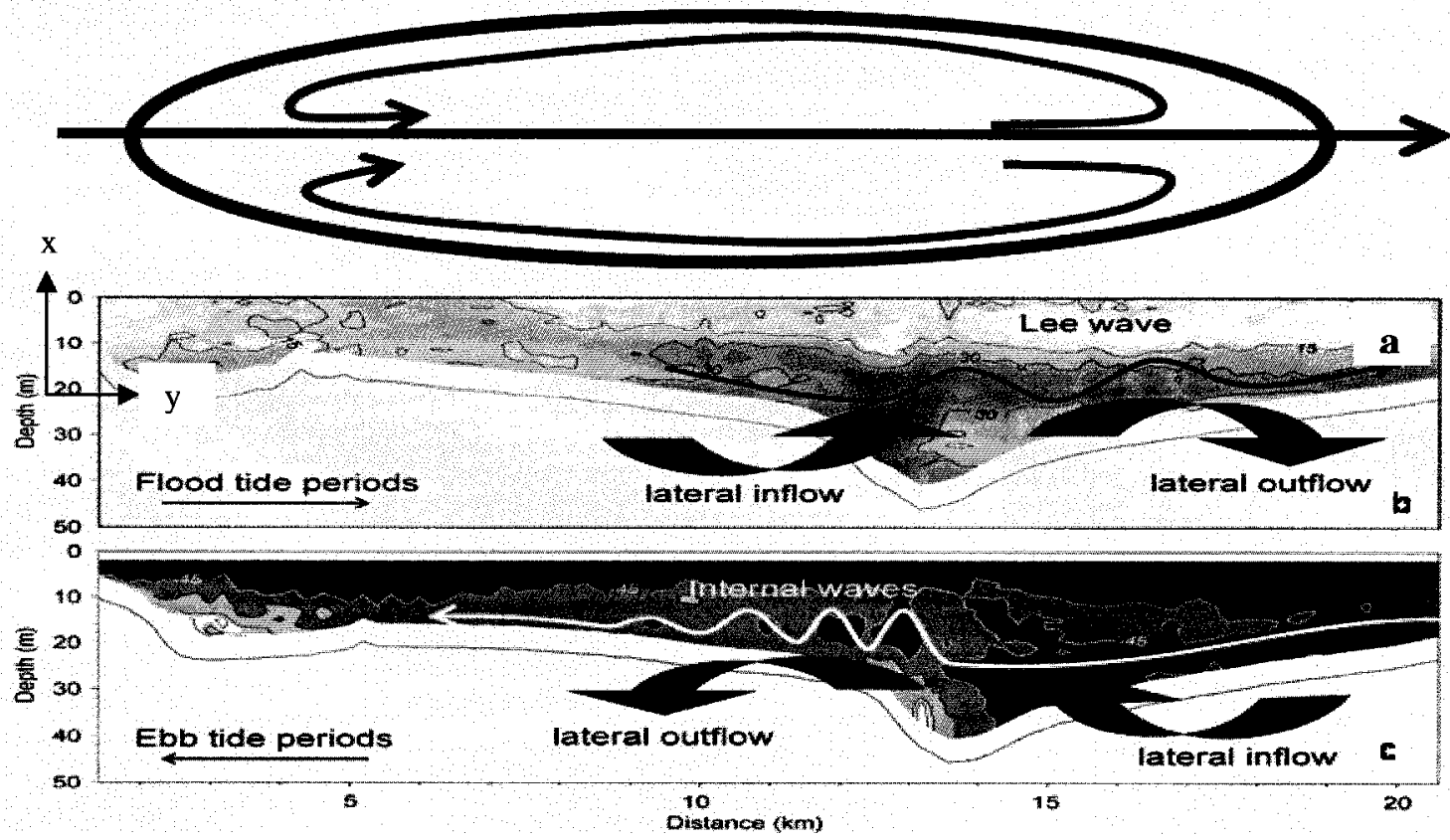

Fig. 19. Schematic representation. a) The surface flow for the horizontal recirculation, and lateral water intrusion into the hollow during, b) floods, and c) ebbs. 


\section{CHAPTER 4}

\section{RAPPAHANNOCK HOLLOW}

The experiments over Rappahannock Hollow were carried out under predominant southerly wind conditions $\left(<4 \mathrm{~m} \mathrm{~s}^{-1}\right)$, and moderate $\left(\sim 3000 \mathrm{~m}^{3} \mathrm{~s}^{-1}\right)$ river discharge (Fig. 4). Southerly wind conditions enhance the surface along-hollow flow during flood, and retard it during ebb tide periods owing to the orientation of the bathymetric depression (Fig. 3). The density profiles over the hollow showed a well defined buoyant surface layer above $10 \mathrm{~m}$ depth (Fig. 20). Density values ranged from 1007 to $1017 \mathrm{~kg} \mathrm{~m}^{-3}$ during ebbs (Fig. 20a), and between 1009 to $1019 \mathrm{~kg} \mathrm{~m}^{-3}$ during floods (Fig. 20c). As expected, the stronger vertical density gradients were observed during ebb tide, when buoyant water was flushed out of the estuary producing a stronger pycnocline than during flood tide. This pattern was consistent with tidal straining (Rippeth et al., 2001), and with the observations over Cape Charles Hollow. What distinguishes this study from the previous observational studies regarding flow dynamics over holes (e.g. Komura, 1973; Mosley and Schumm, 1977) is the presence of a strong pycnocline during ebbs, located near $10 \mathrm{~m}$ depth, according to the buoyancy frequency $\left(N^{2}\right)$. The marked difference in vertical density stratification from flood (Fig. 20d) to ebb (Fig. 20b) tide periods was observed over the hollow. However, away from the hollow's influence over the southern side (seaward), the tidal variation in vertical density stratification was not as strong as over the hollow. 

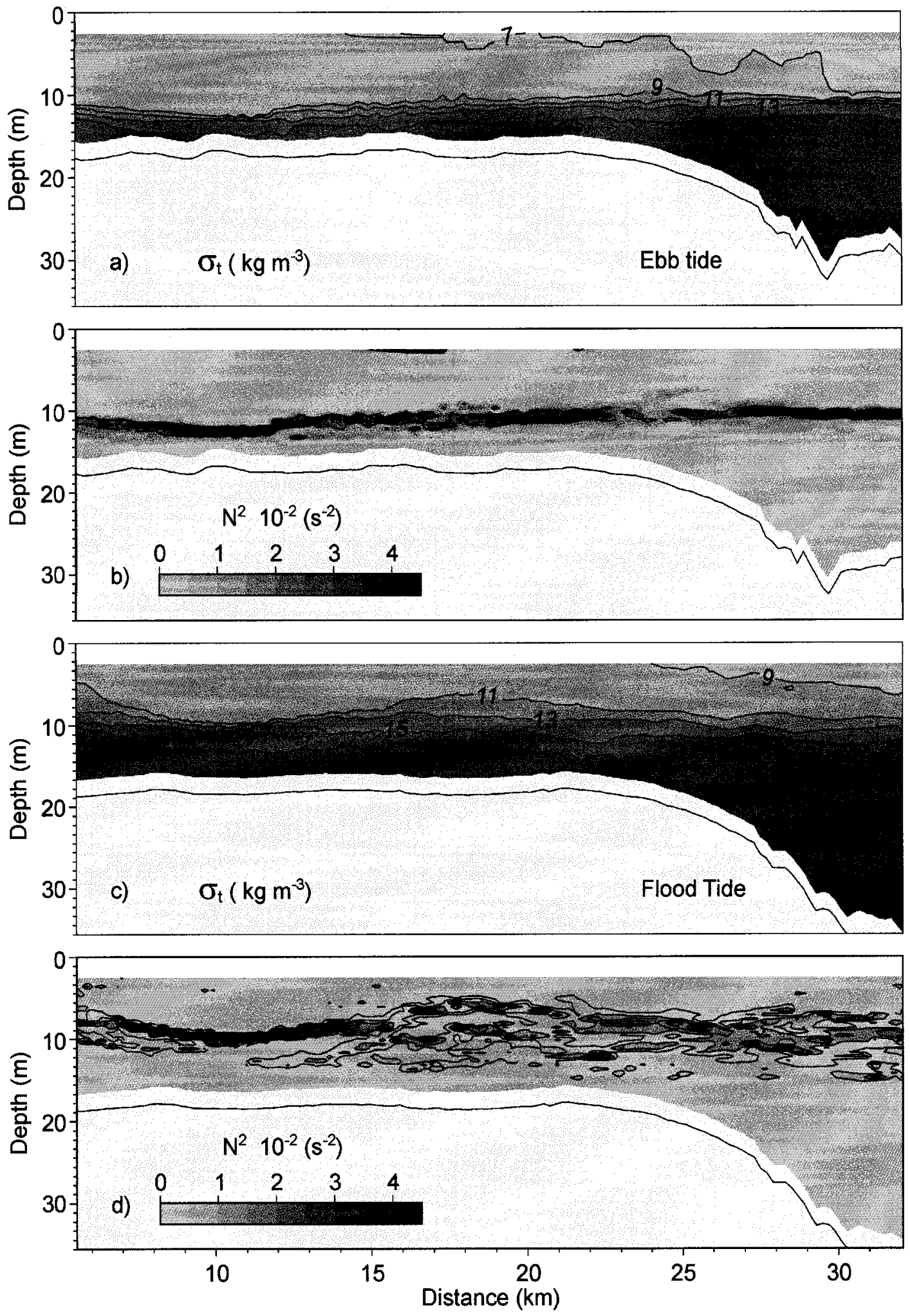

Fig. 20. Instantaneous velocities 1 at Rappahannock Hollow. Contours of the alonghollow a) sigma-t, b) buoyancy frequency during ebb (repetition six), c) sigma-t, and d) buoyancy frequency during flood (repetition eight) tide periods. 


\subsection{Flood tide periods}

The velocity structure during flood tide periods showed an acceleration of the flow as it moved toward the deepest part of the hollow (Figs. 21a, e and 22a, e), in contrast to what could be expected from two dimensional hydraulic theory (e.g. Stommel and Farmer, 1952; Farmer and Freeland, 1983; Farmer and Armi, 1986). In twodimensional Bernoulli-type dynamics the flow is expected to decelerate as it moves toward an increasing bathymetry, or through an expansion in cross sectional area, owing to mass conservation. The acceleration of the near-bottom along-hollow flow suggested strong lateral water intrusion, also suggested by the divergence of the along-hollow flow (Figs. $21 b, f$, and $22 b, f$ ), i.e. for mass conservation to exist, $\partial u / \partial x+\partial w / \partial z$ must be negative if $\partial \mathrm{v} / \partial \mathrm{y}$ is positive. The divergence is then associated with lateral water intrusions, as for Cape Charles Hollow. The subsurface flow acceleration (kilometer 25 in Figs. 21 and 22), where the strongest along-hollow flow was observed, suggested weak bottom friction, in contrast with various findings where friction is important (e.g. ValleLevinson and Lwiza, 1995). If bottom friction were important the near-bottom flow should be expected to be weaker than the near surface flow. However, the influence of bottom friction was observed over the seaward side of the transect away from the influence of the hollow. At this location, between 0 to $15 \mathrm{~km}$ from the starting point of the transect, the bottom velocity was retarded by friction, allowing the near-bottom flow to respond faster to tidal changes.

Transect repetitions during flood, (repetitions sixth and seventh, Figs. 21a, e) had their maximum along-hollow velocities just above the depth where the strongest vertical density gradients were observed (Figs. 21c, g), according to the buoyancy frequency 
(Figs. 21d, h). This feature was consistent with the mid-depth maximum flow observed during flood tide periods over a continuously stratified hollow in shallow waters (Cape Charles Hollow). However, during the tenth and eleventh transect repetition (Fig. 22a, e) the maximum along-hollow flow followed the bathymetry, showing the highest values near the bottom. The strong bottom flow during those repetitions also suggested weak bottom friction over the hollow. During the tenth and eleventh repetition, the pycnocline curved up in contrast to the relatively flat pycnocline in Fig. 21. This feature is most likely produced by the strong lateral water intrusion as suggested by the divergence of the along-hollow flow (positive values in Figs. 22c, g). The predominant easterly winds during those repetitions (Fig. 4) produced a stronger lateral water flow over the hollow than the southerly winds which dominated during the first repetitions.

The curvature of the pycnocline in Fig. 22 (d, h), suggested an expansion of the bottom layer toward the increasing bathymetry, as a consequence of lateral water intrusion (Figs. 22b, f). This feature constrained buoyant water to a thin surface layer over the deepest part of the hollow (Fig. 22c, g). The expansion of the subsurface layer as flow moved toward an increasing bathymetry was opposite to what could be expected from a two-dimensional Bernoulli-type dynamics, unless there is a strong lateral water intrusion.

As for the experiment over Cape Charles Hollow, a vertically integrated scaling analysis of the along-hollow momentum equation (3) was performed, as a first attempt to elucidate the dynamics over the Rappahannock Hollow. The vertical water velocity used in equation (3) is the averaged ADCP vertical velocity over a $10 \mathrm{~km}$ distance during $2 \mathrm{~h}$. The obtained values using equation (3) and table (4), leads to: $4.63 \times 10^{-5}+7.14 \times 10^{-5}+4$ 
$\mathrm{x} 10^{-5}+0.308 \times 10^{-5}+4.44 \times 10^{-5}=20.5 \times 10^{-5}+0.036 \times 10^{-5}$ in $\mathrm{m} \mathrm{s}^{-2}$. Those values indicated a balance between horizontal advection, pressure gradient and Coriolis acceleration. According to those dynamics, the along-hollow flow will be accelerated by lateral water intrusion, as observed in figures (21) and (22). The along-hollow flow in turn, will be deflected toward the right side of the flow, owing to Coriolis acceleration, as seen later.

The relevance of horizontal advection, and Coriolis acceleration in the alonghollow momentum equation was also suggested by the magnitude of the ratio of horizontal advective acceleration versus Coriolis acceleration (Fig. 23). The largest ratios were related to low values of $U$ and large convergence of along-hollow flow. Horizontal advective accelerations seem to dominate near the surface, where the higher values of the along-hollow velocity component were found. Near the bottom, over the hollow and at the shoals away from the influence of the hollow, both terms were of comparable magnitude $(<|3|)$. In turn, the ratio between horizontal advective acceleration and internal friction showed the dominance of advection over the hollow $(>|10|)$. Over the shoals, away from the hollow, advective acceleration dominated near the surface where the highest values of the along-hollow flow were found. However, near the bottom those terms were of comparable magnitude $(<|2|)$, as expected for a partially mixed estuary under the influence of bottom friction. Therefore, there seems to be a marked difference between the dynamics over the hollow, i.e., three-dimensional Bernoulli-type dynamics, and those observed over the shoals, away from the influence of the hollow. 

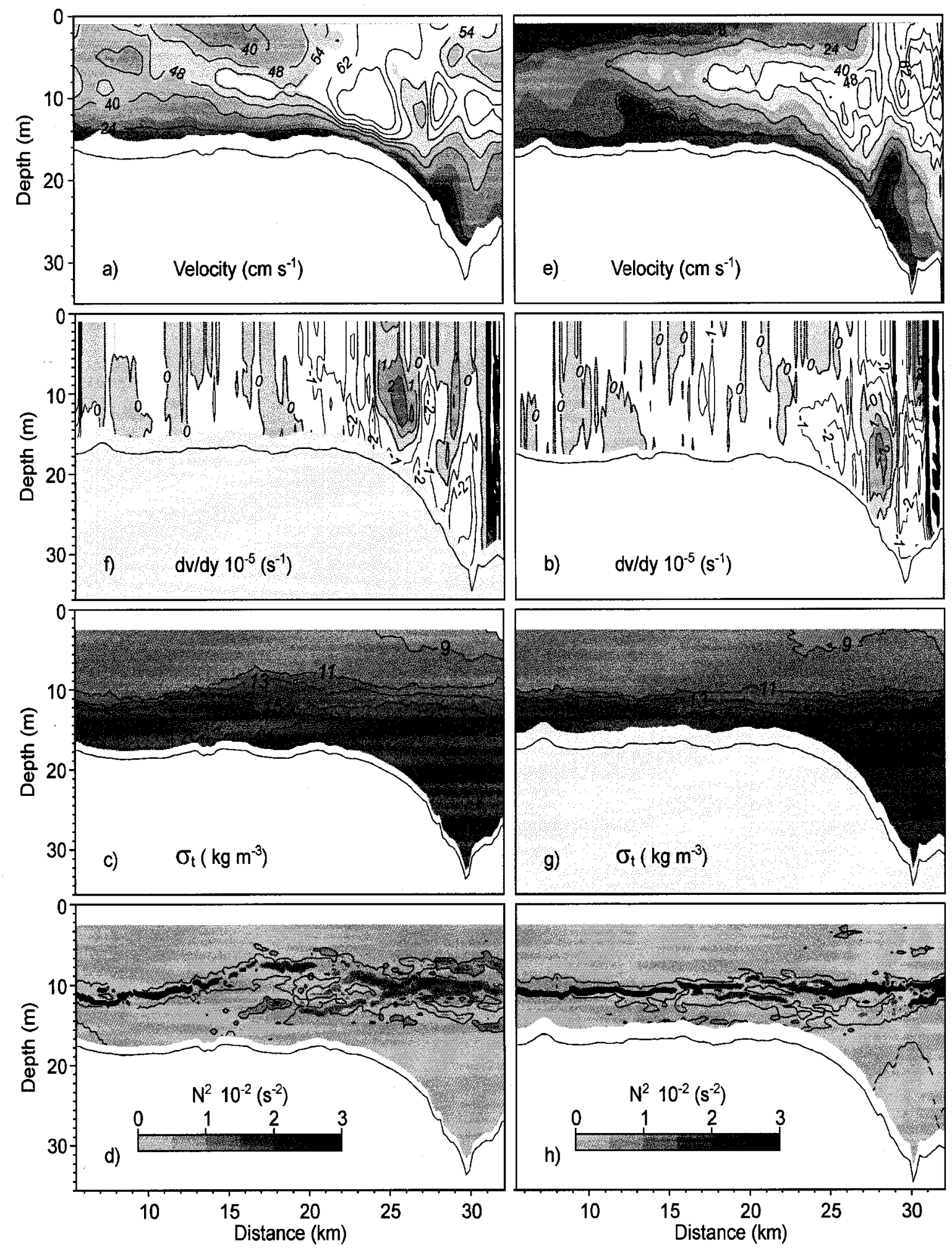

Fig. 21. Instantaneous velocities 2 at Rappahannock Hollow. The along-hollow a) instantaneous velocity, b) divergence, c) sigma-t, d) buoyancy frequency $\left(\mathrm{N}^{2}\right)$ for the sixth repetition, e) the instantaneous velocity, $f$ ) divergence, g) sigma-t, and $h$ ) buoyancy frequency $\left(\mathrm{N}^{2}\right)$ for the seventh repetition during flood tide periods on April 21, 1998 . 

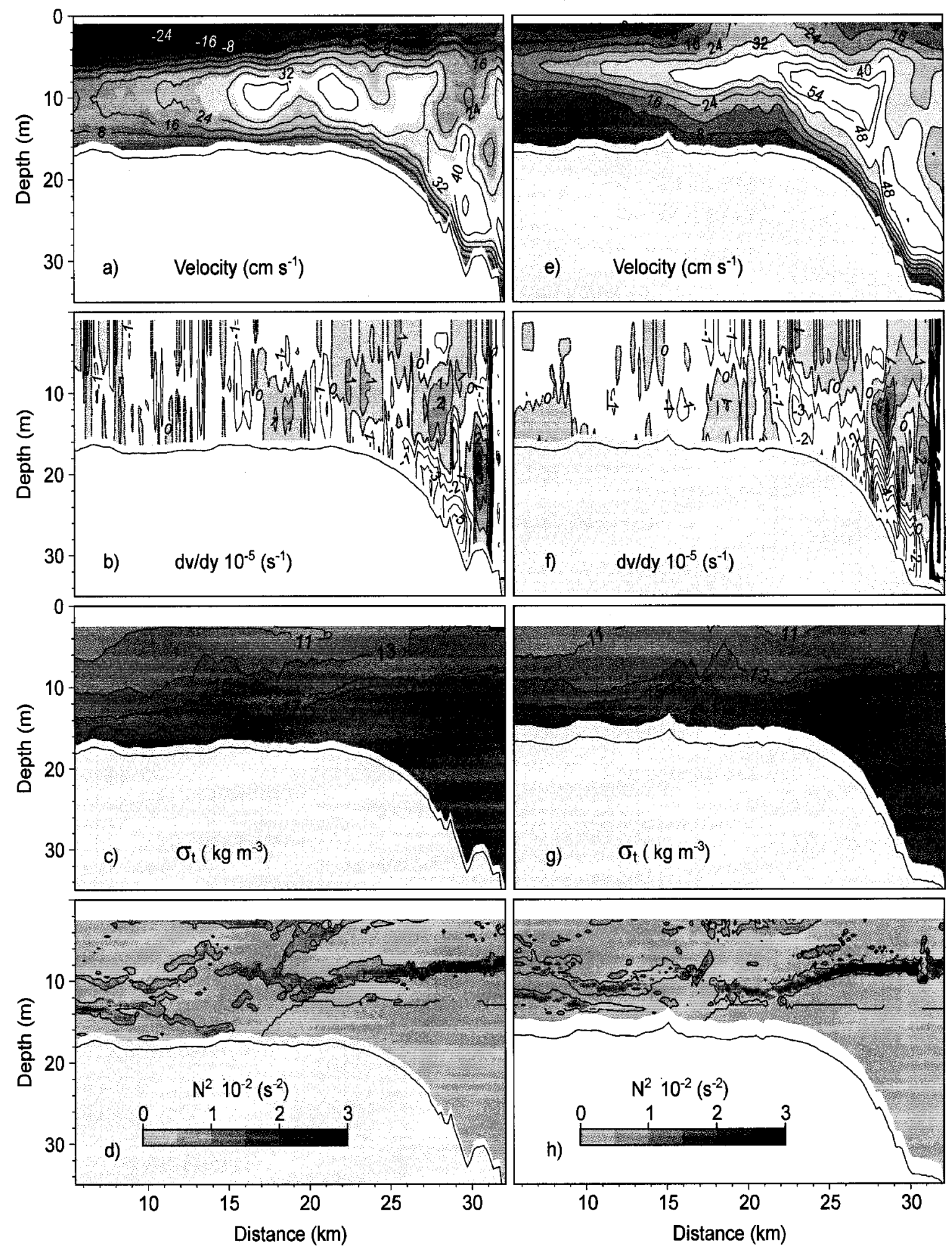

Fig. 22. Instantaneous velocities 3 at Rappahannock Hollow. The along-hollow a) instantaneous velocity, b) divergence, c) sigma-t, d) buoyancy frequency $\left(\mathrm{N}^{2}\right)$ for the tenth repetition, e) the instantaneous velocity, f) divergence, g) sigma-t, and h) buoyancy frequency $\left(\mathrm{N}^{2}\right)$ for the eleventh repetition during flood tide periods on April 22, 1998. 

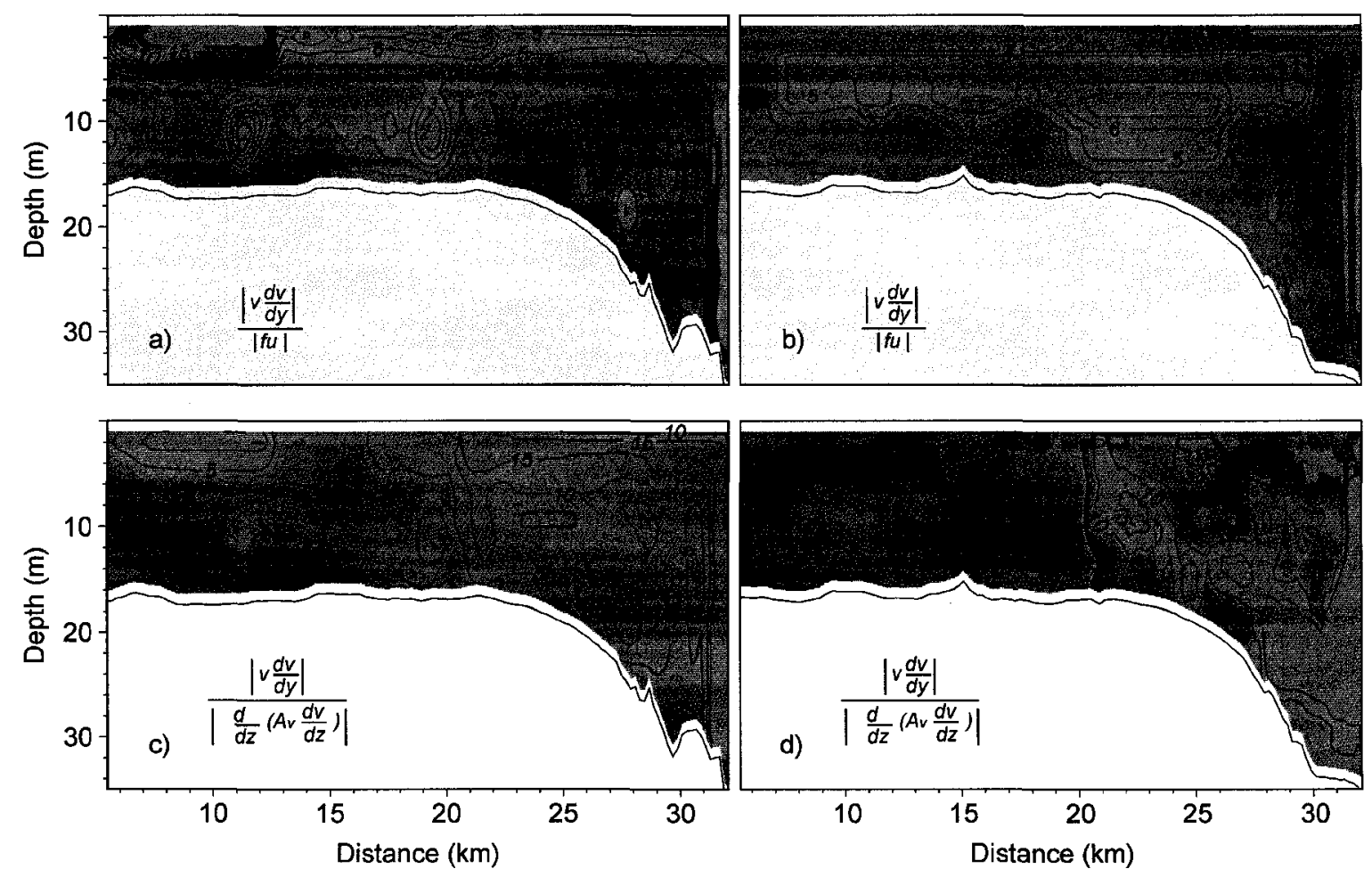

Fig. 23. Acceleration ratio 1 at Rappahannock Hollow. The ratio between horizontal advective acceleration versus Coriolis acceleration for the a) tenth repetition, b) eleventh repetition, and versus internal friction for the c) tenth, and d) eleventh repetition on April $22,1998$.

Table 4

Typical values during ebb and flood tides at Rappahannock Hollow. Typical values for instantaneous $(u, v, w)$ and residual water velocities, length scale $(x, y, z)$, densities $(\rho)$, and vertical eddy viscosity $\left(A_{v}\right)$, for the residual flow, and during ebb and flood tide periods

\begin{tabular}{llccccccc}
\hline \multicolumn{1}{c}{$u$} & $v$ & $w$ & $x$ & $y$ & $z$ & $\rho$ & $A_{v}$ \\
\hline & $\left(\mathrm{m} \mathrm{s}^{-1}\right)$ & $\left(\mathrm{m} \mathrm{s}^{-1}\right)$ & $\left(\mathrm{m} \mathrm{s}^{-1}\right)$ & $(\mathrm{m})$ & $(\mathrm{m})$ & $(\mathrm{m})$ & $\left(\mathrm{kg} \mathrm{m}^{-3}\right)$ & $\left(\mathrm{m}^{2} \mathrm{~s}^{-1}\right)$ \\
\hline$<v>$ & 0.25 & 0.5 & $0.5 \times 10^{-4}$ & $7 \times 10^{3}$ & $25 \times 10^{3}$ & 35 & 1012.5 & $4.1 \times 10^{-4}$ \\
Flood & 0.5 & 1 & $1.1 \times 10^{-4}$ & $7 \times 10^{3}$ & $25 \times 10^{3}$ & 35 & 1013.1 & $4.5 \times 10^{-4}$ \\
Ebb & 0.5 & 1 & $0.8 \times 10^{-4}$ & $7 \times 10^{3}$ & $25 \times 10^{3}$ & 35 & 1011.6 & $4.0 \times 10^{-4}$ \\
\hline
\end{tabular}




\subsection{Ebb tide periods}

The instantaneous velocity during ebb tide periods (Figs. 24a, e, and 25a, e) showed intensification as the water moved toward a decreasing bathymetry. However, there was a flow deceleration where the slope of the hollow started to increase sharply (kilometer $\sim 27$ ). Similarly to the case of Cape Charles Hollow, the deceleration of the flow over the seaward side of the hollow suggested lateral water outflow. In a twodimensional Bernoulli-type dynamics the flow is expected to accelerate as it moves toward a decreasing bathymetry or to a contraction in cross sectional area, owing to mass conservation, unless there is a strong lateral water flow. The deceleration of the alonghollow flow is linked to along-hollow flow convergence and lateral outflow (negative values in Figs. 24b, f, and 25b, f), i.e., for mass conservation to exist, $\partial u / \partial x+\partial w / \partial z$ must be positive if $\partial \mathrm{v} / \partial \mathrm{y}$ is negative.

The interesting features of the density field during ebb tide periods, was the generation of a second pycnocline at mid-depth ( $15 \mathrm{~m}$ depth) during maximum ebbs as depicted with the buoyancy frequency (Figs. $24 \mathrm{~h}$ and $25 \mathrm{~h}$ ). The shape of the buoyancy frequency over the increasing bathymetry, i.e., where the slope of the hollow starts to increase sharply, is typically observed in systems with three density water types (Martins et al., 2001). This feature was not observed over the less-stratified Cape Charles Hollow. The strongest vertical density gradients were observed just before maximum ebbs (Figs. $24 \mathrm{~d}$ and $25 \mathrm{~d}$ ), when buoyant water was flushed out of the estuary. During those periods, the strongest along-hollow flows (Figs. 24a and 25a) were observed above the pycnocline (Figs. 24d and 25d) where buoyant water was located (Figs. 24c and 25c). However, the most intriguing feature was observed during maximum ebbs, when two pycnoclines were 
formed. The deepest pycnocline was most likely created by lateral water intrusion, as suggested by flow divergence (Figs. $24 \mathrm{f}$ and $25 \mathrm{f}$ ). The combination of lateral water intrusion which mixed with the along-hollow flow near $10 \mathrm{~m}$ depth, generated a third density layer, i.e. a second pycnocline. The lateral recirculation is generated when the near-bottom along-hollow flow moves toward a decreasing bathymetry. The bathymetric constriction will not allow all the flow to make its way throughout the reduced bathymetry, therefore some of the near-bottom flow will then recirculate, owing to mass conservation. The water recirculation will then mix near-bottom water with buoyant water at a mid-depth. The new water layer will then be constrained to a mid-depth (Figs. $24 \mathrm{~g}$ and $25 \mathrm{~g}$ ) equivalent to the maximum depth of the shoals surrounding the hollow. The recirculation over the Rappahannock Hollow explained up to $16 \%$ of total flux during maximum ebbs. This feature was not observed before maximum ebbs (Figs. 24c and 25c) because most of the along-hollow flow was able to make its way throughout the reduced bathymetry. Further, weaker lateral water extrusion was observed throughout the hollow (Figs. 24b and 25b) and therefore the second pycnocline could not be generated. This feature did not developed over the continuously stratified Cape Charles Hollow, either. Nor it appeared during flood tide periods over the Rappahannock Hollow (Figs. 21 and 22) because of the relatively weaker vertical stratification. Even strong lateral water intrusions did not result in the creation of a second pycnocline.

The scaling analysis of the along-hollow momentum equation (3) during ebb tide periods was as follows: $4.63 \times 10^{-5}+7.14 \times 10^{-5}+4 \times 10^{-5}+0.24 \times 10^{-5}+4.44 \times 10^{-5}=$ $20.4 \times 10^{-5}+0.0326 \times 10^{-5}$ in $\mathrm{m} \mathrm{s}^{-2}$. The scaling analysis again indicated a balance between pressure gradient, Coriolis acceleration and the horizontal advective terms. The presence 
of the bathymetric slope during ebb tide, and the lateral water outflows, will produce the minimum along-hollow velocity near the bottom, as observed in Figs. 24 and 25 . At the surface, the barotropic and baroclinic pressure gradient work together to flush the buoyant water from the estuary, intensifying the flow at this location. The expected intensification of the absolute value of the surface flow (Fig. 25), when compared to flood tide periods, was diminished in the first repetitions (Fig. 24) by strong southerly winds $\left(>3 \mathrm{~m} \mathrm{~s}^{-1}\right)$ that opposed the southward outflow during ebb tide. The magnitude of the lateral horizontal advective term $\left\langle u \frac{\partial v}{\partial x}\right\rangle$ in the scaling analysis, confirmed the idea of strong lateral flow over the hollow. The lateral water flow produced the deceleration of the along-hollow flow where the slope of the hollow start to increase sharply. This term was calculated assuming that the $u$ component of the velocity was zero at the shoals of the hollow near the bottom. The relevance of Coriolis acceleration in the along-hollow dynamics was suggested with the vertically integrated scaling analysis of the alongmomentum equation, and confirmed by the magnitude of the ratio of horizontal advective acceleration to Coriolis acceleration (Fig. 26). Even though the ratio was predominantly greater than one, the values were mostly $<|2|$, implying that Coriolis acceleration was less than two times smaller than horizontal advective acceleration throughout the transect. In turn, the magnitude of the ratio between horizontal advective acceleration to internal friction was greater over the hollow $(>|10|)$ than over the shoals $(>|5|)$, away from the influence of the hollow. This pattern will reveal the significance of internal friction over the shoals, and the weak contribution it has over the along-hollow dynamics. 

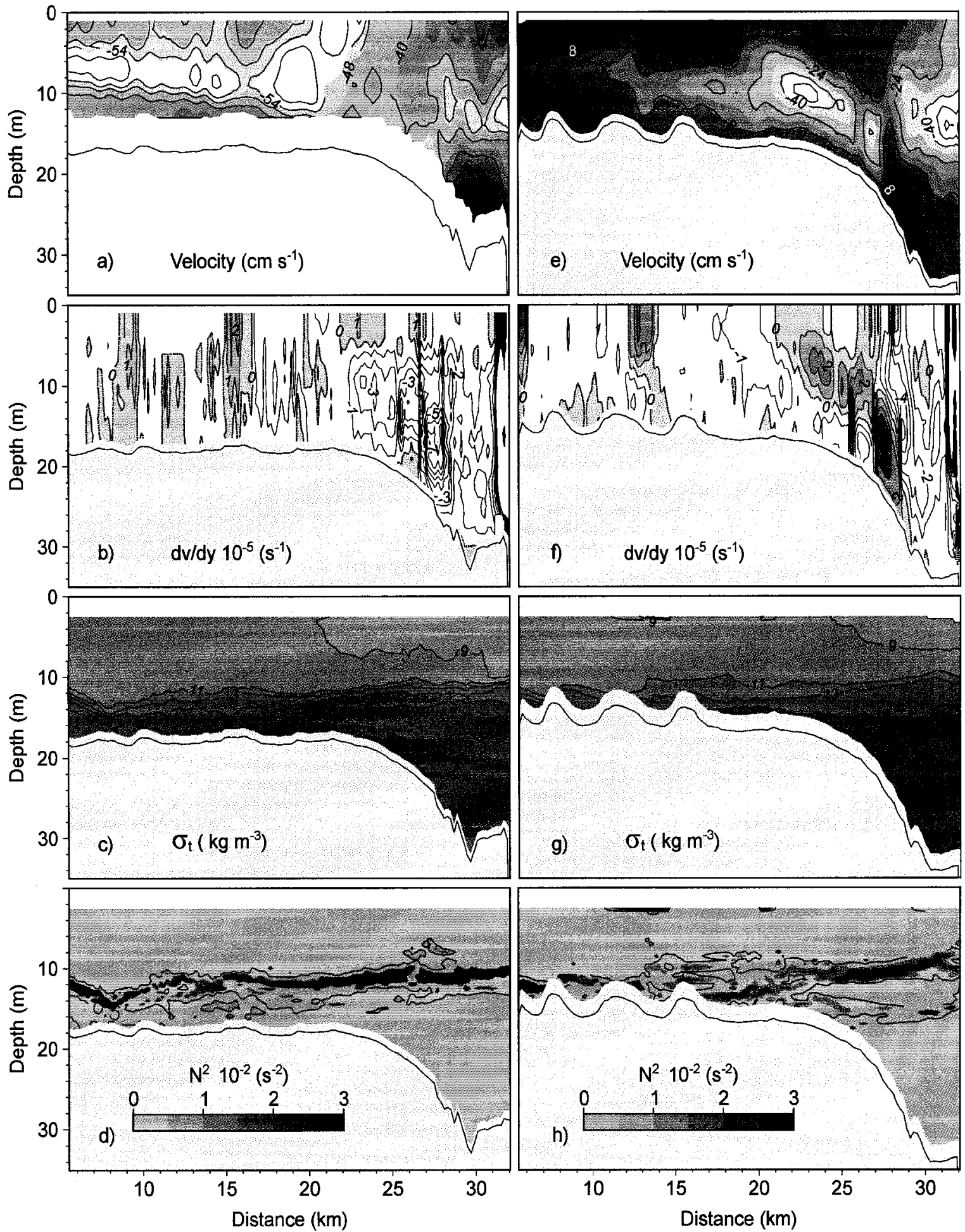

Fig. 24. Instantaneous velocities 4 at Rappahannock Hollow. The along-hollow a) instantaneous velocity, b) divergence, c) sigma-t, d) buoyancy frequency $\left(\mathrm{N}^{2}\right)$ for the second repetition, e) the instantaneous velocity, f) divergence, g) sigma-t, and $h$ ) buoyancy frequency $\left(\mathrm{N}^{2}\right)$ for the third repetition during ebb tide periods on April 21, 1998. 

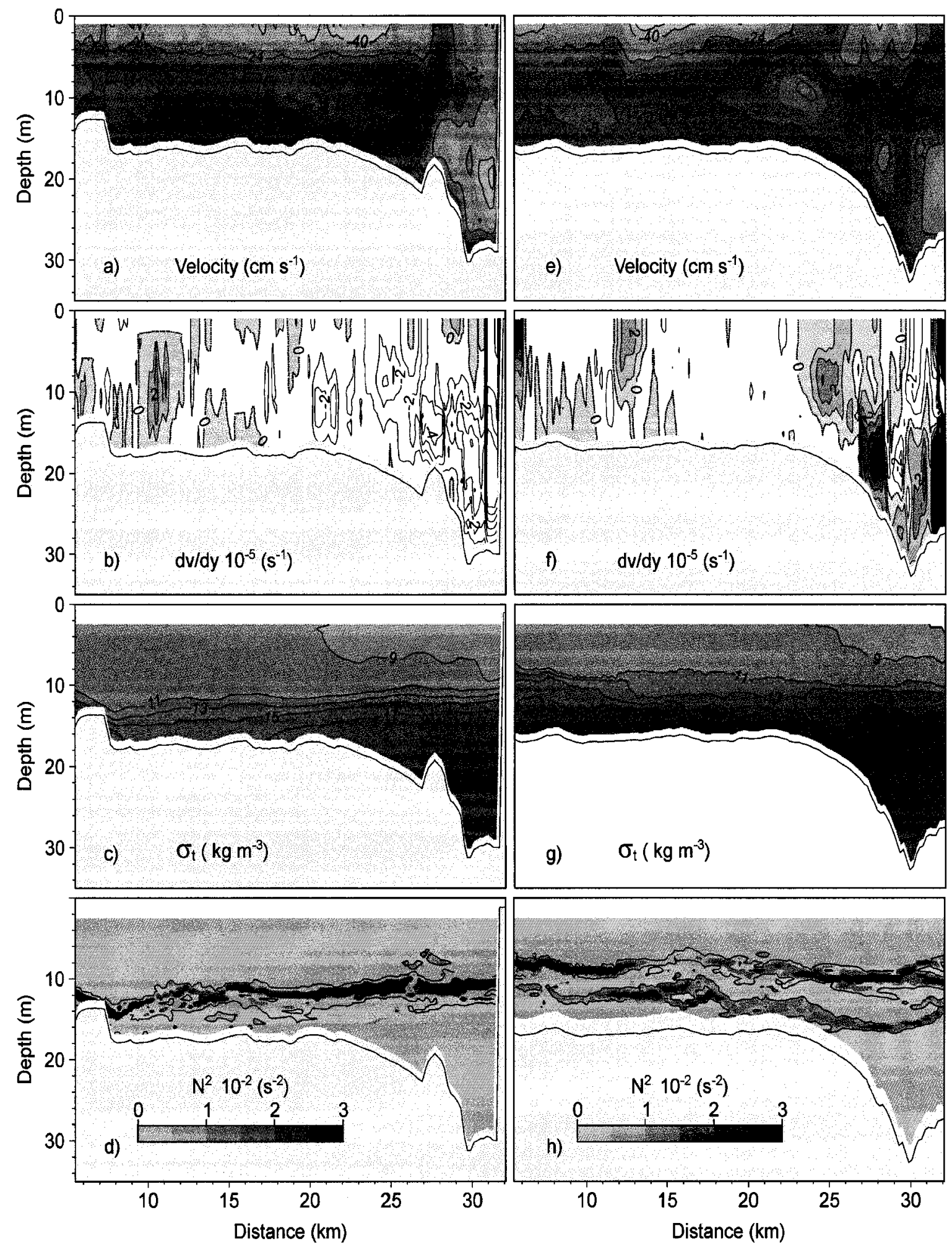

Fig. 25. Instantaneous velocities 5 at Rappahannock Hollow. The along-hollow a) instantaneous velocity, b) divergence, c) sigma-t, d) buoyancy frequency $\left(\mathrm{N}^{2}\right)$ for the eight repetition, e) the instantaneous velocity, f) divergence, $g$ ) sigma-t, and $h$ ) buoyancy frequency $\left(\mathrm{N}^{2}\right)$ for the nine repetition during ebb tide periods on April 22, 1998. 

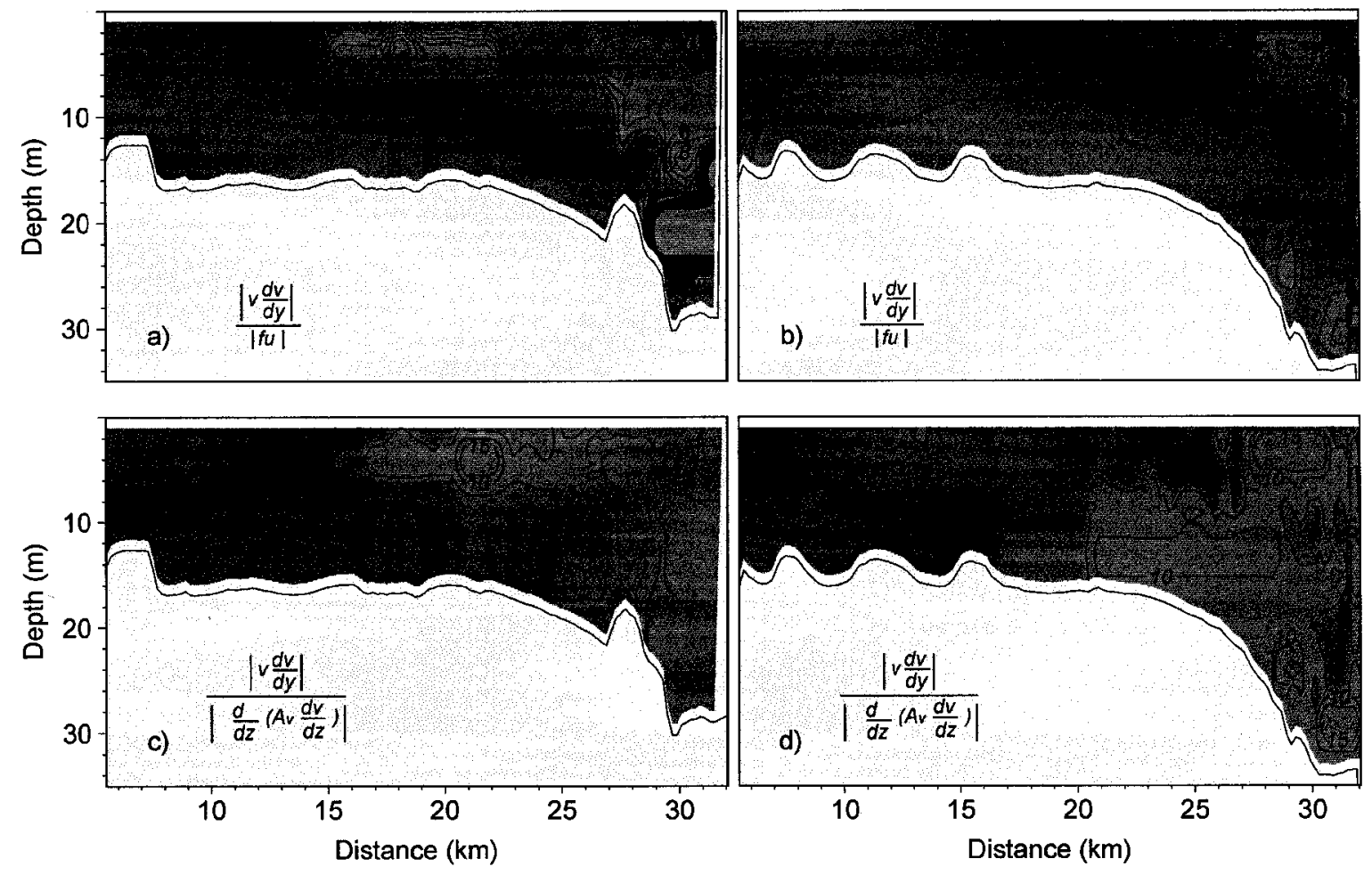

Fig. 26. Acceleration ratio 2 at Rappahannock Hollow. The ratio between horizontal advective acceleration versus Coriolis acceleration for the a) eight, b) third repetition, and versus internal friction for the c) eight, and d) third repetitions on April 21-22, 1998.

\subsection{Amplitude of semidiurnal tidal currents}

The amplitude of the tidal current (Fig. 27), obtained via a least-square fit to diurnal and semidiurnal harmonics, also indicated weak bottom friction over the hollow. The stronger ( $>0.32 \mathrm{~m} \mathrm{~s}^{-1}$ ) tidal current amplitudes over the hollow were observed locally in the deepest parts, in contrast to various findings (e.g. Valle-Levinson and Lwiza, 1995) where friction is important. However, over the shoals away from the hollow, the greatest amplitudes were observed at the surface as expected for a partially mixed estuary under the influence of bottom friction. 


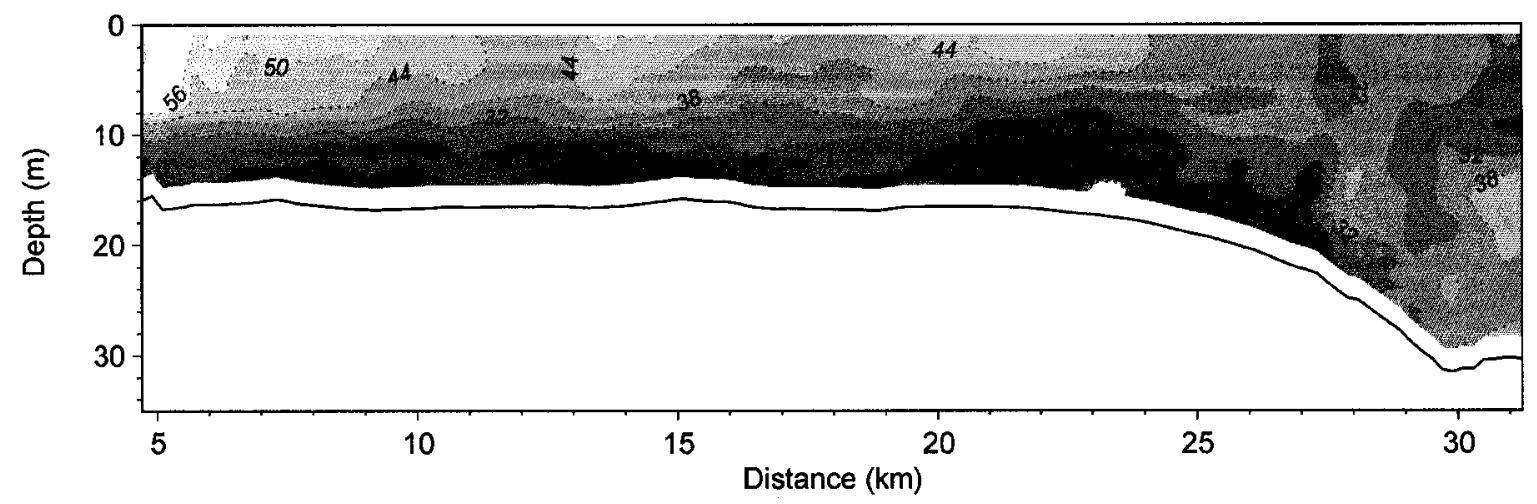

Fig. 27. Contours of the tidal current amplitude on April 21-22, 1998.

\subsection{Subtidal flow}

The lateral water intrusion in the along-hollow dynamics was also suggested by the residual flow during April 21-22, 1998 (Fig. 28). The appearance of the strongest along-hollow residual flow (contours of $30 \mathrm{~cm} \mathrm{~s}^{-1}$ in Fig. 28a) where the slope of the hollow start to increase sharply suggested lateral water intrusion. The lateral water intrusion was also suggested with the along-hollow vertically integrated volume flux (Fig. 28b), which showed an increment of the volume flux between $\mathrm{km} 15$ to 29 . The absolute value of the ratio between horizontal advective acceleration at the bottom versus bottom friction (eq. 4) indicates the dominance of horizontal advective acceleration over bottom friction close to the hollow $(>20 \mathrm{~km}$ from the starting point of transect repetition), where three-dimension Bernoulli-type dynamics are suggested. However, over the shoals away from the influence of the hollow $(<20 \mathrm{~km})$, bottom friction dominated over bottom horizontal advective acceleration. At this location, a typical residual estuarine circulation was observed (Pritchard, 1959), i.e. outflows at the surface and inflows near the bottom. 
The absolute value of the vertical shear in the horizontal subtidal flow (Fig. 29a) showed almost constant values over the deepest part of the hollow, indicating similar velocities over the entire water column. This feature reinforced the fact that the frictional term did not play an important role in the along-hollow subtidal momentum equation (3). If friction were important in the system, a strong vertical gradient of the horizontal velocity would be expected over the hollow, because near-bottom currents would be retarded by bottom friction. The absence of the frictional term in the along-momentum equation over the hollow was also suggested with the vertically integrated scaling analysis of the residual flow, which suggested a balance between horizontal advection, pressure gradient and Coriolis acceleration, according to the values obtained for equation (3) and table (4), those values were as follows: $0.810 \times 10^{-5}+3.5 \times 10^{-5}+1.96 \times 10^{-5}+$ $0.1 \times 10^{-5}+3.11 \times 10^{-5}=9.4 \times 10^{-5}+0.0234 \times 10^{-5}$ in $\mathrm{m} \mathrm{s}^{-2}$. The along-hollow residual flow and the instantaneous flow during any tide period over the hollow can then be described with three-dimensional Bernoulli-type dynamics modified by Coriolis acceleration. The intensification of the near-bottom flow as it moves toward an increasing bathymetry was produced by lateral water intrusion, which in turn was deflected toward its right side owing to Coriolis acceleration.

The residual density structure over the hollow (Fig. 29b) showed a monotonic vertical increase until $10 \mathrm{~m}$ depth where the pycnoline was located (Fig. 29c). This features suggest a common water type, i.e., same density, below $10 \mathrm{~m}$ depth where the strongest lateral variation of streamwise flow was observed. 

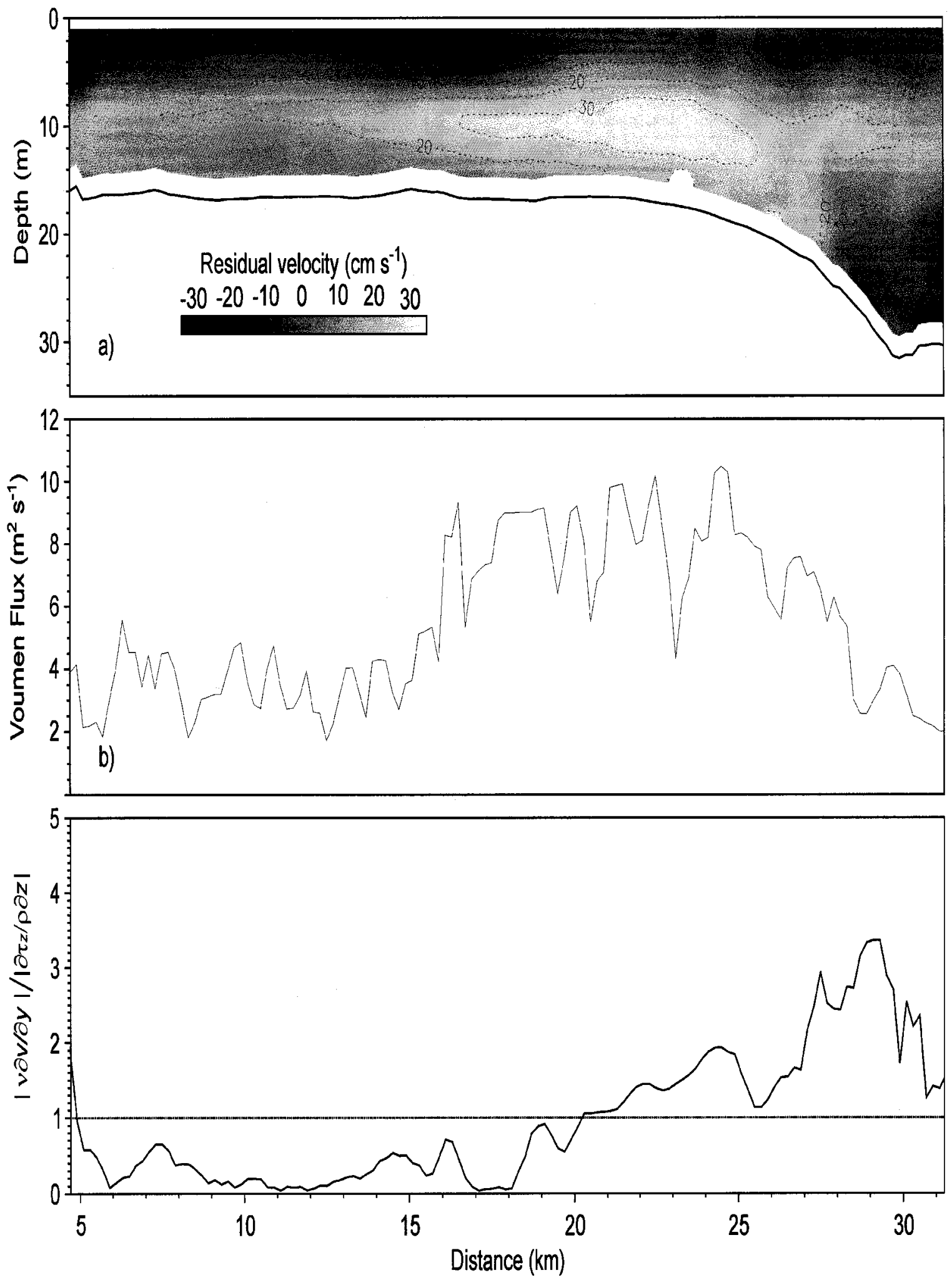

Fig. 28. Residual flow at Rappahannock Hollow. a) Along-hollow residual flow, b) vertically integrated volume fluxes, and c) the ratio between horizontal advective acceleration versus bottom friction on April 21-22, 1998. 

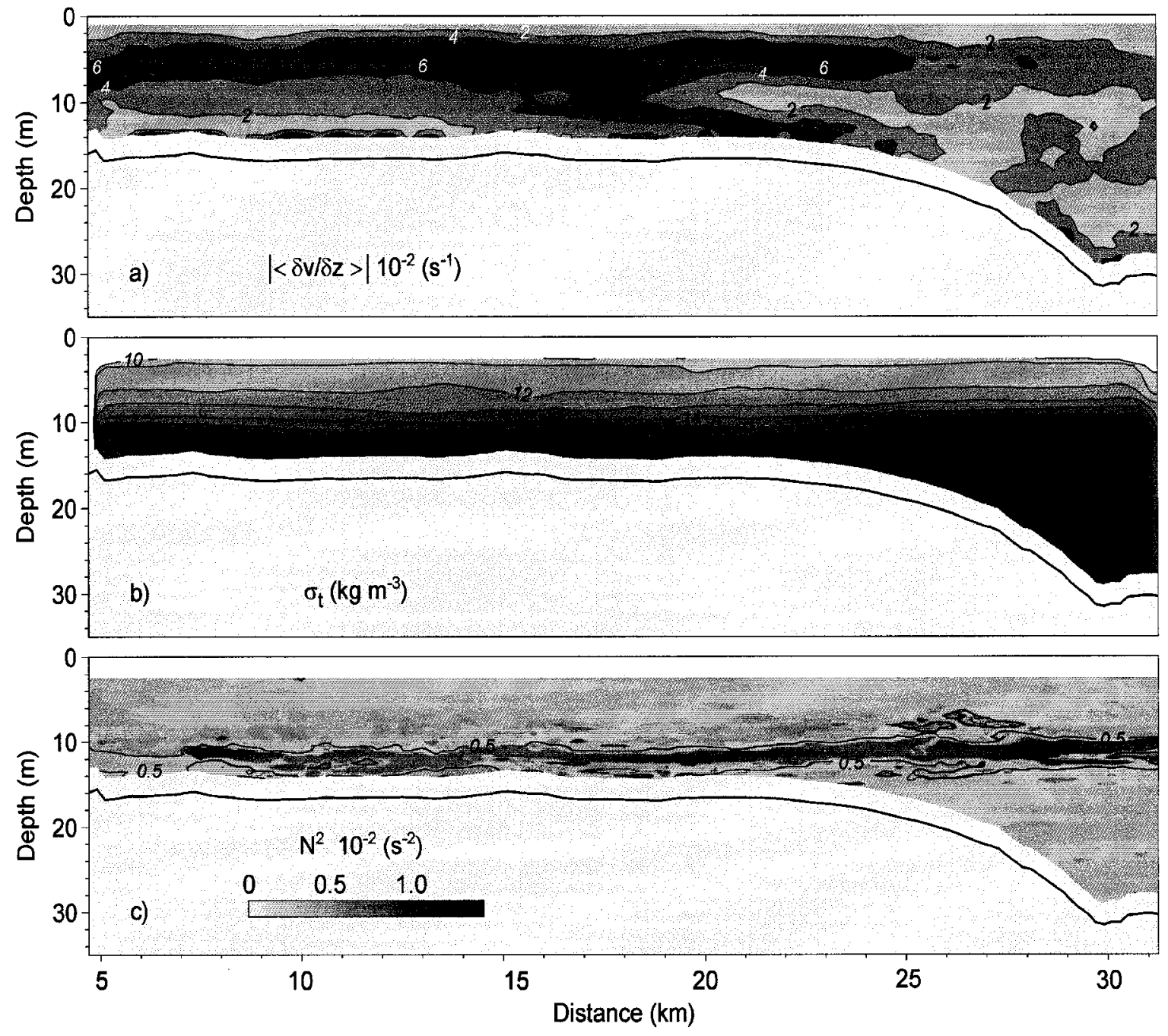

Fig. 29. Density derivatives at Rappahannock Hollow. a) Vertical shear of the along transect velocity, b) sigma-t, and c) buoyancy frequency $\left(\mathrm{N}^{2}\right)$ contours on April 21-22, 1998.

\subsection{Transverse structure}

The transverse transect of April 22-23, 1998 (Fig. 30a) confirmed lateral water intrusion below the pycnoline. The lateral flow, depicted with the arrows, showed a surface convergence over the deepest part of the hollow. However, the most important feature of the transverse flow was the strong lateral water intrusion below $10 \mathrm{~m}$ depth 
from the shoals into the hollow. This feature reinforced what was previously described with the along-hollow velocity profiles and with the vertically integrated scaling analysis of the along-momentum equation. The across transect residual velocity had the highest values toward the right side of the hollow (light colors in Fig. 30) owing to Coriolis acceleration. This pattern confirmed the fact that Coriolis acceleration should be influential to the along-hollow three-dimensional Benoulli-type dynamics.

The common features between Cape Charles Hollow and the Rappahannock Hollow were the acceleration of the flow as it moved toward an increasing bathymetry owing to lateral water intrusion from the shoals. The deceleration of the along-hollow flow as it moved toward a decreasing bathymetry, owing to lateral water extrusion toward the shoals, and the modification of the along-hollow flow by Earth rotational effects (Coriolis acceleration). Therefore, the common dynamics between those two hollows with a marked different in vertical density stratification was the dominance of the horizontal advective acceleration, pressure gradient and Coriolis acceleration, on the along-hollow momentum equation.

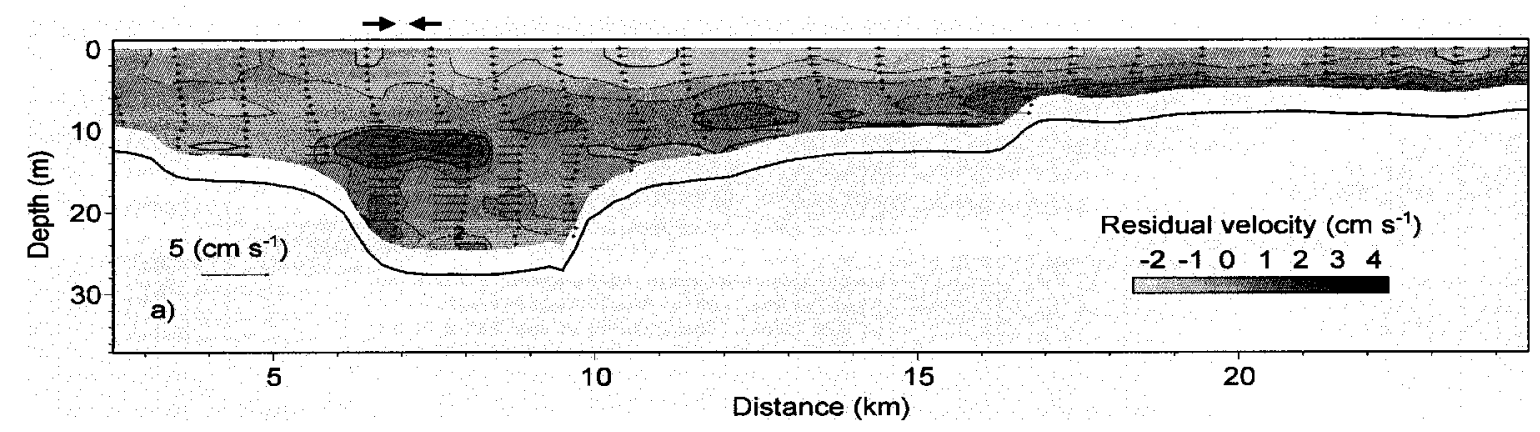

Fig. 30. Transverse transect at Rappahannock Hollow. a) Along-estuarine residual velocity represented with contour, and across-estuarine velocity represented with arrows, for April 22-23, 1998. 


\section{CHAPTER 5}

\section{THE CHESAPEAKE BAY MOUTH HOLLOW}

The establishment and evolution of the flow at a bathymetric depression in the Chesapeake Bay mouth will be described in order to elucidate a common feature over a hollow in shallow waters. The Chesapeake Bay Mouth Hollow has a side channel which discerned from the previous cases described in this study. The density profiles over the hollow at the Chesapeake Bay mouth (Fig. 5) showed a continuously stratified water column, ranging from 1019.0 to $1025.5 \mathrm{~kg} \mathrm{~m}^{-3}$ during flood, and from 1016.5 to 1024.5 $\mathrm{kg} \mathrm{m}^{-3}$ during ebb (Fig. 31). The highest density values were found at CTD station A owing to its proximity to the coastal ocean water. The strongest vertical density gradients were observed during ebb tide and the weakest during flood tide. This was consistent with tidal straining (Rippeth et al., 2001) and with the observations over the Rappahannock and Cape Charles hollows.

\subsection{Establishment and evolution of the flow}

The velocity structure during the flood tide period (Fig. 32a) showed a clear deceleration of the flow as it moved toward a decreasing bathymetry, i.e. a reduction in vertical sectional area. The vertically integrated volume flux (Fig. 32b), previously used to estimate lateral volume flux, suggested lateral water extrusion. A decrement in the vertically integrated volume flux per unit channel width is associated with lateral water outflows, while an increment is related to lateral water inflows. The strongest velocity current over the hollow during flood were not located at the surface as would have been 
expected from bottom frictional influences. Instead, the strongest flows were located at mid-depth (contours of $-65 \mathrm{~cm} \mathrm{~s}^{-1}$, in Fig. 32a). However, over the landward side of the first transect, away from the influence of the hollow $(<7 \mathrm{~km})$, the strongest velocities were located at the surface as typically observed in partially mixed estuaries under the influence of bottom friction (Valle-Levinson and Lwiza, 1995). The mid-depth deceleration of the along-hollow flow was attributed to lateral water extrusion to the shoals and toward the side channel, i.e. along-hollow flow convergence (Fig. 32c). The convergence, just like in previous cases, was linked to lateral water extrusions, i.e. for mass conservation to exist $\partial \mathrm{u} / \partial \mathrm{x}+\partial \mathrm{w} / \partial \mathrm{z}$ must be positive if $\partial \mathrm{v} / \partial \mathrm{y}$ is negative.

At the end of flood the current decreases (Fig. 32d) and the vertically integrated volume flux showed a constant value throughout the transect (Fig. 32e). This indicated no major lateral water volume outflow or inflow (Fig. 32f). The lack of lateral volume at the end of flood was in contrast to maximum flood (Fig. 32a), when lateral water extrusion decreased the volume flux per unit channel width. As a consequence of the relatively weak lateral flow, when compared to maximum flood, the absolute value of the divergence was reduced considerably (Fig. 32f). However, the convergence was still observed where the slope of the hollow start to increase sharply, at a depth equivalent to the maximum depth of the surrounding shoals. One of the most important characteristics of the hollow studied in this chapter is the side channel, which allowed the along-hollow flow to decelerate faster than for the previous cases. 

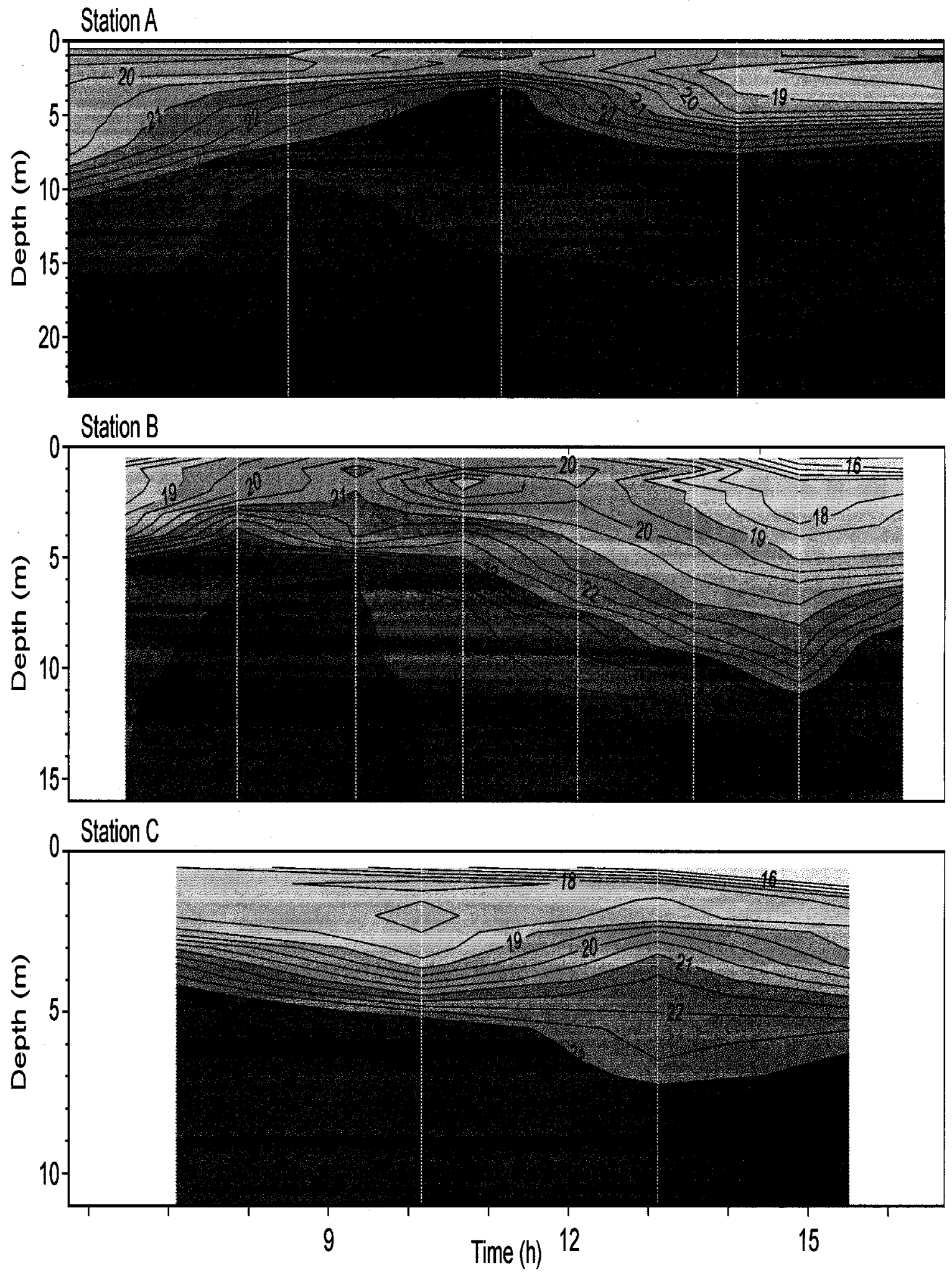

Fig. 31. Time series 1 at Chesapeake Bay Mouth. Time series of sigma-t $\left(\mathrm{kg} \mathrm{m}^{-3}\right)$ at CTD stations $\mathrm{A}, \mathrm{B}$, and $\mathrm{C}$ during February 25,2000 . The times of CTD recording at stations are shown as dotted lines. 

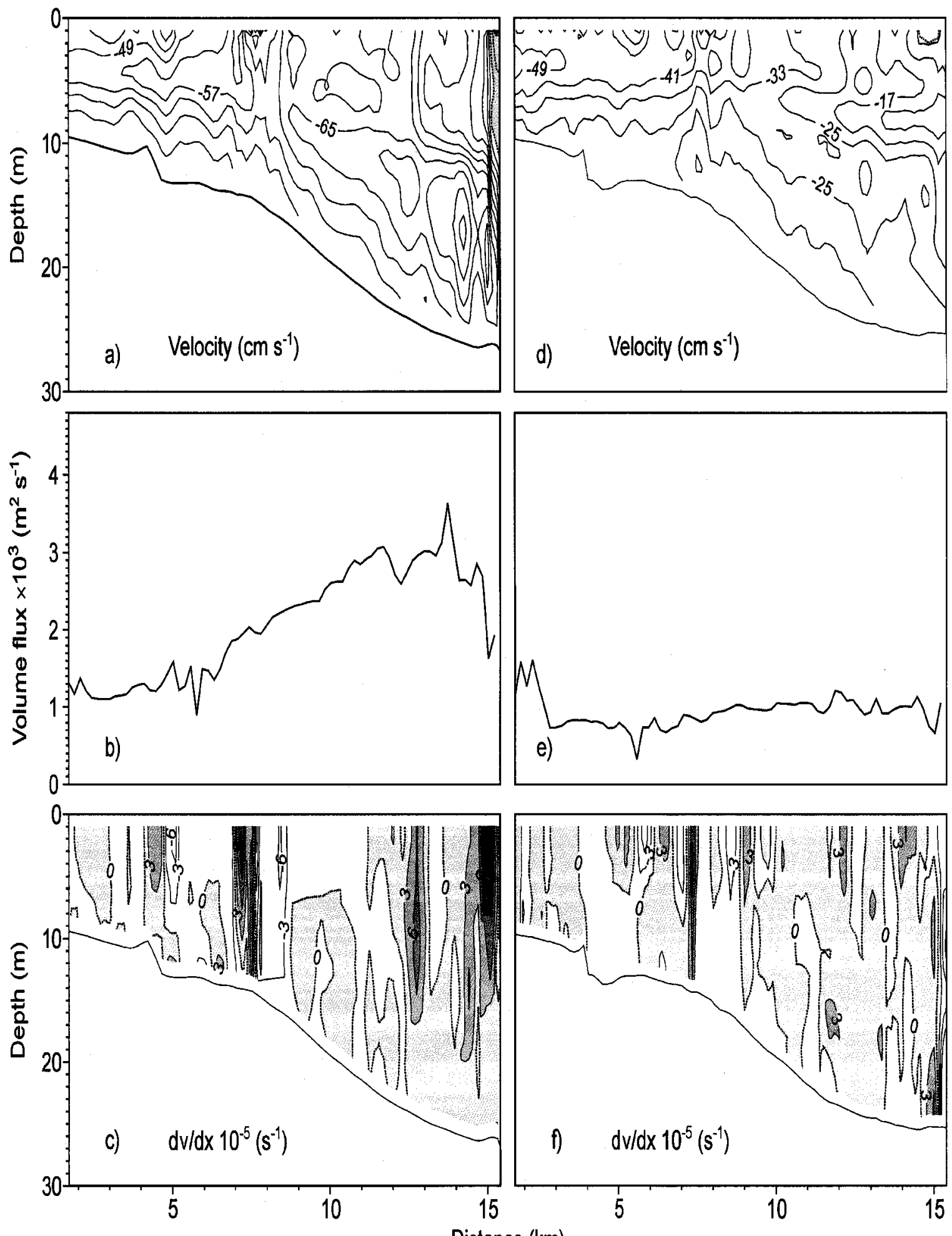

Fig. 32. Instantaneous velocities 1 at Chesapeake Bay Mouth. The along-hollow a) instantaneous velocity $\left.\left(\mathrm{cm} \mathrm{s}^{-1}\right), b\right)$ vertically integrated volume flux, c) convergence for the first repetition, d) the instantaneous velocity $\left.\left(\mathrm{cm} \mathrm{s}^{-1}\right), e\right)$ vertically integrated volume flux, and f) convergence for the second repetition during February 25, 2000. 
The subsequent repetition during slack tide (Fig. 33a) showed a faster response to tidal changes away from the influence of the hollow $(<7 \mathrm{~km})$. This feature was produced by bottom friction which retarded the along-hollow flow (e.g., Pritchard, 1965). However, at a mid-depth over the hollow, where the strongest divergence was previously observed, the flow (contours of $-17 \mathrm{~cm} \mathrm{~s}^{-1}$ in Fig. 33a) was not able to respond to tidal changes as fast as the near bottom or surface flow. The tidal response at mid-depth was a consequence to its faster velocities when compared to its overlying and underlying water. This feature suggested a phase lag between the flow at this depth, i.e. the depth equivalent to the maximum depth of the surrounding shoals, with the surface and bottom flow. During slack tide, a relatively weak divergence $\left(<3 \times 10^{-5} \mathrm{~s}^{-1}\right)$ was still observed over the deepest part of the hollow. The convergence that was usually observed during flood at the hollow slope was not apparent at slack tides (Fig. 33c). This suggested weak lateral water extrusion during slacks, which was also suggested by the vertically integrated volume flux per unit channel width (Fig. 33b).

At early ebb periods, the strongest currents were located at the surface (Fig. 33d) because the baroclinic and barotropic pressure gradients act in concert to flush the buoyant surface estuarine water. The vertically integrated volume flux per unit channel width indicated an increasing volume throughout the transect (Fig. 33e). The increment of the volume flux was attributed to lateral water intrusion, i.e. along-hollow flow divergence (Fig. 33f) at a depth equivalent to the maximum depth of the surrounding shoals. The strongest velocity throughout the entire water column (contours $>33 \mathrm{~cm} \mathrm{~s}^{-1}$ in Fig. 33d) was located at the surface and at the distance where the hollow started to slope $(\sim 7 \mathrm{~km})$ throughout the entire water column. This feature indicated lateral water 
intrusion from the shoals, which was also suggested by the divergence of the alonghollow flow and by the vertically integrated volume flux per unit width. Lateral water intrusions were also evident during the maximum ebb (Fig. 34a). During the fifth repetition (Fig. 34), the flow acceleration at a mid-depth was again inconsistent with what could be expected from two-dimensional Bernoulli-type dynamics. The acceleration of the flow, the increment of the vertically integrated volume flux per unit channel width (Fig. 34b), and the strong divergence $\left(>6 \times 10^{-5} \mathrm{~s}^{-1}\right)$ at mid-depth (Fig. 34c) are indicative of lateral water intrusion, i.e. three-dimensional flow dynamics, as previously documented over the Cape Charles Hollow and the Rappahannock Hollow.

At the end of ebb (Figs. 34d), the vertically integrated volume flux showed an almost constant value throughout the transect (Fig. 34e). The weak along-hollow variations suggested no significant lateral variations in streamwise flow variation. Also, divergence values decreased throughout the transect (Fig. 34f). However, the relatively strong surface velocity $\left(47 \mathrm{~cm} \mathrm{~s}^{-1}\right)$ and divergence $\left(>6 \times 10^{-5} \mathrm{~s}^{-1}\right)$ where the slope of the hollow start to increase sharply $(\sim 7 \mathrm{~km})$, i.e. the hollow shoulders, was still observed. At this distance in the transect $(<7 \mathrm{~km})$, bottom friction was more important than horizontal advection, while after this point $(>7 \mathrm{~km})$ horizontal advection is more important than bottom friction, as seen later. This feature was consistent with the observations over the Rappahannock and Cape Charles Hollow. During the subsequent slack tide (Fig. 35a), the direction of the currents changed faster near the bottom than at the surface over the shoals, owing to bottom friction (e.g., Pritchard, 1965). However, as for repetition 3 (Fig. 33a) the flow direction throughout the water column at the hollow shoulders $(\sim 7 \mathrm{~km})$ alternate between outflows and inflows (Fig. 35a). This feature suggested a phase lag, 
which increased between the mid water depth $(\sim 10 \mathrm{~m})$ toward the bottom and surface. This phase lag would not be observed if lateral variations of streamwise flow were not significant. If lateral water intrusions were negligible over the hollow, there would not be an acceleration of the flow as it moves toward an increasing bathymetry. This would then result in a monotonically increase of the tidal phase toward the surface.

The following flood tide period (Fig. 35d) also suggested lateral water outflow. As for repetition 1 , the along-hollow flow decelerated, owing to strong lateral flow as suggested by the vertically integrated volume flux per unit channel width (Fig. 35e) and with the convergence of the along-hollow flow (Fig. 35f). The convergence located at the hollow shoulders $(\sim 7 \mathrm{~km})$ during floods, changed to divergence during ebb tide periods. The along-hollow convergence is related to lateral water outflows, which in turn produce the along-hollow velocity to decelerate as it moves to a decreasing bathymetry. The divergence, in turn, is associated to lateral water intrusion, which produce an acceleration of the along-hollow flow as it moves toward an increasing bathymetry, or an increasing cross sectional area. Those patterns oppose what could be expected from a twodimensional Bernoulli-type dynamics, under the absence of lateral variation of streamwise flow. 

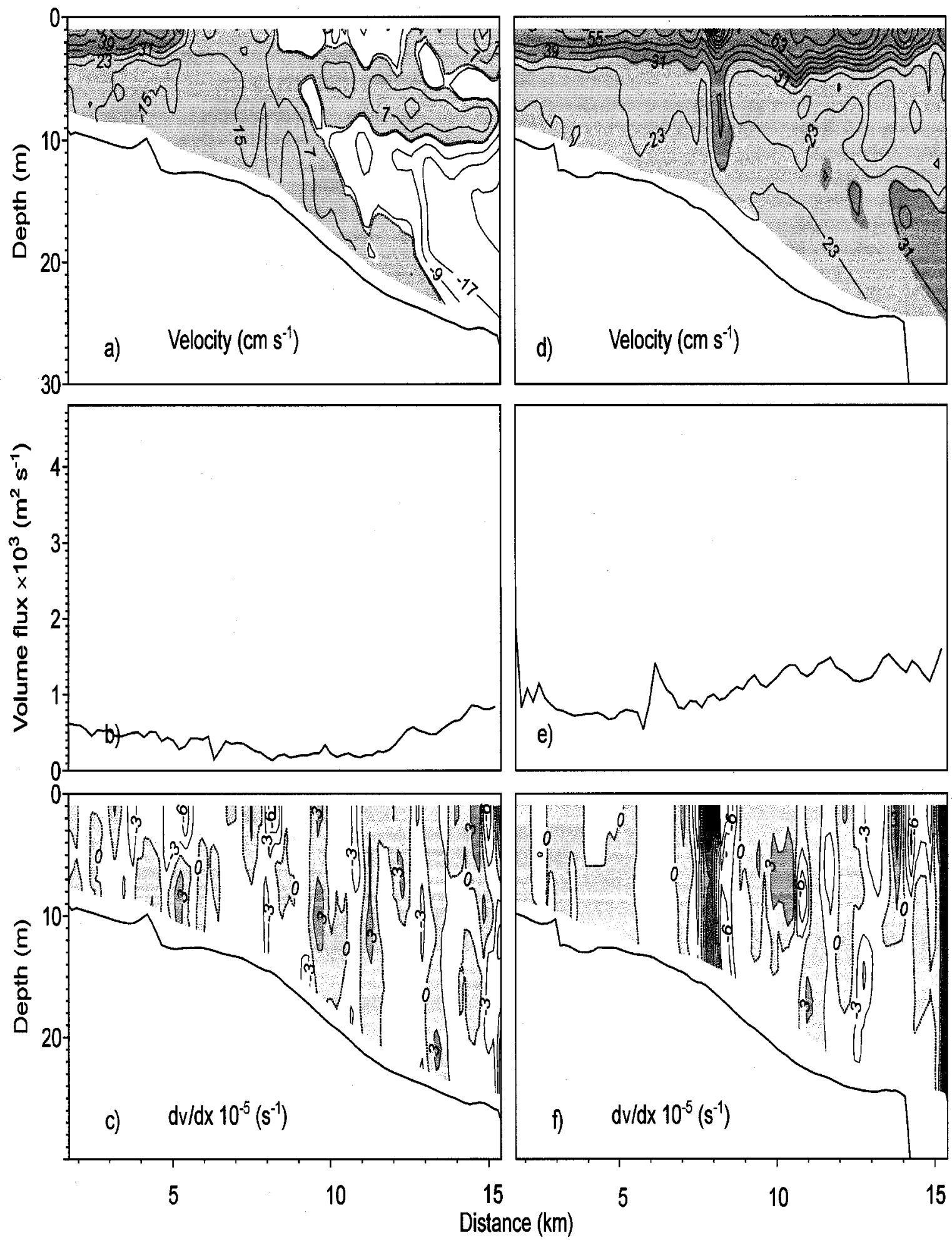

Fig. 33. Instantaneous velocities 2 at Chesapeake Bay Mouth. The along-hollow a) instantaneous velocity $\left.\left(\mathrm{cm} \mathrm{s}^{-1}\right), b\right)$ vertically integrated volume flux, c) convergence for the third repetition, d) the instantaneous velocity $\left.\left(\mathrm{cm} \mathrm{s}^{-1}\right), e\right)$ vertically integrated volume flux, and f) convergence for the fourth repetition during February 25, 2000. 

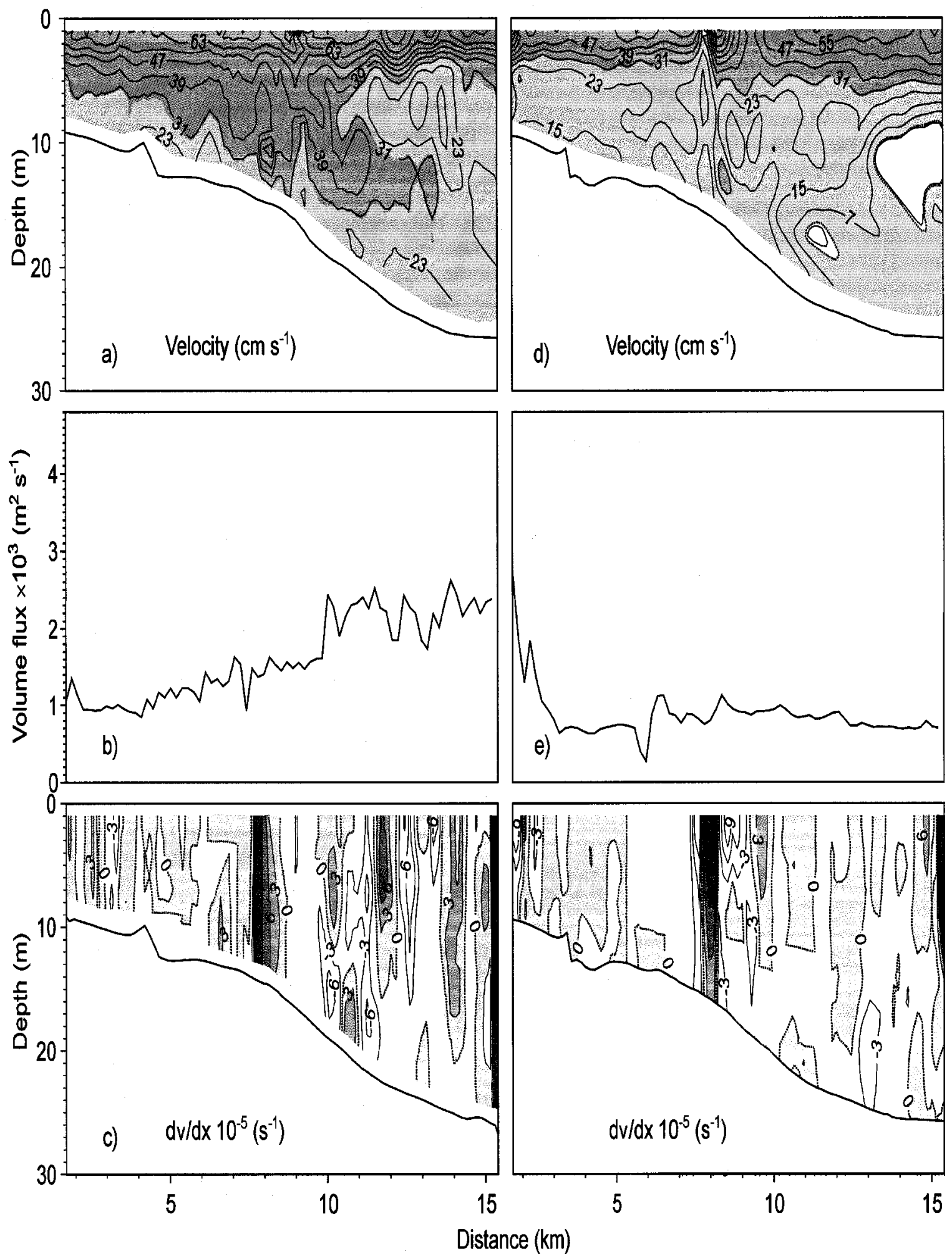

Fig. 34. Instantaneous velocities 3 at Chesapeake Bay Mouth. The along-hollow a) instantaneous velocity $\left(\mathrm{cm} \mathrm{s}^{-1}\right)$, b) vertically integrated volume flux, c) convergence for the fifth repetition, d) instantaneous velocity $\left.\left(\mathrm{cm} \mathrm{s}^{-1}\right), \mathrm{e}\right)$ vertically integrated volume flux, and f) convergence for the sixth repetition during February 25, 2000. 

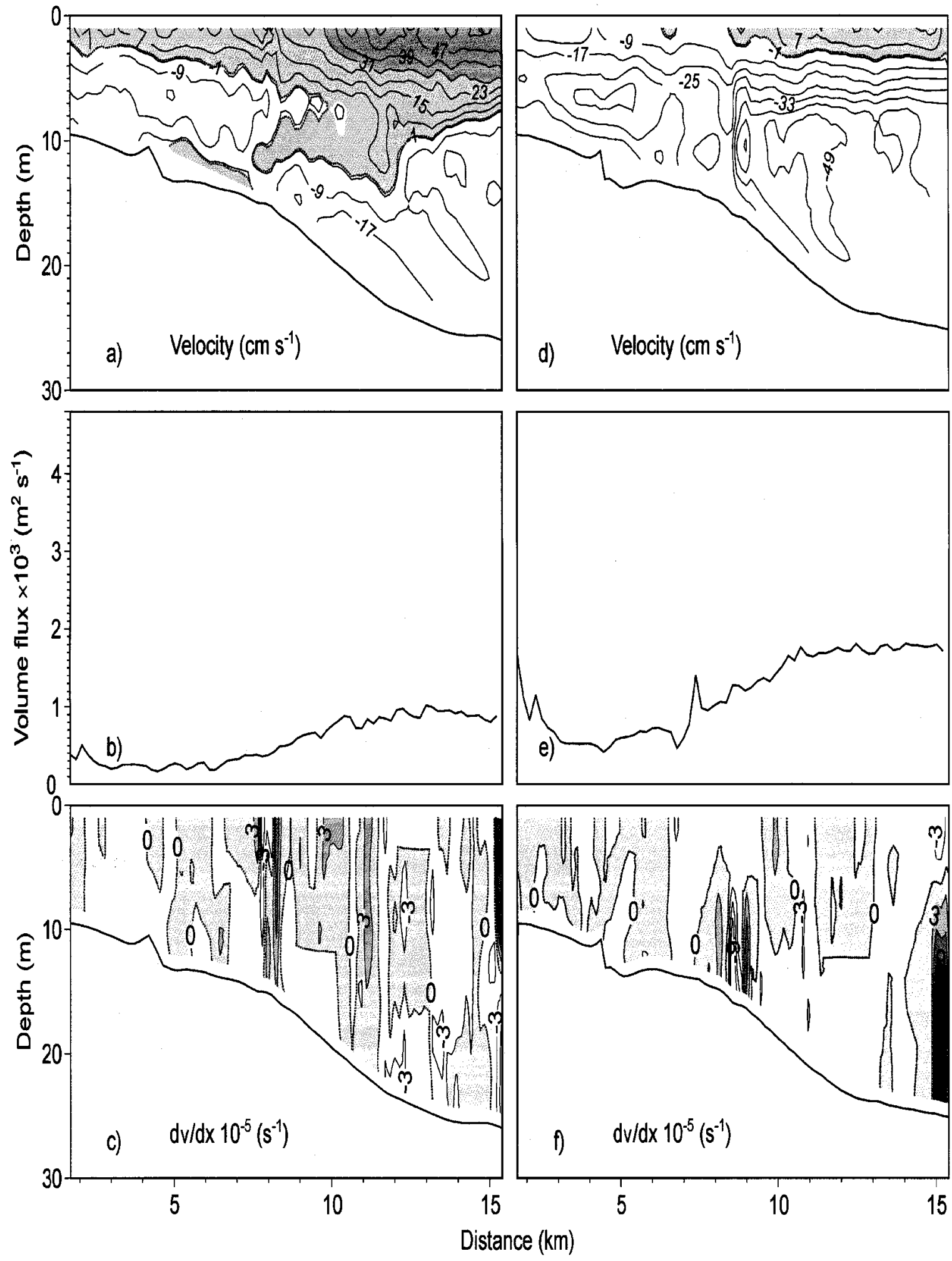

Fig. 35. Instantaneous velocities 4 at Chesapeake Bay Mouth. The along-hollow a) instantaneous velocity $\left.\left(\mathrm{cm} \mathrm{s}^{-1}\right), b\right)$ vertically integrated volume flux, c) convergence for the seventh repetition, d) the instantaneous velocity $\left(\mathrm{cm} \mathrm{s}^{-1}\right)$, e) vertically integrated volume flux, and f) convergence for the eighth repetition during February 25, 2000. 


\subsection{Amplitude of the semidiurnal tidal currents}

The amplitude of the semidiurnal tidal currents (Fig 36a), obtained via a leastsquares fit to semidiurnal harmonics, showed the high values (contours of $52 \mathrm{~cm} \mathrm{~s}^{-1}$ in Fig. 36a) at the surface over the shoals $(<7 \mathrm{~km})$, far from bottom friction. High values of semi-diurnal tidal currents were also observed at a mid-depth equivalent to the maximum depth of the surrounding shoals over the hollow. At this depth, lateral water intrusion, i.e. divergence, accelerated the along-hollow flow. The phase of the semi-diurnal tidal amplitude, in turn, showed a monotonic increase toward the surface (Fig. 36b) at the distance where bottom friction dominated over horizontal advective acceleration, i.e. away from the influence of the hollow (Fig. 36c). However the interesting feature was the $1 \mathrm{~h}$ phase lag at a mid-depth $(\sim 10 \mathrm{~m}$ depth) where horizontal advective acceleration dominated over bottom friction (Fig. 36c). At this depth, the lateral variation of streamwise flow contributed to accelerate the along-hollow currents, producing a phase lag of $0.5 \mathrm{~h}$ (Fig. 36b) relative to its surrounding water. Thus, the difference in distribution of a) the tidal phase and b) the ratio between horizontal advective acceleration and bottom friction along the transect, suggested different dynamics over the hollow relative to the shoals.

\subsection{Residual flow}

The residual density profiles during February 25, 2000 showed a continuously stratified water column down to the depth equivalent to the maximum depth of the surrounding shoals, i.e. $12 \mathrm{~m}$ depth (Fig.37). After this depth the density structure was more homogeneous, suggesting the same type of water within the hollow. The lower 
density values were located at CTD station $\mathrm{C}$ and the highest values at CTD station A owing to its proximity with coastal water. However at mid-depth, the residual density was higher at CTD station A, owing to strong lateral water intrusion of oceanic water, just above 12-m depth.

The residual velocity structure (Fig. 38a) showed outflows at the surface and inflows near the bottom, as expected for a partially mixed estuary (Pritchard, 1965). The current inflow showed a deceleration of the flow at the hollow shoulders $(\sim 7 \mathrm{~km})$. This is the transect distance where horizontal advective acceleration started to dominate over bottom friction (Fig. 36c). At this point the vertically integrated volume flux (Fig. 39b) suggested lateral water outflow, as during flood tide periods. This was attributed to a combination of the decreasing bathymetry and the strong currents. Since not all the incoming volume flux could pass throughout the reduced bathymetry, close to $35 \%$ of the volume flux had to exit the hollow throughout the shoals and side channel. The lateral water outflows and inflows were common features for all the hollows described in this study. Therefore, the along-hollow flow can be described with three-dimensional Bernoulli-type dynamics. 


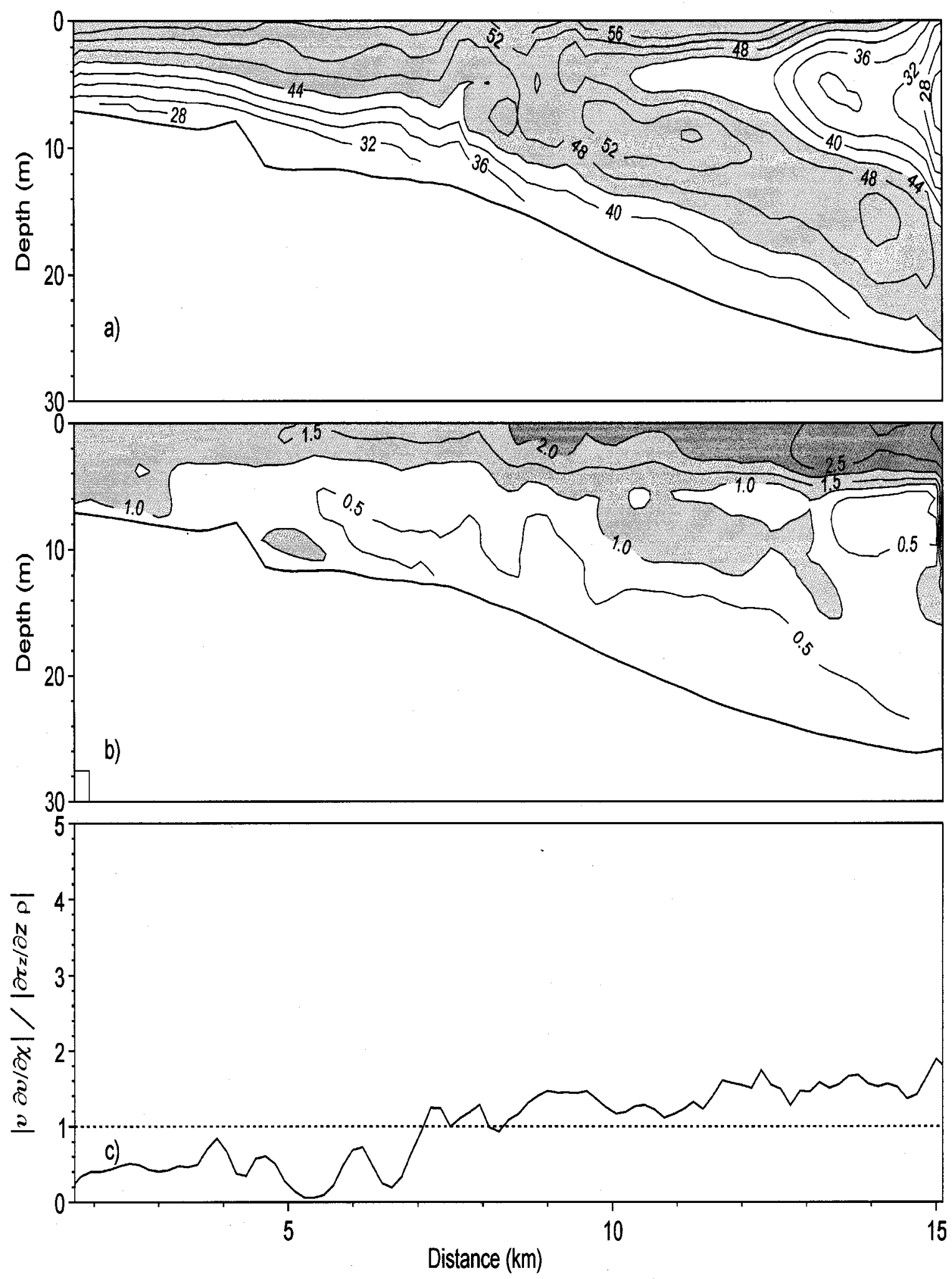

Fig. 36. Tidal amplitude at Chesapeake Bay Mouth. Contours of the a) semidiurnal tidal amplitude of the current $\left(\mathrm{cm} \mathrm{s}^{-1}\right)$, b) the phase of the semidiurnal tide, and c) the ratio between horizontal advective acceleration to bottom friction during February 25, 2000. 


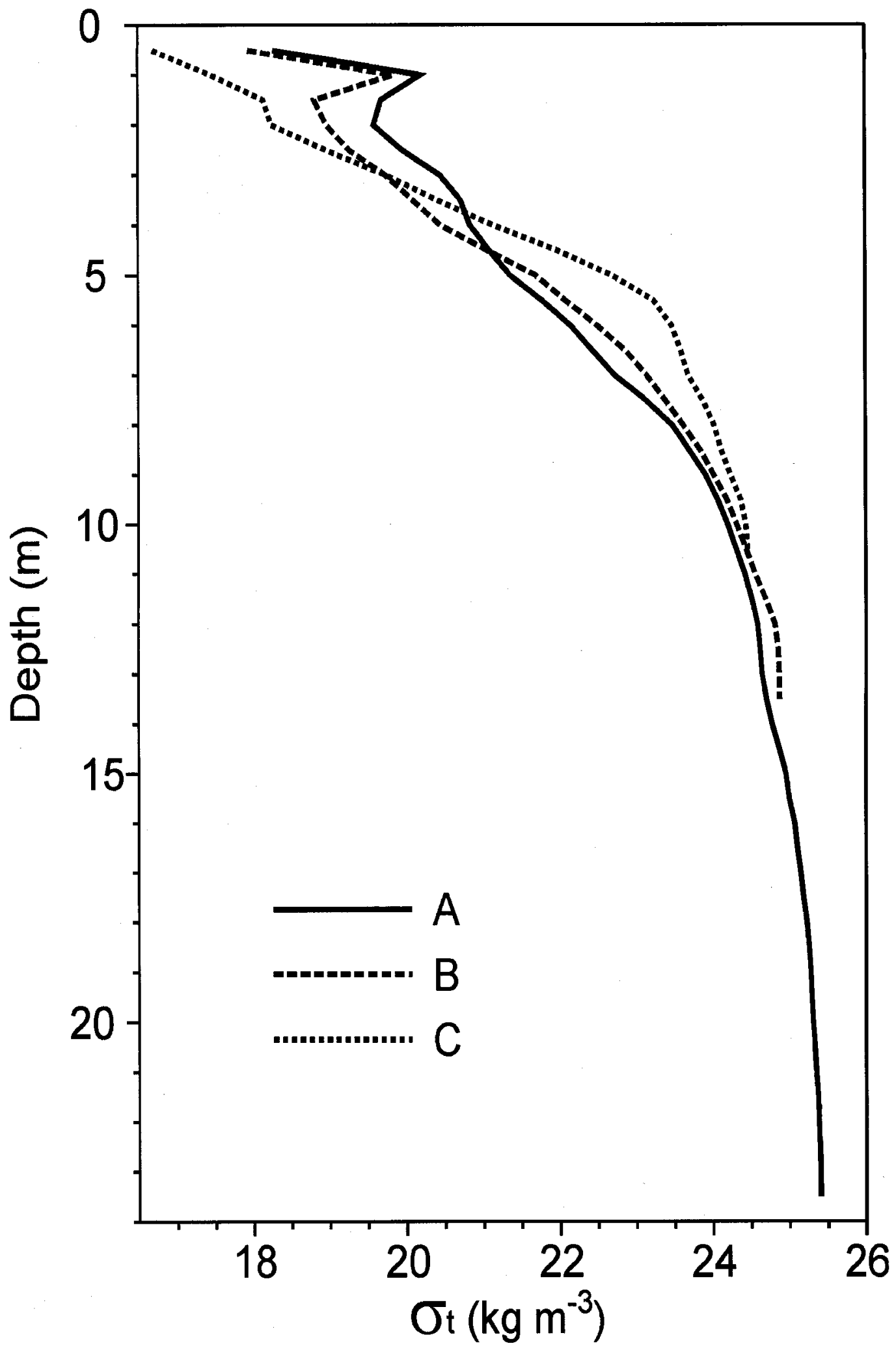

Fig. 37. Residual density. Residual density profiles for CTD station A (solid line), B (dashed line) and C (dotted line) during February 25, 2000. 

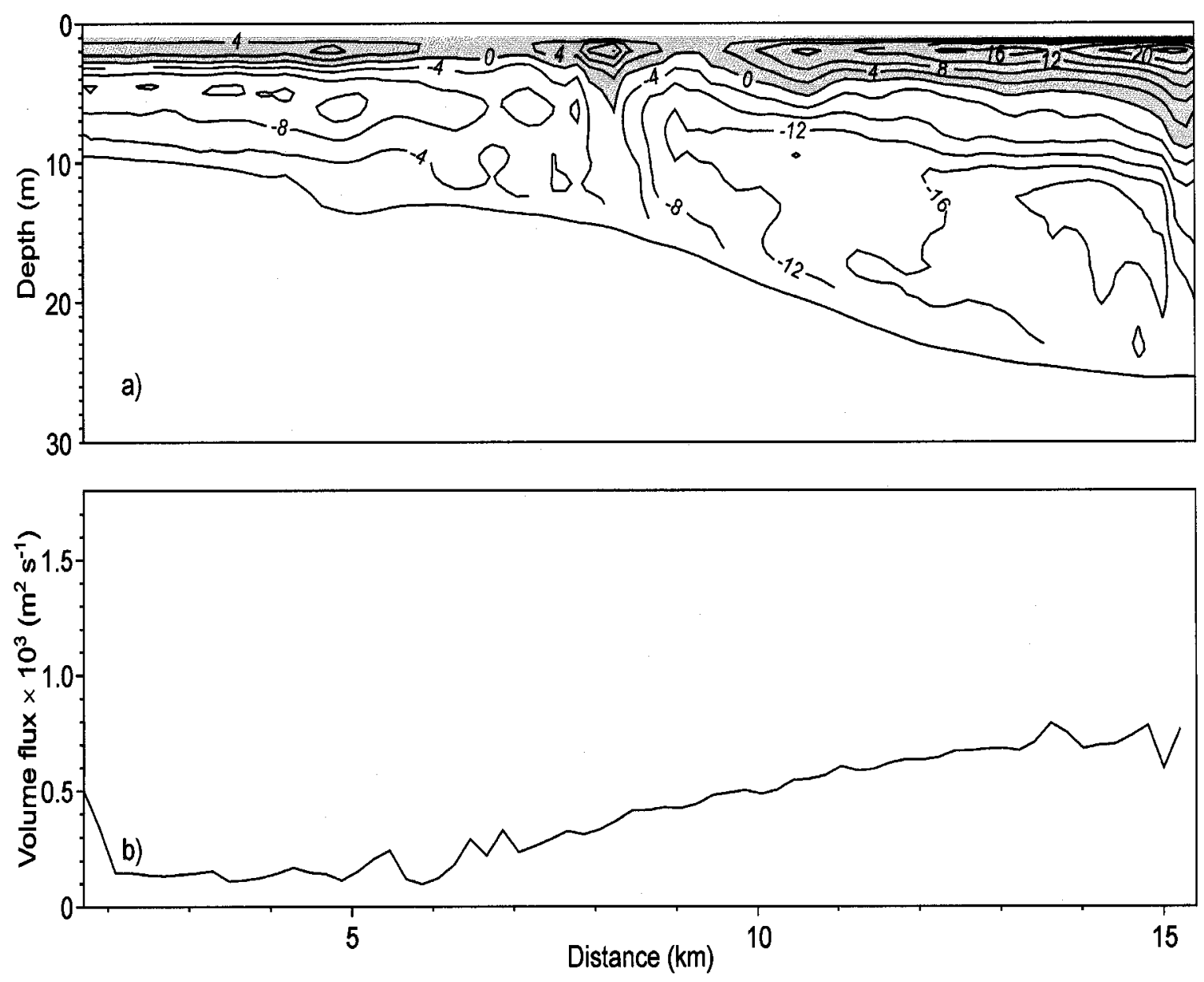

Fig. 38. Residual flow. a) Residual flow $\left(\mathrm{cm} \mathrm{s}^{-1}\right)$, and b) along-hollow vertically integrated volume flux during February 25, 2000. 


\section{CHAPTER 6}

\section{COMMON FEATURES}

The most common feature of the flow over the three bathymetric depressions in the lower Chesapeake Bay (Cape Charles, Rappahannock and the Chesapeake Bay Mouth Hollow) was the acceleration of the along-hollow flow as it moved toward an increasing bathymetry. This feature was described with three-dimensional Bernoulli-type dynamics modified by Coriolis acceleration. The acceleration of the along-hollow flow was attributed to lateral water intrusion from the shoals. In turn, the deceleration of the flow as it moved toward a decreasing bathymetry was produced by lateral water extrusion toward the shoals. The lateral water outflows over a continuously stratified hollow explained up to $35 \%$ of total along-hollow flow. Therefore, lateral variations of streamwise flow over vertically stratified hollows can not be neglected.

The observed flow pattern was opposite to what could be expected from twodimensional Bernoulli-type dynamics, usually assumed when interpreting observational data (e.g., Pierini et al., 2005). At the hollow, horizontal advective accelerations dominated over bottom friction. In the surrounding shoals, bottom friction dominated over advective accelerations. One of the consequences of the strong lateral variation of streamwise flow was observed on the tidal current phase. The tidal current phase over the hollow showed a monotonic increase from the depth of the adjacent shoals toward the bottom and toward the surface. In contrast, the tidal current phase over the shoals increased monotonically from the bottom to the surface.

The intensification of the along hollow flow, explained with three-dimensional 
Bernoulli-type dynamics, was predominantly observed below the pycnocline. The flow acceleration below the pycnocline could have in turn caused a lateral recirculation of the flow as it moved toward a sharp bathymetric slope. The lateral recirculation at mid-depth, in turn, mixed subsurface water with buoyant surface water creating two pycnoclines, instead of the single pycnocline usually observed in an estuary. A situation with three water types, i.e., two pycnoclines, was only found over a strong vertically stratified hollow (i.e., Rappahannock Hollow). In the case of a weakly or continuously stratified hollow system, the lateral recirculation would mix subsurface water with buoyant surface water and hinder the formation of a second pycnocline. Instead, this situation would reduce vertical stratification by mixing the water near the pycnoclcine.

Finally, a common characteristic of hollows with strong bathymetric slopes (e.g., Cape Charles Hollow) must be the adjustment of the pycnolcine, which produced a near bottom maximum of the along-hollow instantaneous velocity. A bathymetric depression with a strong bottom slope generates internal waves that enhance vertical shear of the horizontal flow. In turn, the vertical shear of the along-hollow flow could produce turbulence $(R i<0.25)$ which reduces the velocity of the along-hollow flow.

One of the most important bathymetric characteristics of the hollows studied is the asymmetry of both ends of hollows. One end is deeper than the other one. This characteristic is mostly responsible for lateral water outflows and inflows. When the along-hollow flow moves toward the shallower end, the water moving over the shoals will move into the hollow, i.e., lateral water inflows. This is a consequence of energy conservation. In this way, the water over the shoals shall not spend energy moving up the hill, as it would when moving along the shoals, parallel to the hollow. 
The acceleration of the near-bottom flow as it moves toward an increasing bathymetry was also produced by the pycnocline adjustment to bathymetric depressions over hollows with symmetric ends (similar depth). The pycnocline along the hollow will be tilted down as it moves toward an increasing bathymetry, resulting in an acceleration of the near-bottom flow, as was the case for Cape Charles Hollow. In turn, the pycnocline will oscillate once the bottom slope changes sign, generating lee waves and producing turbulence which resulted in the deceleration of the along-hollow flow at the depth of internal wave activity. 


\section{CHAPTER 7}

\section{CONCLUSIONS}

Acoustic Doppler current profiles and density profiles were measured over three bathymetric depressions in the lower Chesapeake Bay to elucidate the effects of an elongated hole (hollow) on a continuously stratified flow. This study is one of the first describing the dynamics of a continuously stratified flow over a hollow using observational data in shallow waters. The pursuit of the objective in this study yielded six conclusions that advanced our understanding of stratified flow dynamics over irregular topography in shallow waters. The conclusions are listed below.

1) The dynamics over a hollow can be described with three-dimensional Bernoulli-type dynamics modified by Coriolis acceleration $\left(w \frac{\partial v}{\partial z}+v \frac{\partial v}{\partial y}+u \frac{\partial v}{\partial x}+f u=\frac{1}{\rho} \frac{\partial p}{\partial y}\right)$. The acceleration of the near-bottom flow as it moved toward increasing bathymetry (downslope) was produced by lateral water intrusion from the shoals. In turn, the deceleration of the near-bottom flow as it moved toward decreasing bathymetry (upslope) was produced by lateral water extrusion toward the shoals. The accelerated along-hollow flow was deflected toward its right side owing to Coriolis acceleration producing the strongest along-hollow currents at this location. The residual flow over the hollow was explained with the same dynamics.

2) The acceleration of the along-hollow flow as it moved downslope, owing to lateral water intrusion, produced the strongest along-hollow currents at a depth equivalent to the maximum depth of the shoals surrounding the hollow, i.e. below the pycnocline. Most of the lateral water inflow at this depth was observed at the distance where the slope 
of the hollow started to increase sharply. At this location horizontal advective acceleration started to dominate over bottom friction.

3) The ratio between horizontal advection versus Coriolis acceleration showed comparable values among these terms, indicating the relevance of both accelerations in the along-hollow dynamics. The ratio between horizontal advection and internal friction showed the dominance of horizontal advective acceleration over internal friction. However, over a hollow with a sharp bottom slope (i.e. Cape Charles Hollow), internal friction was of the same order of magnitude as horizontal advective acceleration at the depth of the hollow shoulders. The acceleration of the flow and the increasing bottom slope at this depth generated internal waves during flood and ebb tide periods. The formation of internal waves, in turn, created vertical shear in the horizontal velocity, which enhanced turbulence during any period of time $(R i<0.25)$. This feature reduced the horizontal velocity at this depth.

4) The deceleration of the near-bottom flow as it moved toward a decreasing bathymetry was attributed to lateral water extrusion. The weakest lateral water outflows were observed over the hollow with the strongest vertical density gradient. The strongest lateral water outflows of up to $35 \%$ of total incoming water were observed over the hollow with the weakest vertical density gradient.

5) During ebb-tide, lateral water intrusions in a strongly stratified hollow (i.e., Rappahannock Hollow), together with lateral recirculation of the flow, generated by the interaction of the near-bottom along-hollow flow and the increasing bottom-slope, created two pycnoclines. This feature must be unique to strongly stratified hollows when compared to continuously stratified hollows. The strongest vertical density gradients 
were observed during ebbs, at the depth where the lateral water intrusion was located. Therefore, the water volume at this depth will increase owing to lateral water intrusion, generating two pycnoclines instead of the one observed during floods.

6) The amplitude of the semidiurnal tidal current at a distance where bottom friction dominated over horizontal advection, i.e. away from the influence of the hollow, showed the maximum values at the surface, far from bottom friction. At this location the semidiurnal tides showed a monotonic phase lag, which increased with distance away from the bottom. This was expected for a partially mixed estuary under the influence of bottom friction. An interesting feature, however, was observed in the hollow, where horizontal advective acceleration dominated over bottom friction. At this location, the maximum amplitude of the semidiurnal tidal current was observed at a depth equivalent to the maximum depth of the surrounding shoals. The semidiurnal tidal currents had a phase lag that increased monotonically from this depth toward the bottom and toward the surface. This was the depth where strong lateral variations of streamwise flow were observed.

Therefore, hollows modify the flow, generate lee waves, and lateral recirculations that can be described with three-dimensional Bernoulli-type dynamics modified by Coriolis acceleration. 


\section{REFERENCES}

Armi, L., 1986. The hydraulics of two flowing layers with different densities. Journal of Fluid Mechanics, 163, 27-58.

Armi, L., Farmer, D.M., 1988. The flow of Mediterranean water through the strait of Gibraltar. Progress in Oceanography, 21, 1-105.

Baines, P.G., 1995. Momentum exchange due to internal waves and wakes generated by flow past topography. IUTAM Symp. on Physical Limnology, Broome, W.A., Centre for Water Research, University of W.A., 285-90.

Baker, P., Pond, S., 1995. The low-frequency residual circulation in Knight Inlet, British Columbia. Journal of Physical Oceanography, 725-763.

Blamforth, N.J., 2002. Tidal conversion by nearly critical topography, Journal of Physical Oceanography. 32, 2900-2914.

Benjamin, S.G., Seaman, N.L., 1985. A simple scheme for objective analysis in curved flow. Monthly Weather Review, 113, 1184-1198.

Bryden, H.L., Kinder, T.H., 1991. Recent progress in strait dynamics. U.S. National Report Union of Geophysics 1987-1990. Review of Geophysics 29, 617-631.

Broenkow, W.W., McKain, S.J., 1972. Tidal oscillations at the head of Monterey Submarine Canyon and their relation to oceanographic sampling and the circulation of water in Monterey Bay. Moss Landing Marine Laboratories Technical Publications 72-05, 42 pp. 
Cenedese, C., Linden, P.F., 1999. Cyclone and anticyclone asymmetry in a rotating stratified fluid over bottom topography. Journal of Fluid Mechanics, 381, 199223.

Chao, S.Y, Paluszkiewicz, T., 1991. The hydraulics of density currents over estuarine sills. Journal of Geophysical Research, 96, 7065-7076.

Cummins, P.F., Oley, L.Y., 1997. Simulation of barotropic and baroclinic tides off northern British Columbia. Journal of Physical Oceanography, 27, 762-781.

Davis, C.A., 1997. The modification of baroclinic waves by the Rocky Mountains. Journal of Atmospheric Sciences, 54, 848-868.

Del-Rosario, J.J.A., Odriozola, E.A., 2005. A high order linear model for the prediction of internal lee waves at the main sill of the Strait of Gibraltar. Journal of Marine Systems, 53(1-4), 197-216.

Eriksen, C.C., 1991. Observations of amplified flows atop a large seamount, Journal of Geophysics Research, 96, 15227-15236.

Farmer, D.M., Armi, L., 1986. Maximal two-layer exchange over a sill and through the combination of a sill and a contraction with barotropic flow. Journal of Fluid Mechanics, 164, 53-76.

Farmer, D.M., Armi, L., 1999. Stratified flow over topography: the role of small-scale entrainment and mixing in flow establishment. Proceedings of the Royal Society of London A, 455, 3221-3258.

Farmer, D.M., Freeland, H.J., 1983. The physical oceanography of fjords. Progress in Oceanography, 12, 147-220. 
Farmer, D.M., Smith, J.D., 1980. Tidal interaction of stratified flow with a sill in Knight Inlet. Deep-Sea Research, 27A, 239-254.

Gade, H.G., Edwards, A., 1980. Deep water renewal in fjords, Fjord oceanography, edited by H.J. Freeland, D. Farmer, and C. Levings, Plenum Press. 453-486 pp.

Genin, A., 2004. Bio-physical coupling in the formation of zooplankton and fish aggregations over abrupt topographies. Journal of Marine Systems, 50, 3-20.

Gill, A.E., 1982. Atmosphere-Ocean Dynamics. Academic Press, 30, 662 pp.

Ginsberg, S., Perillo, J.M., 1999. Residual flow structure at a scour-hole in Bahia Blanca estuary. Journal of Coastal Research, 21(4), 784-793.

Guo, X., Valle-Levinson, A., 2005. Tidal effects on estuarine circulation in the Chesapeake Bay, submitted.

Hibiya, T., LeBlond, P.H., 1993. The control of fjord circulation by fortnightly modulation of tidal mixing processes. Journal of Physical Oceanography, 23, 2042-2052.

Hickey, B.M., 1995. Coastal submarine canyons, in Proc ‘Aha Huliko’a, Hawaiian winter workshop, Topographic Effects in the Ocean, pp 95-110. School of Ocean and Earth Science and Technology, University of Hawaii at Manoa, Honolulu, HI.

Hogg, A.M., Ivey, G.N., Winters, K.B., 2001. Hydraulics and mixing in controlled exchange flows, Journal of Geophysical Research, 106, (C1), 959-972.

Klinck, J.M., 1995. Circulation near submarine canyons: a modelling study. Journal of Geophysical Research, 101, 1,211- 1,223.

Klymak J.M., Gregg, M.C., 2001. The three-dimensional nature of flow near a sill. Journal of Geophysical Research, 106 (C10), 22, 295-311. 
Komura, S., 1973. River-bed variations at confluences. Proceedings of the Symposium on River Mechanics, Bangkok, 9-12 January, Paper A66, 773-784 pp.

Llewellyn Smith, S.G., Young, W.R., 2002. Conversion of the barotropic tide. Journal of Physical Oceanography. 32, 1554-1566.

Llewellyn Smith, S.G., Young, W.R., 2003. Tidal conversion by a very steep ridge. Journal of Fluid Mechanics, 67, 705-722.

Martins, F., Neves, R., Leitao, P., Silva, A., 2001. 3D modeling in the Sado estuary using a new genetic coordinate approach. Oceanologica Acta, 24(N1) 551-562.

Mellor, G.L., 1998. User's guide for a three-dimensional, primitive equation, numerical ocean model, Program in Atmospheric \& Oceanic Sciences resport, Princeton University, $41 \mathrm{pp}$.

Monreal-Gomez, M.A., Salas-de-Leon, D.A., 1990. Simulacion de la circulacion en la Bahia de Campeche. Geofisica Internacional, 29(2), 101-111.

Mosley, M.P., Schumm, S.A., 1977. Stream junctions. A probable location for bedrock placers. Economic Geology 72, 691-694 pp.

Pacanowski, R.C., Philander, S.G.H., 1981. Parameterization of vertical mixing in numerical models of the tropical oceans. Journal of Physical Oceanography, 11, $1443-1451$.

Park, M-L, Wang, D.P., 1991. Transient tidal vorticity over a hollow. John Wiley \& Sons, New York.

Pierini, J.O., Perillo, G.M.E., Carbone, M.E., Marini, F.M., 2005. Residual flow structure at a scour-hole in Bahia Blanca Estuary, Argentina. Journal of Coastal Research, $21,784-796$. 
Pickard, G.L., Rodgers, K., 1959. Current measurements in Knight Inlet, British Columbia. Journal of Fisheries Research Board of Canada. 16, 635-678.

Pond, J.S., Pickard, G.L., 1986. Introductory dynamical oceanography $2^{\text {nd }}$ edition Pergamon Oxford.

Pratt, L.J., 1986. Hydraulic control of sill flow with bottom friction. Journal of Physical Oceanography, 16, 1970-1980.

Pritchard, D.W., 1965. Kinsman's Notes on Lectures on Estuarine Oceanography. Chesapeake Bay Institute and Department of Oceanography. The Johns Hopkins University.

Rippeth, T.P., Fisher, N.R., Simpson, J.H., 2001. The cycle of turbulent dissipation in the presence of tidal straining. Journal of Physical Oceanography, 31 (8), 2458-2471

Salas-de-León, D.A., Monreal-Gómez, M.A., Signoret, M., Aldeco, J., 2004. Anticyclonic-cyclonic eddies and their impact on near-surface chlorophyll stocks and oxygen supersaturation over the Campeche Canyon, Gulf of Mexico. Journal of Geophysical Research (C0), 109, 5012-5025.

Salas-Monreal, D., Valle-Levinson, A., 2006. Sea level slopes and volume fluxes produced by atmospheric forcing in estuaries: Chesapeake Bay by case. Journal of Coastal Research, in press.

Salas-Monreal, D., Valle-Levinson, A., 2006. Continuously stratified flow dynamics over a hollow. Submitted.

Salas-Monreal, D., Valle-Levinson, A., Boicourt, W.C., 2006. Three dimensional flow dynamics over a hollow. Submitted. 
Salas-Monreal, D., Valle-Levinson, A., 2006. Lateral variations of streamwise flow over an elongated hole. Submitted.

Stenstrom, P., 2003. Mixing and recirculation in two-layer exchange flows. Journal of Geophysical Research, 108 (C8), 3256-3269.

St. Laurent, L., Stringer, S., Garrett, C., Perault-Joncas, D., 2003. The generation of internal tides at abrupt topography. Deep-Sea Research, 50, 987-1003.

Stommel, H., Farmer, H.G., 1952. Abrupt change in width in two layer open channel flow. Journal of Marine Research, 11, 205-214.

Trasvina-Castro, A., de Velasco, G.G., Valle-Levinson, A., Gonzalez-Armas, A.R., Muhlia, A., Cosio, M.A., 2003. Hydrographic observations of the flow in the vecinity of a shallow seamount top in the Gulf of California. Estuaries Coastal and Shelf Science, 57, 149-162.

Trump, C.L., Marmorino, G., 1997. Calibration a gyrocompass using ADCP and DGPS data. Journal of Atmospheric and Oceanic Technology, 14(1), 211-214

Valle-Levinson, A., Lewiza, L., 1995. Effects of channels and shals on the exchange between the lower Chesapeake Bay and the adjacent ocean. Journal of Geophysical Research, 100(C9), 18, 551-563.

Valle-Levinson, A., Wilson, R.E., 1994. Effects of sill bathymetry, oscillating barotropic forcing and vertical mixing on estuary/ocean exchange. Journal of Geophysical Research, 99 (C3), 5149-5169.

Valle-Levinson, A., Reyes, C.A., Sanay, R., 2003: Effects of bathymetry, friction, and rotation on estuary-ocean exchange. Journal of Physical Oceanography, 33 (11), $2375-2393$. 
Wesson, J.C., Gregg, M.C., 1994. Mixing at Camarinal Sill in the Strait of Gibraltar. Journal of Geophysical Research, 99, 9847-9878.

Winters, K.B., Seim, H.E., 1999. The role of dissipation and mixing in exchange flow through a contrating channel. Journal of Fluid Mechanics, 407, 265-290. 


\section{VITA}

\section{DAVID SALAS-MONREAL}

\section{PERSONAL DATA}

I was born the $4^{\text {th }}$ of November 1974, in San Francisco, Villa de Arriaga, San Luis Potosi, Mexico.

\section{EDUCATION}

B.S. Physics, July 2000, National Autonomous University of Mexico. Facultad de Ciencias, Circuito Exterior S/N, Ciudad Universitaria, Mexico. With a thesis entitled "Numerical simulation of winds over the Mexican Valle and its effects on pollutants" (in Spanish).

M.S. Oceanography, December 2002, Center for Coastal Physical Oceanography. Department of Ocean, Earth and Atmospheric Sciences, Old Dominion University, Norfolk, VA. 23529, USA. With a thesis entitled "Sea level slopes and volume fluxes produced by atmospheric forcing in the Chesapeake Bay".

Ph.D. Doctor of Philosophy in Oceanography, August 2006, Center for Coastal Physical Oceanography. Department of Ocean, Earth and Atmospheric Sciences, Old Dominion University, Norfolk, VA. 23529, USA. With a thesis entitled "Continuously stratified flow dynamics over a hollow".

\section{MEMBERSHIP}

Member of the American Geophysical Union since 2000.

Member of the Estuarine Research Federation since 2004.

Member of "Consejo Nacional Ciencia y Tecnologia" (Mexico).

\section{PUBLICATIONS}

Salas-de-Leon, D.A., M.A., Monreal-Gomez, D., Salas-Monreal, M.L., RiveronEnzastiga, N.L., Sanchez-Santillan, 2006. Inter-Annual sea level variability in the Southern Gulf of Mexico (1966-1976), Geophysical Research Letters, 33, L08610, doi:10.1029/2006GL025832.

Salas-Monreal, D., A., Valle-Levinson, 2006. Sea level slopes and volume fluxes produced by atmospheric forcing in estuaries: Chesapeake Bay by case, Journal of Coastal Research, in press.

Salas-Monreal, D., A., Valle-Levinson, 2006. Continuously stratified flow dynamics over a hollow, submitted.

Salas-Monreal, D., A., Valle-Levinson, W.C., Boicourt, 2006. Three dimensional flow dynamics over a hollow, submitted.

Salas-Monreal, D., A., Valle-Levinson, 2006. Lateral variations of streamwise flow over an elongated hole, submitted. 